Illinois State University

ISU ReD: Research and eData

Theses and Dissertations

7-22-2014

\title{
Using Writing Studio Pedagogy To Help Students Reclaim Their Disabilities And Sexualities In A High School Writers' Workshop
}

Matthew Kim

Illinois State University, makim@ilstu.edu

Follow this and additional works at: https://ir.library.illinoisstate.edu/etd

Part of the Lesbian, Gay, Bisexual, and Transgender Studies Commons, and the Rhetoric Commons

\section{Recommended Citation}

Kim, Matthew, "Using Writing Studio Pedagogy To Help Students Reclaim Their Disabilities And Sexualities In A High School Writers' Workshop" (2014). Theses and Dissertations. 244.

https://ir.library.illinoisstate.edu/etd/244

This Dissertation is brought to you for free and open access by ISU ReD: Research and eData. It has been accepted for inclusion in Theses and Dissertations by an authorized administrator of ISU ReD: Research and eData. For more information, please contact ISUReD@ilstu.edu. 


\title{
USING WRITING STUDIO PEDAGOGY TO HELP STUDENTS \\ RECLAIM THEIR DISABILITIES AND SEXUALITIES \\ IN A HIGH SCHOOL WRITERS’ WORKSHOP
}

\author{
Matthew A. Kim
}

227 Pages

December 2014

This dissertation is an exploration into what students stand to gain from being mentored in terms of reclaiming their disabilities and sexualities. Writing studio pedagogy supports the following ideas: an understanding that composition is a social process and, therefore, must take place in a social environment, an acceptance of multiple composing tools, multiple problem-solving strategies, an acceptance that students possess many and different creative thinking processes, an awareness that spatial design matters for successful teaching and learning, and, finally, an understanding of writing as play. My primary research question is: How can practicing writing studio pedagogy transform the writing classroom into a space for students who identify as learning-disabled and LGBT to reclaim their disabilities and sexualities? My research project reveals that students who identify as learning-disabled and LGBT can reclaim their disabilities and sexualities when they are empowered, by others and themselves, to relearn their differences into strengths and use those strengths to become agents of social change by means of composing activist texts for their schools and their communities. By becoming agents of social change at school and in their communities, learning-disabled and LGBT students can motivate teachers and peers to unlearn accommodations and stereotypes. 
I bring a feminist methodology to my dissertation, committing myself to a deep listening to my research participants' personal stories — triumphs and failures — and what Royster and Kirsch call "critical imagination" to their academic projects that are composed in our writers' workshop. One distinguishing feature of my research project from other research projects about writing studios and about learning disabilities is the grounded theory method that I implement to discover answers to my research question. Grounded theory, with the mantra "everything is data," made it possible for me to consider not only the interviews I collected from my two research participants and their academic work but also the memos that I wrote about my interactions and observations with my research participants in our writers’ workshop course.

Another distinguishing feature of this dissertation is how I contextualize my research project in stories from my life as a learning-disabled, LGBT student and teacher. I weave into the chapters reports from my pediatrician, neurologist, neuropsychiatrist, teachers, and one of my residence counselors, which point to how critical my own successes and failures were to brining this dissertation to fruition. My mother saved eighteen years of documentation on me, and when I asked her why she went to all the trouble to move literally pounds of reports with her from house to house, she replied that she didn't know. She just imagined them to be useful one day.

Perhaps the most distinguishing feature of my dissertation is my focus on secondary students who are both open about their learning disabilities and their sexualities. My research participants are courageous because they came to this research project looking for an opportunity to help make a positive change in how I and my colleagues teach a demographic of student who receives little positive attention in the public schools across the United States. The projects my two research participants 
compose - a video on being a transgender teenager, a coming out blog on Tumblr, a mural for our classroom, and an invisible theater project on bullying aimed to engage our school in an important dialogue — highlight their courage to advocate for social change in their lives and at their school and also their strengths as multimodal writers. 


\title{
USING WRITING STUDIO PEDAGOGY TO HELP STUDENTS \\ RECLAIM THEIR DISABILITIES AND SEXUALITIES \\ IN A HIGH SCHOOL WRITERS’ WORKSHOP
}

MATTHEW A. KIM

\author{
A Dissertation Submitted in Partial \\ Fulfillment of the Requirements \\ for the Degree of \\ DOCTOR OF PHILOSOPHY \\ Department of English \\ ILLINOIS STATE UNIVERSITY
}

2014 
Copyright 2014 Matthew A. Kim 


\section{USING WRITING STUDIO PEDAGOGY TO HELP STUDENTS RECLAIM THEIR DISABILITIES AND SEXUALITIES \\ IN A HIGH SCHOOL WRITERS’ WORKSHOP}

MATTHEW A. KIM

COMMITTEE MEMBERS:

James Kalmbach, Chair

Janice Neuleib

Karla Saari Kitalong 


\section{ACKNOWLEDGMENTS}

I thank my mother for years of banging loudly on doors of so-called experts, demanding that I have a better life than the one I was going to receive from my public school.

I thank my husband, JongHun Kim, for sacrificing his dreams over the last several years so I could finish this degree. I cannot imagine what my life would be like had we not met on the Red Line train in Chicago on January 3, 2008. I imagine I would still be an adjunct teacher during the day and working at the Walgreens on North and Wells throughout the night.

I thank my best friend, Jennifer Bueno, who has been by my side since November of 1997. Jennifer taught me so much about surviving in this world, including how to go grocery shopping, make lime butter chicken, and pay bills. Jennifer also motivated me to stay in college even after earning two Ds and a C in my first three classes at St. Edward's University. Without your friendship, I might have ended up waiting tables at the Waffle House and spending all my free time at the Boyz Cellar doing drugs, instead of growing up and teaching writing.

I thank Br. John Perron, my theories of rhetoric and composition teacher at St. Edward's University and close confidant for so many years. Thank you for taking me to my first CCCC in NYC in 2003 and also for allowing me to take up unofficial residency at Moreau House. 
I want to thank my dissertation director and now good friend James Kalmbach. You believed in me. Thank you so much for mentoring me through this writing process. After my grandfather died last summer, I needed someone to listen to me about my teaching and writing, and you did.

I thank Eagle Hill School, and in particular Michael and MaryAnn Riendeau. You both have been so influential in my life — first in my teenage years and now as a professional. I look forward to learning more from you both.

I want to thank my old friends for helping me grow: Sharon Bueno, Paul Matney, Nick Frimel, BJ Simpson, John Fielder, Joe Ruiz, Crystal Wick, Laura Durant, Kim Menzel, Matthew and Summer Hodgman, Jason Evans, Christy Oslund, Lori Ostergaard and Jim Nugent, Kerstin Lawrence, Br. Steven Walsh, Pat Perry, Dickie Selfe, and of course, Cheryl Ball. I am a better person because of you.

I want to thank new friends Nancy and Bob Martin, Kim Bonica, Jenna Hubacz, Jane Alwis, Sara Kaplan, Becky Miller, Marshall Robinson, Joel Slupnicki, MaryAnn Jackson, Kat Thompson, Rick Raymond, Eric Stone, Dottie Bachtold, Jane Cronin. I forced you all to listen to my dissertation plans, and I know it was not something to which you wanted to listen, but you did and I am grateful.

I want to thank so many students who have helped me be a better teacher: Nia Bernard, Scott Villarreal, Bruce Nino, Kasey LaRocca, Megan Moody, Bruce Nino, Dagny Piasecki, Kateri Kugelmann, Amy Crowder, Brandon Maxwell, Noah Friedman, Matthew Bissonette, Jack Demeo, Caroline Curtis, Danny Feinblatt, Alice Sullivan, David Hafer, Jahmeelah Nash-Fuller, and Frieda Myers. 
I also need to thank the interesting and weird people I have met over the years wherever I go. Whether it is in coffee shops, bars, or on the public bus, we find each other, and your stories have given me so much to consider.

I thank Bob Datz for taking the time to format my dissertation. You have helped me in ways you cannot even imagine.

Finally, I thank the superintendent of my public school, MaryAnn Lanzo, for telling my parents that I was not destined to go to college but to pump gas for a living at the Cumberland Farms in our small, fishing town. Her unkind forecast for my life has always motivated me to do my best.

This dissertation is dedicated to my grandparents, Stephen H. Gens and Fredricka S. Gens. If it had not been for them taking me into their home and loving me as their own son after I graduated from high school and for many, many years afterwards, this accomplishment would never come to pass.

M.A.K. 


\section{CONTENTS}

\section{Page}

ACKNOWLEDGMENTS $\quad$ i

CONTENTS iv

\section{CHAPTER}

I. INTRODUCTION 1

The Research Project 1

Overview of the Dissertation 2

On Being LGBT and LD: My Own Coming Out Story 4

I am Gay $\quad 4$

I am Learning-Disabled $\quad 8$

I am a Scholar? $\quad 19$

$\begin{array}{ll}\text { Some Key Terms } & 21\end{array}$

Writing Studio Pedagogy $\quad 21$

Reclamation 23

Unlearning 24

Foucault's Theory of Heterotopia 25

CHAT and Chronotopic Lamination 28

II. THEORIZING THE WRITING STUDIO 31

Introduction 31

Postmodern Geography and the Writing Studio 35

The Writing Studio as a Place to Socialize,

Problem-Solve, Think, Design and Play 37

A Commitment to Conversation 38

An Acceptance of Multiple Composing Tools 39

Privileging Multiple Problem-Solving Methods 41

Writing Studio Pedagogy Drives Space Design 43

The Creative Process: Divergent, Convergent, and Lateral Thinking 
III. APPLYING FEMINIST METHODOLOGY, AND THE METHODS OF CASE STUDY, GROUNDED THEORY, AND CULTURAL HISTORICAL ACTIVITY THEORY TO UNDERSTAND HOW STUDENTS RECLAIM THEIR DISABILITIES AND SEXUALITIES

Introduction $\quad 55$

The Research Site $\quad 56$

LGBT Students in Secondary Education $\quad 57$

The LGBT Population of Eagle Hill School $\quad 59$

Writers' Workshop 60

Methods and Methodologies in Feminist and Computers-and-Writing Studies $\quad 67$

$\begin{array}{ll}\text { The Case Study Strategy } & 72\end{array}$

$\begin{array}{ll}\text { Research Design } & 75\end{array}$

Data Collection $\quad 76$

Using Grounded Theory to Analyze Case Study Data 78

Mapping Rhetorical Activities in the Writing Studio 84

$\begin{array}{ll}\text { IV. } & \text { ALICE AND DELEVAN }\end{array}$

$\begin{array}{ll}\text { Introduction } & 87\end{array}$

Becoming Familiar with Common Terms and

A First Foray into Rhetorical Analysis $\quad 97$

Creating an Intimate Relationship between Students and Writing: Teaching Cultural Historical Activity

Theory in the Studio Space $\quad 102$

Alice’s Video Poem 103

$\begin{array}{ll}\text { Alice Comes Out on Tumblr: A Final Project in Rhetorical } & \\ \text { Genre Studies and Critical Awareness of Genre } & 109\end{array}$

Alice Launches http://gbtandlearningdisabilities.tumblr.com 115

Delevan Conrad $\quad 120$

Delevan’s Semiotic Remediation Project: Making a Mural 121

Delevan’s Final Project: No More Gay Bashing 128

A Brief Introduction to Augusto Boal and Theatre of the Oppressed 130

The Exhibition 136

V. GROUNDED THEORY AND ANALYSIS 144

Introduction $\quad 144$

Relearning Differences as Strengths $\quad 145$

Grit and Empathy 154

$\begin{array}{ll}\text { Self-Efficacy } & 160\end{array}$ 
$\begin{array}{ll}\text { Interest } & 164\end{array}$

Rhetorical Agency 168

Acquiring Literacies in Laminated Heterotopia 170

Delevan's Letter 175

Alice's Letter 178

Reflection on the Letters $\quad 179$

VI. UNLEARNING ACCOMMODATIONS AND STEREOTYPES 181

$\begin{array}{ll}\text { Introduction } & 181\end{array}$

A Framework for Unlearning $\quad 182$

Re-conceptualizing Unlearning 183

Unlearning Heteronormativity in the Composition Classroom 184

Unlearning Learning- Disabled Accommodations 188

Unlearning Pedagogy: The Significance of My Grounded

Theory Categories to Composition Studies 192

A Creative and Collaborative Approach to Unlearning

Accommodations and Confronting Stereotypes

Final Thoughts: How Researching and Writing the Dissertation

Impacted Me

$\begin{array}{ll}\text { REFERENCES } & 204\end{array}$

APPENDIX A: Writers’ Workshop Syllabus $\quad 217$

APPENDIX B: Michel Foucault’s Six Principles of Heterotopia 220

APPENDIX C: Literacy Interview Questionnaire With Answers 221 


\section{CHAPTER I \\ INTRODUCTION}

Coming out stories serve a purpose. They help us live our lives honestly and help us build self-esteem by being honest about ourselves. Coming out is a lifelong process of understanding, accepting, and acknowledging our identities. When we come out we stand a chance to develop closer, more genuine relationships with friends and family. We also alleviate the stress of hiding our identities and even helping to dispel myths and stereotypes by speaking about our own experiences and educating others. This dissertation is a coming out for learning-disabled and LGBT people who are students and colleagues in our profession. Their voices are unheard in our professional literature; they exist, both invisibly and as visible targets in our classrooms and hallways and meetings. Being able to come out is a liberating act, and the practice of liberty is essential to each person's personal and professional growth. Coming out, or the act of claiming, writes Simi Linton, “disrupts the social order” (3).

\section{The Research Project}

The question I pose in this dissertation is: How can practicing writing studio pedagogy transform the writing classroom into a space for students who identify as learning disabled and LGBT to reclaim their disabilities and sexualities? In answering my research question, I look at the process of unlearning accommodations and stereotypes. So that I can identify the ways in which students use their space, I also look closely at 
how students engage in a variety of rhetorical activities in the writing studio, which I consider a heterotopic space, or an Other space that mirrors real space.

\section{Overview of the Dissertation}

In this introduction, Chapter I, I begin by sharing my own coming out story as an LGBT and LD student and teacher. I next introduce the three models of learning disabilities: the medical model, the social construction model, and the learning diversity model. The learning diversity model is gaining popularity amongst educators, but I critique it because it provides students and teachers an opportunity to pass as able-bodied, which I argue is detrimental to the fight for people with disabilities because when we pass, we lose a powerful social and political constituency. In Chapter II, I share with readers why I moved from Illinois State University, where I was a graduate student, to Eagle Hill School, where I currently teach writing. I devote the rest of the chapter to defining writing studio pedagogy. I have subsections on a commitment to conversation, an acceptance of multiple composing tools, problem-solving strategies, an awareness of spatial design, the importance of convergent and divergent thinking, and writing as play and the writing classroom as playground.

In Chapter III, I discuss the location of my research site, the LGBT student population at Eagle Hill School, and the Writers' Workshop course that I teach. I then introduce feminist methodology and the methods of case study, grounded theory, and cultural historical activity theory. In Chapter IV, I introduce Alice and Delevan, two LGBT and LD students in my writing class. Alice and Delevan provide compelling accounts of what it is like to be an LD and LGBT teenager in high school, citing 
interactions with teachers, friends, peers, and parents. They discuss their writing disabilities and also strategies and respond to the activist projects they each compose in the writing class: a rhetorical analysis, a semiotic remediation project, and a final, multimodal project. Alice composes a video about being a transgender teen and also composes a coming out blog on Tumblr. Delevan composes an invisible theater project, modeled after the work of Augusto Boal, where he begins a dialogue on gay bashing and other forms of bullying at our school. Readers will be blown away by the creativity and honesty each of my students brings to the writing classroom and by the discoveries my students make about themselves.

In Chapter V, I use the grounded theory method to create a theory that answers my primary question. The theory is: Students who identify as learning-disabled and LGBT can reclaim their disabilities and sexualities when they are empowered, by others and themselves, to relearn their differences into strengths and use those strengths to become agents of social change by means of composing activist texts for their schools and in their communities. By becoming agents of social change at school and in their communities, LD and LGBT students can motivate their teachers and peers to unlearn stereotypes and accommodations. I then discuss in depth each of the grounded theory categories that helped me arrive at my theory: relearning strengths as differences, grit and empathy, selfefficacy, interest, and rhetorical agency. The chapter ends with letters each student wrote about the importance of being self-advocates and activists. I imagine readers tearing up reading Alice and Delevan's letters and then have a lot on which to reflect about what and how their own students are learning. And, finally in Chapter VI, I examine what it means to unlearn stereotypes and accommodations, as part of providing opportunities for 
students to reclaim their disabilities and sexualities. I use a framework of unlearning established in the organizational behavior discipline. I discuss in depth unlearning stereotypes, citing work LGBT research in composition studies and learning-disabilities research in composition studies. I end the chapter by sharing my own creative and collaborative suggestion for both reclaiming disability and sexuality in the writing classroom and unlearning stereotypes and accommodations in the writing classroom.

\section{On Being LGBT and LD: My Own Coming Out Story} I am gay

I came out as a gay man during the 1994-1996 school years. I had known I was gay from an early age, as I suspect do many gay people. I remember confiding first in my close friends with whom I shared a dormitory. I was never embarrassed to tell people I am gay; however, I was apprehensive to tell my family because they had initially had an unpleasant reaction when my uncle came out a year before. Of course, even though my peers and I were united in that we each had our own learning disabilities, there were several students who were not comfortable with my being gay and out. I can remember my archrival teasing me horribly about being gay from the moment we met in 1993 - a year before I came out. The majority of the students and the faculty were supportive of me as I came out, particularly my good friends and the teacher with whom I was close. My residential counselor during the 1994-1995 school year documented my coming out process in a series of log notes that told of how pleased he was that I was finally leaving campus on weekends and going to coffeehouses and independent movie theatres in Northampton, Massachusetts, a city known for embracing LGBT citizens socially, culturally, and politically. While these log notes do not specifically say "Matthew is 
beginning his coming out process,” they do allude to my coming out in a language that supports me and also that protects me:

11/2/94: I believe Matt has had a revelation in his life: He went on my Saturday trip and even though we saw two long drawn out films with subtitles, he proclaimed “having the time of his life.” In a coffee shop at Northampton he read the dialogue out loud of Pinter’s “The Birthday Party.” He then proceeded to buy the Book.

11/10/94: Everyday Matt becomes a little more extroverted. Yesterday he told me that when he goes home he's going to protest on the town square. I asked him what he was going to protest, his reply was “I don't know yet, it doesn't matter.” Everything is fine in the dorm floor.

11/30/94: Matt seemed to be very proud of the changes he's going through. He is now meditating daily and looking forward to the weekend. 1/20/95: Matt continues to grow as a person. He is becoming extremely diverse and wants to know as much as he can about different things. He is reading a lot of unusual texts and takes pride in his creative writing. Having faculty support during my coming out process was crucial. I recognize that not all students are so fortunate to have mentors. It was also at Eagle Hill, a residential boarding school for students with learning disabilities, that I began to develop my sexual literacy practices. The value of New Literacy Studies has been welldocumented in linguistics, composition studies, and computers-and-writing studies (New London Group 1996; Street 2001; Gee 2001; Selfe Hawisher 2004; Selfe and Hawisher 2007; Alexander 2008). Literacy “is an ideological event, a conduit of power through 
access to different socially enabling discourses," reminds Alexander, so, therefore, "understanding literacies of sexuality is vitally important to understand themselves, their relationships with others, and their possibilities for meaningful self-articulation and social connection” ("Literacy” 63). Sexual literacy, defined by Jonathan Alexander, "asks us to take seriously the sexual and sexuality as significant dimensions through which we can understand the relationship between literacy and power” (17). For Alexander, sexual literacy should not just be "knowledge about sex" but also "should be an intimate understanding of the ways in which sexuality is constructed in language and the ways in which our language and meaning making systems are always already sexualized” (18). Sexual illiteracy, conversely, "positions people in comparably disempowered positions — particularly in terms of their ability to name their own bodies, their experiences, their relationships, their connections through relationships, and intimacies to the larger social order” (63). My own sexual literacies were learned and practiced through meaningful conversations, reading fiction and non-fiction, and watching television programs and movies with faculty and friends, and revolutionary for 1994-1996, chatting online in an AOL room. I read Leaves of Grass and assorted work by Edna St. Vincent Millay; I was obsessed with William Burroughs's Queer; I watched the film Heavenly Creatures; I read poetry from the Nuyorican Poets Café; I had long conversations with gay faculty who were out, as well as straight facul ty and close friends in my peer group about coming out, dating on campus, having sex, and a lot of discussions about AIDS prevention. Upon leaving Eagle Hill School for college in 1997, I was, for my age, more sexually literate than most students I met in college. 
Then, in 1997, something fairly terrifying happened. The summer I graduated from Eagle Hill School, my parents divorced, and I moved to Amarillo, Texas to live with my maternal grandparents. That was not horrifying. What was horrifying was, although I did not have the word for it at eighteen years old, I attempted passing as a heterosexual to avoid conflict with my grandparents, my friends, and my peers at the community college that I attended. Passing is "seeking or allowing oneself to be identified with a race, class, or other social group to which one does not genuinely belong" and "reasons for passing can be as complex as the social structure, but passing has most often occurred for reasons of economic security or physical safety, when exposing one's true identity might attract violence; or for the avoidance of stigma” (GLTBQ Encyclopedia n.p.). In the course of a year, I got a girlfriend in whom I eventually confided, came out, and moved on with my life. Although, the two years we dated were difficult because I was always scared that I would be discovered a gay man in West Texas, and listening to the way students and even faculty at the college spoke about LGBT members of the college community was heartbreaking and even, at times, terrifying. I would hear the word "faggot” regularly blurted out across campus, and away from the campus I would hear members of the Amarillo community tell anyone who would listen — and even those who refused to listen — that homosexuals will burn in Hell. While I knew I wasn't going to burn in Hell (Jews don't believe in Hell), I still did not feel safe coming out. I did finally come out to more people than my then girlfriend when she and I moved to Austin and I felt that I was mostly out of harm's way. I found the Austin Men's project and met some really good guys, some my age and some older, who persuaded me that living in Texas is just as safe and just as dangerous as other 
places in the country. It is important to be true to yourself and have a solid group of friends to go dancing with at the Boyz Cellar on the weekend, and with whom to have coffee and study. I also eventually came out to my grandparents, and they accepted me without hesitation.

I am Learning-Disabled

In a letter to my parents on my progress in the first grade, my special needs teacher wrote: "Matthew has exhibited an uncertainty of his position in space, a protectiveness against falling, and a lack of refinement in controlling velocity.” My mother saved this letter and handfuls of other letters, reports, summaries, and findings about me and the learning disabilities with which I was diagnosed from the age of six. Michel Foucault writes in Discipline and Punishment that one method of enacting discipline as a means of control is by examination. Part of the examination process involves those in power intensely documenting the lives of individuals. "The examination that places individuals in a field of surveillance also situates them in a network of writing," writes Foucault, and this "power of writing was constituted as an essential part in the mechanisms of discipline” (201). I have been documented by doctors and teachers as a docile body, subjected to tests and observations and medicine, used as an example of what not to be or how not to act, transformed into a body that is categorized and classified, and perhaps improved. Thirty-four years of documentation has revealed to me that I still have an uncertainty of my position in space.

I was born on June 22, 1979 at Yale New Haven Hospital in New Britain, Connecticut. My discharge summary dated December 17, 1979 and dictated by Dr. Sam Rosenberg, documents that I was born with bronchopulmonary dysplasia and 
hyperventilation and was on oxygen support up until one week prior to my discharge. What this meant was that for the first six months of my life I remained on oxygen support, my physical space restricted to a respirator in the neonatal unit of the hospital. This is how Dr. Rosenberg describes me: "Matthew is slightly cyanotic with blue lips, pale blue skin, slightly blue-looking sclerae.” Secondary to my bronchopulmonary dysplasia and course on the respirator, the discharge summary reads that I developed some spasticity and some arching postures. Even after physical therapy, these postures still affect how I interact in a space, whether in the classroom as a student, at a table with my peers, or now at my own desk in the classroom where I teach, and even around my house doing chores and taking care of my child.

My official diagnoses are many. The disability that still affects me personally and professionally is dyspraxia, a form of developmental coordination disorder. "Dyspraxia is distinct from other motor disorders such as cerebral palsy and stroke, and occurs across the range of intellectual abilities" and although the "exact causes of dyspraxia are unknown; it is thought to be caused by a disruption in the way messages from the brain are transmitted to the body ... which affects a person's ability to perform movements in a smooth, coordinated way” (“dyspraxiafoundation.org”). Plainly, I have a challenging time controlling my movements in space. Not only do I have a difficult time formulating a (motor) plan of action, but also I have a hard time recognizing how much physical energy I should expend in a space. While my students can appreciate my energy and movements in the classroom, my colleagues over the years have been less appreciative or worse toward my energy and movements in meetings, hallways, and in their own undergraduate and graduate classes. In the early 1980s, doctors recommended to my 
parents that tactile exploration would be helpful for me, so my parents provided activities for me that were comprised of a variety of textures and sensations. Other recommendations to help me negotiate space were to play engaging in new movement activities, where my parents would manually move me through an activity, so movement can be learned through experiencing it in the "proper" way. I still have difficulty negotiating space.

I offer here a short list of regular difficulties I had throughout school and still have: I have poor balance; I have poor hand-eye coordination; I have difficulty changing direction, stopping and starting actions; I have a lack of manual dexterity. I am poor at two-handed tasks, causing problems with using cutlery, cleaning, cooking, ironing, craft work, playing musical instruments; I have difficulty with organizing the content and sequence of my language; I have poor visual perception; I am over-sensitive to light; I have difficulty in distinguishing sounds from background noise; I have a tendency to be over-sensitive to noise; I am either over- or under-sensitive to touch. I hate being touched, and I also have an aversion to tight clothing; I lack awareness of body position in space and spatial relationships, which can result in bumping into and tripping over things and people, dropping and spilling things; I have little sense of time, speed, distance or weight. I have an especially short-term memory and may forget and lose things; I have known to be unfocused and erratic and also messy and cluttered; I have difficulty with concentration; I am easily distracted; I have difficulty in listening to people, especially in large groups; I am known to be tactless and interrupt frequently; finally, I am prone to emotional outbursts, phobias, fears, obsessions, compulsions, and addictive behavior. 
From 1986 to 1992, my first grade through seventh grade years, in my individualized education plan (IEP), it was constantly emphasized that I had trouble with size, shape, alignment, and directionally in handwriting and art work. I also had trouble paying attention to lectures, staying on task during class time, calculating, as well as a horrible fear of participating in physical activities because of my poor balance and general lack of agility. The approach that my elementary school teachers and counselor recommended to my parents for my dyspraxia and attention deficit hyperactivity disorder was one-on-one tutoring in a resource room setting. Throughout my years in elementary school, my learning environment was the complete antithesis of how I now envision learning should take place. I was not allowed to be near auditory or visual stimuli; being in the resource room, instead of class, I had limited interaction with my friends. When I was in a mainstream class, I had to be seated in the front row where the teacher was fixated on me by mandate, not by choice. It was suggested in my seventh grade IEP that I read, with a teacher or parent, Mel Levine’s 1990 Keeping a Head in School. I have no recollection of reading it. However, I recently picked up a copy at the library and read it. It is a guidebook for students with diagnosed learning disabilities written from the perspective of the medical model, sharing with readers how the brain affects abilities. The first chapter of Levine's book provides a glossary of definitions for medical terminology, as well as an image of the brain with lots of arrows pointing at different lobes explaining their functions. The genre that Levine's book falls under is self-help and the tone is patronizing.

Not all of the suggestions for accommodation were terrible. It was suggested that written work should be reduced whenever possible and a word processing program 
should be considered to supplement what the school named continued functional writing. However, it was the one-on-one tutoring that I despised and feared — the being in a small, enclosed space with my desk and the teacher's desk with no windows and poor lighting and, of course, being away from other kids in total isolation from everyone else. In this confined space is how I spent my time in elementary and middle school.

With my dyspraxia and my accompanying emotional-behavioral issues, it was near impossible for me to pay close attention to details in my schoolwork. Writing and math were nightmares, and physical education was even worse. Teachers and my parents would constantly harangue me over the details, where I was always more interested and also concerned with the big idea, the meaning. Foucault, in Discipline and Punishment, writes that "for the disciplined man ... no detail is unimportant, but not so much for the meaning that it conceals within it as for the hold it provides for the power that wishes to seize it” (184). For students with dyspraxia and attention deficit hyperactivity disorder, details are not often a consideration. We resist the details, the little things, and it angers the political autonomy that creates the public education system in the United States. Children diagnosed with learning disabilities and attention problems resist discipline in the sense that they resist the source of power — teachers, administrators, counselors, and parents - who aim to make us into docile bodies. That does not mean that such students are not disciplined. They are disciplined all the time through observation, normalization, and examination. Students with learning disabilities are locked in the gaze of teachers and peers who perceive them to be unlike them. These students are teased mercilessly by students and treated condescendingly by teachers. Students with learning disabilities in the spaces that compose public education are given tests that they simply cannot pass to 
advance to the next grade or to graduation. The classroom becomes a prison. The school, and more specifically the classroom, like Foucault's architecture in the eighteenth century, becomes "no longer built simply to be seen ... but to permit an internal, articulated, and detailed control — to render visible those who are inside it ... to provide a hold on their conduct, to carry the effects of power right to them, to make it possible to know them, to alter them" (Rabinow 190). Students with learning disabilities and attention issues are subjected to "a whole micropenalty of time, activity, behavior, and sexuality ... a pupil's offense is not only a minor infraction, but also an inability to carry out his tasks” (194). In a sentence, discipline is meant to normalize. I would constantly tell my parents that I hated the resource room, feared my teachers, and felt uncomfortable to be alone in a room with them. I explained all of these feelings to my doctors and therapists and, in a response to my pleas, in a 1992 report, my therapist wrote: "Matthew's verbal manner is pseudomature, pseudoinsightful, and, possibly due to years of psychotherapy, liberally sprinkled with psychological jargon.” My story was not accepted by anyone in a position of power until April 1992.

In April 1992, in the seventh grade, I was evaluated at Franciscan Children's Hospital in Brighton, Massachusetts by a Dr. Noah Federman. After three days of intellectual, physical, and emotional testing, this was his summary and recommendations:

Matthew is a 12 year, 9 month old boy with significant disparity between verbal and nonverbal cognitive abilities. This cognitive profile of right hemisphere learning disabilities is often associated with atypical interaction secondary to reduced ability to discriminate nonverbal social cues and may contribute to Matthew's difficulty with social relationships 
and adversarial relationships with some adults. Matthew is also increasingly prone to obsessive ruminations, aggressive and paranoid fantasies, and immature and bizarre behavior.

1. Matthew will require a more therapeutically intensive educational program. One option would be placement in the Cognitive Behavioral Program of this hospital. If this option is not available, an extended day, 11 month, therapeutic educational placement is recommended. This should include psychotherapeutic intervention, behavioral programming and specific academic services for Matthew's learning disabilities.

2. Matthew should be enrolled in a social skills training group. Participation in recreational social activities should continue to be encouraged.

In the middle of the 1993-1994 school year, and after a long, painful, and costly battle between my parents and my public school, I was admitted to and began high school at Eagle Hill School, located in Hardwick, Massachusetts. At that time, Eagle Hill School was a co-ed private, residential school made up of about ninety-seven students. Now the student body is 211 students and growing, as is the faculty and the physical campus. The class sizes were small, no more than six students to one teacher in any class. Taking classes at Eagle Hill School was my first experience in a studio environment. Having no more than six students in a class with lessons and projects that were created and delivered and accepted back multimodally, every class — even math and science, and especially 
English — was taught as a studio course. The spaces students at Eagle Hill were provided and what I and my peers were able to accomplish in those spaces, academically and socially, was nothing short of miraculous, considering that same year I was told by the superintendent of my public school that I would most likely make a living pumping gas.

Similarly to attempting to pass as straight when I moved to Texas, I also attempted to pass as completely able-bodied and -minded. There were support services, but I refused to even introduce myself. I did not want to be labeled and then judged by my teachers and peers. However, my plan to pass changed when I had to take the Texas Academic Skills Program (TASP). I failed the writing and math portions of the test and therefore was placed in a remedial lab, called the Access Lab. The Access Lab was horrible because instead of tutoring, it was students sitting in a carrel and having to play word and math games on a desktop. I do not learn well, even now, when I do not have opportunities for person-to-person interaction. I actually stayed in the Access Lab for a whole year before I could not take it anymore. I remember the day I reclaimed my disability so well. I was in the lab working on basic Algebra when a man entered the lab, and the tutor on duty walked up to him, threw her arms around him, and said "welcome home.” I couldn’t handle it. I got up from my seat and went right into the lab director's office and demanded to be put in remedial classes. I found myself, my Eagle Hill self, the self that isn't afraid to self-advocate. The director tried to refuse me the right to take classes instead of being in the lab, but I stood my ground. When a student has a learning disability the answer is not to stick them in a lab and leave them alone with a computer playing word games to get them to write more proficiently. I was not even a writing teacher then, and I knew that! I was allowed to begin classes, and I passed them and 
eventually graduated with my associates in radio production. Reclaiming my sexuality and disability in the 1990s was liberating and scary, but liberation is never easy and almost always scary.

Over the last several years, but especially in the last two years, as I became a teacher at Eagle Hill School, I have come to recognize three models of learning disabilities. The first is the medical model. When someone refers to the medical model, they mean using medical terminology and metaphors from within the field of medicine to describe students' disabilities (McDonald and Riendeau 86). The second is the social construction model. Although it is inarguable that certain forms of irregularity in the brain have behavioral consequences, the medical model of learning disabilities should be read as a statement about social and political relationships in our country. The social construction model pushes back on the idea that people are nothing more than elaborate chemical reactions. From a radical structuralist perspective, the history of learning disabilities is a racist history, one that was developed to keep black and Hispanic students from succeeding with the same opportunities as middle and upper-class white students. While this injustice was being delivered across the country, reports Sleeter, "a small number of white middle- and upper-class parents faced a problem: Their own children were unable to keep up with escalated reading standards, and, as a result, were being categorized as slow, retarded, or disturbed” (160). Sleeter maintains that it was more advantageous for these white parents to [use the idea of learning disabilities] than it was for them to do nothing," but perhaps, "the creation of the learning disabilities classification helped to deflect attention away from questions that might have been taken very seriously at that time” (160). It seems obvious that both the medical model and the 
social construction model serve to hold back disabled people — and even people of color — from being successful in school and beyond.

There is a third model, the learning diversity model. The learning diversity model, practiced at Eagle Hill School, comes from a need to move away from the medical model that prescribes learning disabilities and the learning differences model that asks education stakeholders to acknowledge students to learn differently but to educate those students toward an objectified norm. The medical model of disability focuses on biological mani festations of disability. Medical models also rely on medical authorities rather than the experiences of the disabled themselves. The learning diversity model "avoids some limiting assumptions that the learning disability and learning difference paradigms have perpetuated" and instead privileges "all students, all learners, as individuals" (87). Educators must "refuse to reference norms and look instead to individual students' skills, talents, interests, and predilections” (87). Riendeau and McDonald recognize that a risk of moving toward the learning diversity model "is the possibility that [educators] will lose what ground has been gained by the development of the learning disability paradigm” (88); however, moving toward the learning diversity model means "beginning to emphasize what students can do rather than what they cannot do” (88). The learning diversity model, with its focus on individuality and escaping objectifying norms, opens up unique opportunities for secondary and postsecondary writing teachers to focus on knowing and teaching LGBT students who have learning disabilities. Those who subscribe to the learning diversity model teach based on skills that the students need, as opposed to mainly focusing on content. Teachers work hard to individualize per student and make sure to differentiate their lessons based on what they 
believe the student to be capable of; it is, of course, quite subjective, but teachers work to challenge their students while providing a nurturing academically-oriented environment.

I value what the idea of the learning diversity model can bring to my own teaching, and I imagine that I would be hard pressed to find a teacher invested in teaching learning-disabled students who would not want to challenge students while nurturing them. I do, however, have misgivings about the term "learning diversity" and other terms like it, such as "learning differences.” I prefer the term “disability,” which has a complex history. While it has been used by the medical community to pathologize a large group of people, it has also been used by that same group of people as a term used to "identify a constituency, to serve our needs for unity and identity, and to function as a basis for political activism” (Linton 12). Using the term “diversity” and other "nice words” like “different” risks erasing a line between disabled and abled. That erasure takes away the agency that moves forward the hard work of reclamation. That is, terms like diverse and different make it possible to pass as being abled, whereas the term "disabled" is politically and socially charged and compels those who identify as disabled to hope for a future by confronting oppression through activism. I hope I am a good example for my students. I identify as LGBT and learning-disabled. I also have the intellectual, social, and financial means to turn my hope toward activism. I have a university education and I am employed by a wealthy residential school, which means I have access to materials to produce activist text from simple signs to complicated documentaries. My students, also learning-disabled and some LGBT, have at least the means, being at our school, to use their hope to produce activist texts if they choose to be activists. I am unwilling and uninterested in risking my or their own erasure as a constituency that needs attention. 


\section{I am a Scholar?}

I have been in college as a student now since 1997 with a five-year break to teach at a variety of two-year colleges. Since my junior year at St. Edward's University, I have desired to become a college professor. Those dreams were cut short before they even started, which was probably fate since the majority of professors who taught me and the cohort with whom I entered both my master's and doctoral programs did not understand who I am and what I can offer. Oftentimes the people with whom I come in contact are distracted and made uncomfortable by my disability, dyspraxia. Some faculty believe there is a code to crack to understand disability, but no such code exists. Other faculty may be sympathetic but not know how to express themselves. I take solace in Catherine Liu's book American Idyll, where she investigates the roots and current practices of academic antielitism. Liu, in a recent interview with the Los Angeles Review of Books argues:

Academic antielitism masks, among other things, the fact that an academic community is by nature exclusionary, for better and worse. It also allows us to believe that what is important for intellectuals and academics is not refining or communicating knowledge by using substantive arguments to persuade our interlocutors; no, the academic antielitist suggests that all we have to do is create some kind of affective and epistemological “accessibility” in order to have done something politically effective. (qtd. in Lutz)

Liu’s observation has certainly been true in my experiences working with academic antielitists. For so many academics it is satisfying enough to call oneself a 
champion of disability rights and LGBT rights on paper, in an article or book, or at a conference; however, it is an entirely different experience for that person to deny one the right to be disabled or queer behind closed doors or in an email to a student who struggles.

This dissertation was only able to happen after I left my university and moved to Hardwick, Massachusetts, to teach writing at Eagle Hill School, and found a committee chair who understood and embraced me. Eagle Hill School, a residential community for students who are learning disabled-labeled, is where I graduated from high school. As a learning disabled-labeled faculty member, I am completely accepted here. This dissertation weaves together my personal story of being an LGBT student and a teacher with disabilities with relevant scholarship in composition studies, computers-and-writing studies, and English education. I want to begin for some and continue for others an important dialogue about students who are learning disabled-labeled and/or LGBT and the spaces where they resist the dominant ideologies that serve to hold them back from the success they deserve.

I do recognize, though, that I am also part of the academic antielite as I am a product of my mentors and university culture, and that has given me some problems transitioning into my teaching position and relating to my current students and some of my colleagues. I initially approached, and sometimes still do approach, my writing classes with the mindset that my students already knew how to write complexly. However, when they needed concepts broken down so that they could understand them and actually compose their projects, I did not know how to helpfully respond. I would often and not purposefully give them blank stares and become frustrated with having to 
explain information that I, for whatever reason, thought they should know. I still have to grow into the role of a teacher who has to break down complex topics for younger audiences.

\section{Some Key Terms}

In this dissertation, I will be making use of a number of key terms, including “writing studio pedagogy”, “reclamation”, “unlearning”, “Foucault’s theory of heterotopias”, and “CHAT and chronotopic lamination”. I briefly define these terms here to better prepare the reader for the discussions that follow.

\section{Writing Studio Pedagogy}

Not too long ago, in September of 2012, I was sitting in the dining hall at Eagle Hill School with some colleagues and some students. Prior to this impromptu lunch meeting, I had been thinking about how teachers at Eagle Hill are in a unique position to create writing studios out of our classrooms because our mission is to individualize education for each student at our school and our student-to-teacher ratio is small and personable. I asked each to close their eyes and imagine a traditional classroom for about sixty seconds, and then open their eyes and tell the group what images they saw. This mixed group recalled images of "desks in a row”, "hand-raising”, "because of rigid seating and the teacher's need for order, students are unable to have conversations", "the smart kids in the front rows and the dumb kids and troublemakers in the back row”, and “five-paragraph essays” and “the English Language Arts Curriculum.” These images brought out negative emotions and even conjured some terrifying stories from some of the people at the table. After lunch, I walked up the hill back to my classroom thinking 
about the shared images of my colleagues and students at the table and how I wanted to change for them their perceptions of what a writing classroom could be.

I need to confess that I don't teach in an actual writing studio, like the one administered at Eastern Kentucky University by Russell Carpenter or the Pearce Studio at Clemson University formerly administered by Morgan Gresham, but I imagined the ways in which I could reshape my classroom into a space where I and my students embrace a writing studio pedagogy. Writing studio pedagogy does not have an exact definition, but I will define it here briefly and in more depth in Chapter II, by several characteristics. The six characteristics of writing pedagogy that I have selected for my project by no means make up an exhaustive list. These six characteristics stuck out to me as being beneficial to my school's population.

The first characteristic is a commitment to conversation and the understanding that composing is a social experience and should take place in a social environment. Writing studios, therefore, are spaces where students are encouraged to talk in class, particularly about their writing and their peers' writing. The second characteristic is an acceptance of multiple composing tools - no one tool is going to work for all situations. The third characteristic is a commitment to teaching students a variety of problemsolving strategies. The fourth characteristic is a commitment to spatial design. Embracing a writing studio pedagogy means affording students opportunities to make choices over the ecological factors in their learning space by experimenting with seating, tables, lighting, and temperature. The fifth characteristic of writing studio pedagogy is to embrace students' rights to their own creative process, privileging equally divergent, convergent, and lateral thinking. Divergent thinking is a method to unblock conventional 
ways of thinking. Ken Robinson, author of the popular book Out of Our Minds: Learning to Be Creative, says "in logico-deductive thought, ideas build on one another in carefully consistent steps and lead to a number of permissible answers” ... but "divergent thought works by making much freer associations: often by thinking in metaphors and analogies, or even reframing the question itself to make more possibilities” (161-162). Convergent thinking, on the other hand, is how creativity is generated from logic, accuracy, and prior knowledge. Lateral thinking is a strategy that aims to provide people with insight into the natural behavior of the human mind. The sixth characteristic of writing studio pedagogy is a commitment to create an environment where students can play. The ability to play is voluntary and is also indicative of a person or people's feeling of freedom. The ability to play is also constrained by people spaces. Each of these writing studio elements will be further examined in Chapter II with relevant scholarship and observed happening in the studio throughout Chapter V.

\section{Reclamation}

I enter into this project understanding the act of reclamation from Simi Linton's perspective in her book Claiming Disability: Knowledge and Identity. Linton, in her introduction, tells her readers that those people who have been labeled disabled "further confound expectations [of those who label themselves as abled] when we have the temerity to emerge as forthright and resourceful people, nothing like the self-loathing, docile, bitter, or insentient fictional versions of ourselves the public is more used to" (3). I argue that reclaiming disability and sexuality starts from a place of anger which is where most learning disabled-labeled and LGBT students find themselves after being bullied and looked down upon by their teachers, peers, and even parents. Then, after a 
grieving process that includes a lot of inward and outward reflection, that anger turns to hope. Paula Mathieu (“Tactics”) focuses on hope as the concept that best describes the spirit of tactical relationships. Hope, writes Mathieu, “is to look critically at one’s present condition, assess what is missing, and then long for and work for a not-yet reality, a future anticipated. [Hope] is grounded as imaginative acts and projects, including art and writing, as vehicles for invoking a better future” (19). Hope then turns to activism. Broadly, activism is a doctrine that emphasizes vigorous action in opposition to a controversial issue. However in the writing studio, I mentor students to pay "attention to the material conditions and immaterial rhetoric that surround those conditions” (Del Gandio 2). An example of the relationship between material conditions and immaterial rhetoric would be disability as a material rhetoric and the social narratives that surround disability. I also want students to know that the act of reclamation is an intellectual pursuit. Dana Cloud ("Reflections”) writes that "we must fight the battle of ideas as well as battles in our workplaces and the streets” (16). It is the activist student, in my experience, who possesses the power to reclaim her disability and sexuality. I am going into my project imagining the writing studio as a space that has the potential to turn anger into hope and hope into activism.

\section{Unlearning}

In the discipline of education, “unlearning” is defined as the act of making a shift from rejecting prior knowledge to accepting new knowledge. Virginia Lee (“Unlearning”) argues that "prior knowledge is the single most important factor in learning, and, unless we engage prior knowledge — the good, the bad, and the ugly — we risk sabotaging the new learning [teachers] work so hard to put in place” (n.p.). One 
unlearning strategy comes out of the behaviorist tradition where one engages a person's prior knowledge before introducing new material. Another comes out of the cognitive tradition. In this approach, teachers develop two analogies to a desired "target." The first analogy is called an anchor, which is comparable to the target but an analogy that the student can accept, and the second analogy is called the bridge, or an intellectual midway point that shares the features of both the target and the anchor. The cognitive model is best introduced to students in an interactive environment so the teacher can use tangible examples. This is also the model of unlearning that one of my students, Delevan, introduced to his peers in the writing studio to help students unlearn bullying. I also use the cognitive model of unlearning when I talk to colleagues about multiliteracies and writing studio pedagogies. I want them to unlearn unworkable pedagogies in order to learn pedagogies that are designed to bring students into academic discourse, not turn them away from it. In the final chapter, I introduce the idea of unlearning accommodations from a framework provided by organizational behavioral studies, and then I look closely at unlearning as it is proposed by compositionists invested in LGBT and learning-disabilities studies.

Foucault's Theory of Heterotopia

Foucault's unfinished text, titled Des espaces autres, was a lecture given by the author on March 14, 1967 to the Circle of Architecture Studies. The lecture was not published for almost twenty years, though excerpts were published in l'Architettura. The text was published in full, finally, in the French journal Architecture, Mouvement, Continuite. Foucault was also one of the first critics to call our society networked: "We are at a moment, writes Foucault, when our experience of the world is less that of a great 
life developing through time than that of a network that connects points and intersects with its own skein” (14). This realization was an important one for Foucault and still relevant for us as our society is separated into escapements, or spaces that are linked together instead of one whole landscape.

Foucault, believing "that the anxiety of today fundamentally concerns space, no doubt much more than time,” (15) wants us to focus on an outer space, the actually lived (and socially produced) space of sites and the relationships between them. In his "Of Other Spaces: Utopias and Heterotopias, he defines such a space:

The space in which we live, which draws us out of ourselves, in which the erosion of our lives, our time, and our history occurs, the space that claws and gnaws at us, is also, in itself, a heterogeneous space. In other words, we do not live inside a void that could be colored with diverse shades of light, we live inside a set of relations that delineates sites which are irreducible to one another and absolutely not superimposable on one another. (16)

The six principles of Foucault's heterotopia can be found in Appendix B. The most important idea that Foucault's theory offers my research project is the idea that these other spaces act as mirrors. Heterotopic spaces mirror real spaces so that we may understand the flaws and imperfections of real spaces. Using Foucault's notion of heterotopia, I became keenly aware of the flawed spatial designs and ill-constructed policies toward disabled people in American education.

Kevin Hetherington traces the origin of heterotopia to the literal medical definition, "the physiological displacement of organs, deriving from the Greek topos 
(place) and heteros (otherness)” (8). A heterotopia, writes Hook and Vrdoljak, enables one to articulate the larger political rationality of a given site or text's general context of domicile,” as well, [a heterotopia] demonstrates how the logics and practices of place transpose the rationality of power into material practice” (206). Because of Foucault’s death, his concept of a heterotopia "remains an unfinished concept, a theoretical work in progress” (206). Given that Foucault’s theory remains unfinished, argue Hook and Vrdoljak, "one should not assume that heterotopia refers only to a type of place ... heterotopia can be just as much a textual site as a geographical one” (206). Hetherington, in his book The Badlands of Modernity, suggests:

Foucault is interested in the heterotopic character of language and the way that textual discourse can be unsettled by writing that does not follow the expected rules and conventions ... [Although he] ... does go on to speak of heterotopia in relation to specific social spaces whose social meaning is out of place and unsettling within a geographical relationship of sites. (8)

There have been several critical spatial projects that have looked closely at heterotopias. Some of the most interesting are Erik Blair's Further education project, Derek Hook and Michele Vrdoljak’s heterotopology of a security park in Johannesburg, Ben Gallan's concept of heterotopia of an alternative music scene to understand youth transitions through spaces of night-time cultural infrastructure in Wollowong, Australia, and Gunnar Sandin’s most recent work on viewing the Fresh Kills and Spilleperg landfills as social mirrors of human culture. Hook and Vrdoljak, unlike Blair, who only uses heterotopia to focus on space, "apply the notion of heterotopia as an analytics rather than merely as place; as a particular way to look at space, place, or text” (207). 
Heterotopias, then, appear to be sites and texts of resistance. L.H. Lees (Ageographia) defines heterotopia as "a heterogeneous field of potentially contestatory countersites for political praxis and resistance” (322). Heterotopia are also relational and comparative. Kevin Hetherington argues that "heterotopia do not exist in themselves, there is nothing intrinsic about [any site]," so, it is the "heterogeneous combination of the materiality, social practices, and events that were located at this site and what they come to represent in contrast with other sites, that allow us to call it a heterotopia” (8).

Therefore, heterotopias "possess no singular autonomy in themselves, and exist only in a relational or comparative capacity, by virtue of incongruous juxtapositions or combinations” (Hook and Vrdoljak 210).

\section{CHAT and Chronotopic Lamination}

Cultural Historical Activity Theory, or CHAT, is an attitude and approach to studying texts that acknowledges them as complex and situated in specific histories, cultures, and activities that can never be divorced from one another. I use CHAT to both teach my students about the complexities of writers and writing situations and also to theorize in my own research how relationships form and texts are produced when human and nonhuman actors come together in the writing studio. I base my knowledge about cultural historical activity theory in the work of Paul Prior et al., their 2007 Kairos webtext "Re-situating and Re-mediating the Canons: A Cultural-historical Remapping of Rhetorical Activity, A Collaborative Webtext,” and also my own research and practice on CHAT during my time at Illinois State University as a graduate assistant in the First-Year Writing program. 
Prior et al. claim that there is a need for a new mapping of rhetorical activity because the five canons are not sufficient to examine all of the complex elements that make up rhetorical activity. The authors examine the classical canons and explain how the canons are not useful in investigating rhetorical activities, particularly digital new media texts. They claim that it is best to re-map rhetorical activity than to try to "retrofit this ancient tool to do varieties of work it was never designed to address” (8). The classical canon and the re-mapped canon overlooked the role that socialization plays in rhetorical activity. The "cultural-historical activity theory" argues that "mediated activity involves externalization (speech, writing, the manipulation and construction of objects and devices) and co-action (with other people, artifacts, and elements of the socialmaterial environment) as well as internalization (perception, learning)” (17). The primary issue that CHAT explores is "how people, institutions, and artifacts are made in history" (18).

I think of the human and nonhuman actors, activities, formed relationships, madeobjects, and sociohistories that take place in learning space as what Paul Prior Julie A. Hengst ("Exploring Semiotic”) call a sociogenesis. I think of sociogenesis in my research project occurring across three heterotopias — the school, the writing studio and the safe space - as chronotopic laminations, or "the simultaneous layering of multiple activity frames and stances which are relatively foregrounded and backgrounded” (Prior and Shipka 188). The idea of chronotopic laminations comes from Bakhtin’s chronotopes, which are nodes that involve embodied and representational worlds. I think it is productive to consider each of the three heterotopic spaces as independent chronotopes, or nodes, all laminated onto one another to observe they each come together and also 
collide depending on the actors, activities, and mediated objects interacting in the writing studio. 


\section{CHAPTER II}

\section{THEORIZING THE WRITING STUDIO}

\section{Introduction}

Coming home from Illinois State University stressed out by inflated egos and politics, I emailed my former English teacher, who is now the Assistant Headmaster for Academic Affairs at Eagle Hill School. Essentially, he is the principal. I asked the principal if he was hiring an English teacher because I really wanted to come back to Eagle Hill School and teach. To my surprise, since my email was sent on a whim, I got an interview that same week and was offered a job in the week following. The interview was conducted over the phone by the principal and the English Department chair. The first question I was asked was whether or not I remember Hardwick. I was also asked if I thought I could live in Hardwick. Hardwick is a small town. Upper Hardwick, where the school is located, is relatively wealthy with old houses, a traditional town common with a Congregational church, and a post office that is run by one woman who knows each person in town by their post office box number. In contrast, lower Hardwick, known as Gilbertville, is poverty-stricken. It is quite literally a food desert; grocery stories are not at a close or even reasonable walking distance to where the town's poorest citizens reside. As someone who does not know how to drive, living in Hardwick does pose a challenge, but I thought the benefits would outweigh the inconveniences. 
Another question I was asked was if I would teach Writers’ Workshop, the school's foundational writing course. I responded with a resounding “yes.” As it turns out, Writers’ Workshop is not a favorite among my colleagues. In this course, I often have groups of students who have extremely different and often difficult relationships with writing. Teaching Writers' Workshop takes a lot of patience and, fortunately for me, a lot of movement. I am constantly moving around, working with students one-on-one and in groups, and making collages, videos, Web pages, decorating the bulletin board outside my classroom with my classes. It would impossible to stay seated, even if I wanted. I now teach between four and five sections of Writers’ Workshop in a school year.

A third question was how high school teachers could best prepare their students for college and beyond. My response was that teachers need to inspire students to create high expectations and goals for themselves. I followed up with relaying the need to introduce students to different school genres, professional genres, and popular genres, as well as the five modes of communication: linguistic, visual, aural, spatial, and gestural, along with the idea of semiotic remediation, or repurposing a text in one genre into a new genre with a new purpose and for a different audience. I explained to my interviewer that the landscape of first-year composition is changing dramatically in many colleges and universities, and the expectations our students will hopefully encounter will go beyond writing a traditional paper and move toward more digital and multimodal projects. I also responded that giving more homework is not productive. I often find myself wondering if giving homework at all serves a purpose because it appears that students accomplish much more in the workshop/class period than they do in their dorms or library during 
study hall. My answers to the assistant headmaster's questions must have been satisfactory because I was hired the same week, and within two months I had left Bloomington for Hardwick. My husband, four pets, and I moved into faculty housing only minutes from the school, and I began teaching writing in September 2012. My husband began teaching music part-time in January of 2013.

The first day I walked into my classroom it felt, on one hand, traditional with desks in a row and the teacher's workspace (desk, computer and printer) away from the students; however, on the other hand, it felt like I could change the space to optimize learning. The first day of school was successful. I liked my students and they appeared to be interested in the content of the course. That night, though, I went home and could not stop thinking about the design of the classroom. It needed to change. Once the design changed, the energy would change, too, I hoped. I needed to open the space up to create situations where students would socialize about their writing, and engage in divergent thinking and play. This brings me back to the lunch I wrote about in the introduction to this project. I could relate to a lot of the images that my colleagues and students described and I could empathize with their stories. The college classrooms I taught in were not too different from the classrooms they were describing. I began reading scholarship in writing studies that intersected postmodern geography and rereading scholarship in writing studios and their precursors, computer-supported writing facilities and multiliteracy centers. Satisfied with what I was reading, I began putting some theories into practice.

I was moved further to consider what it would mean to reshape my classroom and refocus my pedagogy in terms of a writing studio while reading Nedra Reynolds's 
Geographies of Writing: Inhabiting Places and Encountering Difference. Reynolds asserts that geographic identity is often taken for granted, which is a "missed opportunity for intellectual exchanges about space because geographical locations influence our habits, speech patterns, style, and values — all of which make space a rhetorical concept and important to rhetoric" (11). For writers, argues Reynolds, "location is an act of inhabiting one's words; location is a struggle as well as a place, an act of coming into being and taking responsibility” (11). This passage really resonated with me because I desire for students to utilize the classroom to come into being themselves as writers.

Once the constraints of our space become familiar, notes Reynolds, they "become encoded and thus rarely noticed or questioned;" therefore, "the daily routine elides the process of adapting, and the ideology of transparent space takes over — the idea that space does not matter" (14). Ignoring how people move through the world or, even more locally around the classroom, has devastating effects on students with learning disabilities and, indeed, all students. When teaching practices in the classroom become habitual and the constraints of technology, furniture, and even the walls become encoded in our everyday lives, students' needs become invisible. It is not in the best interests of our students not to question the spaces in which we teach. This passage also speaks directly to the work my colleagues and I are committed to at Eagle Hill School. We are dedicated to individualizing our teaching to our students' needs, meaning that if their needs became invisible, we would no longer be staying true to our mission. Therefore, I encourage my students to question the space in which they learn writing. I want them to question why we use the composing tools we do and why we sit in the arrangements we do, and also why I teach them in the ways that I do. Embracing a writing studio pedagogy means 
being aware that teaching practices can become habitual and that in order for that not to happen, teachers and students have to constantly rebuild the studio to meet students' needs.

\section{Postmodern Geography and the Writing Studio}

The writing studio has been theorized in critical spatial theory before now. Rhonda Grego and Nancy S. Thompson, in their Teaching/Writing in Thirdspaces, provide much insight into how critical spatial theory can affect a studio space as well as the students and teachers who are composing in that space. Grego and Thompson's writing studio, designed for basic writers, was an outcome of the South Carolina Commission of Higher Education’s “revoking the three hours of elective credit for English 100” (“The Writing Studio” 67). Creating a space for small groups of basic writers to come for extra assistance with their writing assignments was a solution that Grego and Thompson argued would "strike a balance between institutional needs and student needs” (66). Grego and Thompson imagined the writing studio as a space outside of and alongside the writing classroom that would "provide an access point for teachers and students to learn more about each other"... and to "reposition early college writing instruction to a place outside the realm of the traditional labels and stereotypes” (66). Grego and Thompson theorize the studio as a thirdspace, using the work of spatial theorists Henri Lefebvre and Edward Soja: “Thirdspace exists in the interstices — between outside and inside — on the boarder; it is like the beach: the space between ocean and land that is sometimes ocean and sometimes land, a space that is both/and” (72). The postmodern cultural geography of Henri Lefebvre and Edward Soja, who expanded Lefebvre’s critical work, writes Grego and Thompson, “closely examines the 
particularities of place and context as a way to move beyond hegemonic and institutional tendencies to pit those particularities against each other” (78), such as teacher and student. While Grego and Thompson's writing studio model was different from the model I created and tested at Eagle Hill School, we do share the objective to use the our writing studios to strike a balance between institutional needs and students' needs. Eagle Hill School is currently discussing our most pressing institutional need, which is to be more inclusive of the varying identities of our growing student body. This student body includes a significant LGBT population, and these students can find academic support in my writing studio.

Grego and Thompson's experimental studio space arguably could be considered a heterotopia. Their students, basic writers who are enrolled at a university, are identified by our disciplinary scholarship and experiences as deviating from the norm, which is beginning college with a traditional first-year composition class. In order to be labeled basic writers, students have to take placement exams and score below average on them. A basic Internet search about the writing studio at the University of South Carolina shows that the studio's function has changed over time to not only work with basic writers, but also to be an integral part of the University's PUSH program, which is an acronym for Preparing Undergraduates for Scholarly Holistic Writing. This has also changed the function the studio has in relation to the rest of the university from one that was once an extension of the English Department to a space that is now an extension of the undergraduate college. The studio can also be seen as a heterochronism, as its function changes with its students' needs and with the new needs of the university. 
The contrast between how Grego and Thompson defined the writing studio in 1992 and how the writing studio is presently defined by studio practitioners shows a turn from a space for basic writers to a space for all students composing online or in a classroom. There has been a shift from specific users, basic writers, to a diverse concept of users, including students from across disciplines and communities. There has also been a dramatic shift from low technology to a combination of both high and low technology, assembling and reassembling how human and non-human actors at a writing studio interact. However, what has remained the same in the last twenty-two years is the intention of writing studio stakeholders to create a writing space that is designed with its users in mind, being outside of the classroom yet also alongside of the classroom.

\section{The Writing Studio as a Place to Socialize, Problem-Solve, Think, Design, and Play}

The Clemson Class of 1941 Studio makes the turn from basic writing to online and mul timodal composition. Gresham and Yancey (2004) and Gresham (2010) argue that their studio model is "centered on learners immersed in communication-rich tasks" (Gresham and Yancey 9). The authors assert that “the Pearce Studio is like Grego’s studio model of composition and unlike it” (Gresham and Yancey 10). It seems quite clear that what set Yancey and Gresham's studio apart from Grego's studio is the access and commitment to digital technologies and online writing spaces as well as the demographic that the studios serve. Whereas Grego's studio was predominantly for basic writers, Clemson's physical studio and online studio are for a wider range of users encountering a variety of writing situations. Another difference was the operational budget allocated to the two studios. Yancey and Gresham's (2010) studio received a one million dollar donation from the class of 1941. The instructional and operational goals 
created for the class of ' 41 online studio were also groundbreaking and set a trend for other physical and online studios, such as the Noel Center at Eastern Kentucky University.

\section{A Commitment to Conversation}

Conversation and socialization are essential in classrooms and have not been privileged enough in the history of schooling. In the 1800s, teachers lectured and students listened. This is the banking model of education. In the last one hundred years, teachers realized that students needed to develop their language use, so then teachers began to call on students. Writing studio pedagogy insists that students take ow nership over conversations that take place in the class and that students socialize about their writing often. Bakhtin realized, “the world in language is half someone else’s. It becomes ‘one’s own' only when the speaker populates it with his own intention, his own accent, when he appropriates the word, adapting it to his own semantic and expressive intention” (293294). When students talk, they learn academic discourse and they also learn about each other, which proves important when students need feedback on a project. In a traditional classroom, most of the talk centers on the teacher asking questions to students, students answering, and then the teacher asking another question. This strategy is referred to as a “popcorn strategy.” However, in the studio, students should engage in several types of talking, such as self-talk, which boosts confidence and self-esteem, and feedback, in which students give constructive criticism to their peers. Students in the studio should also be questioning both the teacher's motives for assigning certain projects and their peer's motives for making specific suggestions on their work. Other types of talk that are 
important for students to practice are discussing problems and solutions and reflecting on their own studio practices.

Privileging tal king in class also means sharing the authority with students. I like to sometimes begin Writers’ Workshop by having students facilitate a conversation and even sometimes delegate responsibility to students for bringing in discussion questions to start a conversation. I welcome productive silence, too. Several of my students have slow processing skills, so they frequently need time to digest a question or activity. Too much silence, however, can be an indicator to me that there is some dissonance between them and the mini-lesson or project, which means I need to intervene. Oftentimes when teaching students with attention deficit hyperactivity disorder, the temptation is great for students to get off topic. When students in the workshop get off topic, I thank them for their comment and I try to link their statements to the discussion at the table. Sometimes, if a student continuously interrupts class with off-topic comments, I ask to visit with him or her after class and attempt to clarify why there are so many off-topic comments. In my experience, when a student is talking nonstop and/or off topic, that is a good indicator that he or she forget to take medication or has other issues to deal with outside of the Writers’ Workshop class.

\section{An Acceptance of Multiple Composing Tools}

In the writing studio, I emphasize to students that not only the digital tools, but any composing tool or mode of communication they select has to be appropriate for the audience, purpose, and situation of the project. This begins as a discussion about media and affordances, or how production of a text affects the distribution and reception from the audience. As Arola, Sheppard, and Ball write in Writer/Designer, “different media 
use different combinations of modes and are good at doing different things.” I impart to my students that "writers/designers think through the affordances of the modes and media available before choosing the right text for the right situation” (14). I do want my students to think about the composing tools they use more complexly than just simply as tools. I want them to know about the important relationship between tools and signs. Kress and van Leeuwen ("Multimodal”) argued that we need to attend to a variety of modes of communication. Bruno Latour, in Reassembling the Social: An Introduction to Actor-Network Theory and his earlier “On Technical Mediation — Philosophy, Sociology, Geneology,” argues that tools — composing tools, building tools, and even tools of destruction - are a critical nonhuman actants with an equal amount of agency as human actors. Latour maintains "if we stick to our decision to start from the controversies about actors and agencies, then anything that does modify a state of affairs by making a difference is an actor — or, if it has not figuration yet, an actant” (Reassembling 71). Taking note of nonhuman actants like cameras, microphones, Flip cameras, and Kuerigs, "does not mean that these participants 'determine' the action” (71); in fact, "things might authorize, allow, afford, encourage, permit, suggest, influence, block, render possible, [and] forbid" (72). People are still causing the actants to act.

Latour's actor network theory is put into context in Bump Halbritter's Mics, Cameras, Symbolic Action, where Halbritter interrogates Burke’s theory of symbolic action as "a territory that includes language as only one of the conventional, arbitrary systems at a writer's disposal” (8). Action, defined by Burke, would involve modes of behavior made possible by the acquiring of a conventional, arbitrary symbol system. Halbritter argues "with the yoke of language lifted, writing may not only be and do new 
work, it may live and breathe in scenes of symbolic action that we may not have been recognizing as scenes of writing” (8). This is a point that I argue vigorously in Chapters V and VI, showing examples of my research participants' multimodal writing and semiotic remediation work as scenes of symbolic action, as well as my showing them that the work they do "for fun" is actually a legitimate scene of writing. Lawrence Lessig claims "text is today's Latin” and that “TV, film, music video" is the "vernacular of today” (qtd. in Halbritter 10). The example Halbritter uses to support Lessig’s claim is that, "iLife can be a vehicle for democratic participation because of the forms of writing it enables are increasingly vernacular in that the texts they enable users to write are the texts most commonly read in American culture” (11). My research participants support Halbritter’s claim for new composing tools being vehicles for democratic participation: one student, Alice, composes a coming out blog so that she and transgender people can be heard by the Tumblr public and Delevan, another student, composes a project using several digital composing tools that introduced the topic of bullying to our campus.

\section{Privileging Multiple Problem-Solving Methods}

The term 'problem solving' refers to the mental process that people go through to discover, analyze and solve problems (Mayer). A student who is willing to recognize that a first plan may not always work means he or she also recognizes the value of emergent problem solving, which is, as I wrote in the introduction, the notion that "a collective solution represents a better solution"... and the solution "emerges iteratively as people, contexts, artifacts, and bureaucracies interact” (Kitalong and Brady 207). I tell students there is so much value in working together. I also tell students that there are different models of problem solving they can choose, such as the solution-first model, which aims 
to find a solution as quickly as possible, but often the problem-solver loses out on opportunities to solve the problem efficiently and effectively because he or she does not take the time to consult others. I caution students that utilizing the emergent problemsolving method may take more time and may be more difficult, but if they are willing to take their time and put their energy into experimentation and exploration and consult with peers and teachers, they will almost always find a solution that benefits all stakeholders involved in the problem.

There are several popular strategies for students to approach problem solving. One such strategy is learning heuristics. Heuristics are mental rule-of-thumb strategies that may or may not work in certain situations but rely on immediate examples that come to mind. When you are trying to make a decision, "a number of related events or situations might immediately spring to the forefront of your thoughts. As a result, you might judge that those events are more frequent and possible than others” (Mayer 21). There is also trial and error, which allows students to test out a number of solutions and rule out the ones that do not work. Students can also engage in problem solving using insight. Insight can occur "because you realize that the problem is actually similar to something that you have dealt with in the past, but in most cases the underlying mental processes that lead to insight happen outside of awareness” (Mayer 21).

The method of problem solving that I bring to my students in the writing studio is the model I was taught as an undergraduate at St. Edward's University; it is largely based on Vincent Ruggiero’s moral decision-making model. The Ruggiero method invites students to study the details of a case, keeping in mind that circumstances alter cases. It encourages students to use creative thinking to speculate about possible answers. 
Students next identify relevant criteria in the case. This means identifying obligations, values, and consequences, considering which of these are most important in the case. Students then determine possible courses of action, recognizing that there is almost always more than one course of action. Students should then have enough information to choose an action that is most morally responsible. In Chapter IV, Alice uses the Ruggiero method to analyze her coming out blog.

Writing Studio Pedagogy Drives Space Design

Both early and recent computers-and-writing research on classroom space design have been influential in my own quest to create a writing studio that engages students in activities such as socializing, thinking, problem solving, and playing. Trent Batson (1993) discusses the importance of education moving away from the chapel model of teaching toward the computer-supported classroom model of learning. The chapel model, writes Batson, comes from a centuries-old model of teaching where “ways of thinking about teaching were strongly influenced by religion...” and, as such, "the quasi-clerical image of the English teacher, and the cultural perceptions and expectations arising from that image make it difficult to think objectively about how we teach writing” (3-4). Batson argues that the move toward teaching writing in the networked classroom will move teachers away from teaching correctness and, instead, teach writing effectively (8). He introduced us to the Electronic Networks for Interaction (ENFI) model. In the ENFI model, communication inside and outside the lab is possible. It's a space where students “move psychologically out of the room and into a virtual space ..." where "the teacher will work modeler and coach" (12). It is important to mention that the ENFI model was originally designed for deaf students because Batson's work shows that the computers- 
and-writing discipline has been long concerned with promoting the advancement of disabled students in the writing classroom. The ENFI model, argues Batson, will allow teachers to know their students better and will also see "the boundaries between 'classtime' and 'out-of-class time' as an artifact of the old classroom/chapel” (16). Batson was a revolutionary in this thinking about how computers can shape writing as a sociocultural activity, taking into account the idea of users, space design, and technology use interacting together and constantly shaping each other.

Other important pioneers of space design in composition and computers and writing are Carolyn Handa (“Designing A”) and Lisa Gerrard (“Designing”). Handa designs a student-centered classroom, arranging the work stations into pods and paying careful and critical attention to the types of hardware and software she purchases for the college’s new writing space. After several years “of conducting writing classes in computer classrooms” her pedagogical stance shifted to one that privileges design, equipment that improves student interactions, and the realization that “the room's technology should help students to move out of the room to the world they will enter after graduation” (104). Gerrard, who was instrumental in setting up computer-supported classrooms at UCLA, urges colleagues to recognize that "the computer classroom must be more flexible than the traditional classroom ... providing a space for writing alone and in collaboration for lectures, conversation in groups and one on one consultations” (150). An ideal computer classroom, writes Gerrard, is "a place for readers, writers, and editors to gather in groups and to work alone ...” (151) and it is also a place where "the daily users [of the lab] are the people most likely to know how to make the electronic classroom a stimulating place to write and learn” (162). 
In more current research in scientific and technical communication on designing models that emphasize the important relationships amongst users, space design, and technology use as central to the creation of a writing space, Bemer, Moeller, and Ball (“Designing Collaborative”) examine how a combination of movable furniture and mobile technology can enhance students' collaboration in group-based writing assignments in the Utah State University English Department lab. The authors focused on how material conditions affected student collaboration. One finding of their research project was "that giving students the ability to create and adapt their technological spaces will help them work in collaborative ways in a typical writing scenario" (152).

Interestingly, the researchers discovered that "students desire familiarity, confidentiality, and presence, and they will take the affordances of technology and shape it into the closest approximation of a boundary” (159). Even in a small writing space like the classrooms at Eagle Hill, students desire familiarity, confidentiality, and presence in their classrooms. I think because of our small class sizes, achieving familiarity and presence are easy. Within days of the first week of a new class, students have chosen their seats at the tables and do not switch. I have found with tables in a classroom, instead of desks in rows, it is more difficult for students to secure confidentiality. However, if a student really does desire confidentiality, all he or she has to do is put up his or her laptop screen and he or she is less likely to be engaged in conversation by peers. Therefore, it appears that the portable technology that students do have, in fact, does create a border between them, their peers, and teacher.

Bateson's discussion of the chapel model and the networked model classrooms, even twenty years later, is still relevant for public and private schools. While some 
teachers at Eagle Hill prefer the chapel model, others, such as me, prefer the networked model. I believe that this design preference has to do with the power relationship a teacher desires to have with his or her students. The chapel model, and models like it, position the teacher as more powerful than students, and the network model is certainly supposed to be more egalitarian. For example, in the beginning of Chapter IV I write about how a math teacher at our school wanted to trade her tables for traditional desks, which is how I received two round tables. This teacher, a personal friend of mine, was dealing with substantial behavior problems this year in her classroom. She had large groups of teenage boys who frequently argued in class, which can be a soul-crushing experience. She grew tired of making little progress and chose to have the traditional desks brought in as a method of control. The traditional design of the students' desks is an instrument of disciplinary power, built to "provide a hold on their conduct, to carry the effects of power right to them, to make it possible to know them, to alter them” (Foucault, “The Means” 190). I do not disagree with my friend and colleague’s choice to embrace a chapel model, but I think that both teacher and students should be involved in the decision-making process regarding classroom spatial design. Knowing this teacher's story got me questioning what a writing studio model might look like across disciplines. In what ways could a math studio be different from a writing studio? Someday I may take on that project.

The Creative Process: Divergent, Convergent, and Lateral Thinking

Like all schools and workplaces, Eagle Hill School's student body is comprised of convergent, divergent, and lateral thinkers, and in the writing studio all thinkers are given equal opportunities to share their ideas. I urge students in the writing studio to attempt to 
apply each of the three thinking methods together when thinking about creating projects and completing in-class activities. Convergent thinking is oriented toward deriving the single best or most correct answer, while divergent thinking involves producing multiple or alternative answers from available information. Any discussion of creative thinking should begin with the early theoretical work of J.P. Guilford. Guilford, who in 1950 published a short article in American Psychologist, asked how we could discover creative promise in our children and our youth and how we could promote the development of creative personalities. Guildford stated that "a creative act is an instance of learning.... [and that] a comprehensive learning theory must take into account insight and creative activity” (446).

Often in conversations about creativity, I hear colleagues both at Eagle Hill and in other institutions remark that learning-disabled students only excel in divergent thinking, since convergent thinking is too linear an approach for them. This is a preposterous assumption. Some students I have had the privilege to teach are quite linear, particularly students who possess nonverbal learning disabilities like Asperger’s Syndrome. These students are almost always convergent thinkers and need time in class to develop as divergent thinkers. Conversely, students who possess attention deficit hyperactivity disorder can be strong divergent thinkers and need time to develop as convergent thinkers. My response is that one needs to learn both divergent and convergent thinking because, jointly, these skills help students create productions that are both effective and novel.

Arthur Cropley (“In Praise”) argues the need for applying divergent and convergent thinking to the creative process, and, in fact, argues that not applying both is 
risky and will ultimately not get the outcome one is hoping for. One example I can introduce from the writing studio to emphasize the importance of urging students to apply convergent and divergent thinking in their creation of a project is the creative process in which Alice and Delevan engaged with the CHAT project. The CHAT project is explained in depth in Chapter IV, however, briefly, the project is for students to take a text that they have already composed and remediate the text in a new genre for a new audience. Alice started her project with a small collection of poetry she wrote for another writing class. Alice began thinking about her project divergently: brainstorming ideas on paper, seeing new possibilities, such as the genre she eventually chose, video poems, and then drawing a CHAT map to figure out what she already knows about the complexities of her text, specifically about the seven areas of literate activity (see Chapter IV for a full overview of this project). Once Alice realized what she already knew about her text, she acted as a convergent thinker: being logical, combining what "belongs" together (in her case words, images, and sounds), and achieving accuracy and correctness in composing a video poem with rhetorically appropriate utilization of contrast, repetition, alignment, and proximity in her design.

Margaret Boden argues in her book Dimensions of Creativity that knowledge is the basis of creativity. What Cropley calls knowledge, Boden calls cognitive maps of a conceptual space. The example she uses is Mozart and how his creativity arose from his vast musical knowledge. She also writes about how creativity is paradoxical. What she means by this is that "people of a scientific cast of mind ... generally define creativity in terms of novel combinations of old ideas" and the "surprise caused by a creative idea is said to be due to the improbability of the combination” (75). Boden's theory on the 
origins of creativity makes a lot of sense in the context of my students' experimenting with multimodal composition and semiotic remediation in the writing studio. Students are so accustomed to writing with words, but when a student gets the idea to combine words and images and sounds as one text, he or she feels a sense of creativity and that sense of creativity leads to a sense of accomplishment.

The third type of thinking I introduce to my writing studio is lateral thinking, which was made popular by Edward de Bono in the 1970s. Lateral thinking, writes de Bono, is closely related to creativity, but whereas "creativity is too often only the description of a result, lateral thinking is the description of a process” (11). De Bono emphasizes lateral thinking as a method to gain insight into the natural behavior of the human mind. De Bono is frank: mere exhortation and goodwill are not enough. If one is to develop a skill one must have some formal setting in which to practice it — and some tools to use (17). So that students can tap into their insight so that they can begin, continue, or complete a project, I encourage students to bring in a variety of materials, including visual materials like photographs from their own personal collections or from a basic image search online, drawn pictures and created storyboards. De Bono encourages lateral thinking by asking students to think and write about themes and anecdotes and other stories. He suggests people find themes by looking around their classrooms or workplaces for objects that resonate with them. He suggests finding anecdotes and stories both from fables and from one's own experiences. Other aspects of lateral thinking include fractionation, which engages thinkers in looking for divisions in unified patterns; challenging assumptions; suspended judgment, or looking at multiple alternatives and possible outcomes of a problem before making a judgment; and the reversal method, in 
which thinkers purposefully go in the opposite direction of what appears to be a fixed solution. De Bono urges us that neither reversed arrangement is better because "it is not a matter of choosing the more reasonable reversal or the more unreasonable one. [A thinker is] searching for alternatives, for change, for provocative arrangements of information” (142-143). Lateral thinking, while useful for some students, can be too logical and not abstract enough for some students with learning disabilities. However, I have found that most of the students I work with in the writing studio benefit from a mixture of convergent, divergent, and lateral thinking.

\section{The Writing Studio as a Playground}

Theories of play and the idea of the writing studio as playground are important to writing studio pedagogy. I have found play to be an essential component of my pedagogy because I believe it to be important to teach students that they must find enjoyment in the hard work of writing and in the projects they compose. Johan Huizinga (Homo Ludens) argues that the contrast of play and seriousness is always fluid: the inferiority of play is continually being offset by the corresponding superiority of its seriousness. Play turns to seriousness and seriousness to play (8). Huizinga identifies five characteristics of play: play is free, and is in fact freedom; play is not "ordinary" or "real” life; play is distinct from "ordinary" life both as to locality and duration; play creates order, and is order; play demands order absolute and supreme; and play is connected with no material interest, and no profit can be gained from it (13). The third characteristic, which looks at the space where one plays as a playground, is particularly important to the writing studio. Huizinga challenges us to accept that "all play moves and has its being within a playground marked off beforehand either materially or ideally, deliberately or as a matter of course” and that 
"inside the play-ground an absolute and peculiar order reigns" (10). The writing studio is marked materially with a variety of composing tools and distribution tools students can use to compose texts of a variety of media and affordances; however, the writing studio is also a playground marked ideally by me, as the instructor, as a space where students have the freedom to voluntarily compose texts that position them to make positive impacts on social problems that are relevant to them and their communities. "Into an imperfect world and into the confusion of life, Huizinga writes, "it brings a temporary, a limited perfection” (10). The order that reigns in the writing studio, as playground, can be best understood through the rules that the studio class creates together and also how students in the studio execute a project from start to finish. Students first invent a project, pitch the project, answer questions about the project from peers, and then either revise the project plan, carry out the project plan, or discontinue the project. If a student chooses to continue the project, he or she will keep submitting their drafts and storyboards or raw footage to the studio for feedback until the project is completed. The temporary and limited perfection that students find in the writing studio is discussed more at the end of this chapter when I examine the writing studio as a heterotopia that mirrors the illconstructed designs and policies of a traditional writing classroom. In Chapter IV, I introduce and examine the ramifications of a student, Edwin, who broke one of the agreed-upon rules and therefore managed to temporarily collapse the students' playworld.

Michael Ellis, in his 1973 book Why People Play, argues that, ideologically, a human is most human, as defined by our culture, when at play. He writes that play is "commonly considered to be the behavior emitted by an individual not motivated by the 
end product of the behavior and that play is assumed to be free" (2). In contrast to Huizinga theory of play, Steinman (1970) "has argued cogently that to consider play free is to assume arrogantly that we can control all the effects of our environment on behavior" (qtd. in Ellis 2). Ellis supports Steinman, writing that even "if we remove the teachers, behavior will not become random or free of all constraints. There are hosts of other factors modulating the behavior of the child” (3). While I find Huizinga's concept of the playground useful because I can apply it to the writing studio, I do tend to agree with the argument Ellis and Steinman put forward that play is not really free because of the constraints put on students by teachers and the physical environment of the school and the studio. At Eagle Hill School students' time is managed precisely. Students wake up at 6:45 a.m. and their time is managed from then until bedtime. Our students need structure; even their free time after dinner and until study hall takes place in supervised locations on campus. Regardless of its value, structuring students' days in this manner often triggers resentment, and that resentment can impact their schoolwork in the studio and in other learning spaces. The writing studio also has constraints. My classroom is not large and students can only move around so much, which limits the ways in which students can produce work.

Ellis also examines what were, at the time of his book's publication, recent theories of play. Ellis explains play from both cathartic and psychoanalytic perspectives. Play, argues Ellis, "greatly reduces aggression and frustration, and stress and anxiety" (49) from past experiences. These perspectives look backward at "the antecedent experiences, and see play as a strategy for erasing or working out the effects of those experiences” (49). Even taking Ellis and Steinman’s arguments into consideration, I still 
argue that the writing studio does offer students more opportunity to play than other learning spaces at Eagle Hill and in traditional writing classrooms in public schools. Mihaly Csikszentmihalyi’s theory of flow is an important aspect of play because in it he examines the importance of autotelic activities, or activities that have an intrinsic reward, and important to my writing studio pedagogy is the idea that students compose projects that provide intrinsic rewards such as knowing that their writing has helped another person or group of people be heard by an audience that would not have otherwise listened. Csikszentmi halyi (Beyond) has dedicated his career to examining why people engage in activities that only provide intrinsic rewards to them. He argues that a society could not survive for long if people were exclusively involved in playful pursuits. He and his research team "assumed, however, that there is no unbridgeable gap between 'work' and 'leisure.' Hence, by studying play, one might learn how work can be made enjoyable” (5). Csikszentmihalyi also asks why patterns of stimulation that under some conditions are neutral or even aversive can suddenly become enjoyable (6). Activities in which one chooses to participate are called autotelic, and the intrinsic rewards in autotelic activities range amongst friendship, developing skills, and emotional release.

Csikszentmihalyi argues that autotelic activities maximize intrinsic rewards (21) and that autotelic people enjoy what they are doing regardless of reward (22). The autotelic experience that bridges people to activities brings people to Funktionalist state, or what Csikszentmi halyi calls "the pleasurable sensation that an organism experiences when it is functioning according to its physical and sensory potential” (24). Csikszentmihalyi eventually names the autotelic experience "flow.” Flow is when a person is not experiencing boredom but also not brought to a state of anxiety. Flow, therefore, is 
beyond boredom and anxiety. It is “complete involvement making full use of one’s skills” (36). There are six characteristics of the flow experience. The first characteristic is a merging of action and awareness, in other words one is aware of his actions but not of the awareness itself. Csikszentmi halyi writes when "awareness becomes split, so that one perceives the activity from the 'outside,' flow is interrupted” (38). Such a split occurs when the person in flow begin to ask questions such as "what am I doing here" and "should I be doing this?" Another important characteristic of flow is that it seems to only occur when "tasks are within one’s ability to perform" (39). A third characteristic of flow is it occurs when one's attention is centered, losing his or her ego. A fourth characteristic is that in a state of flow, one is not worried about the lack of control. A person "has no active awareness of control but is simply not worried by the possibility of lack of control” (44). A fifth characteristic is that flow "usually contains coherent, noncontradictory demands for action and provides clear, unambiguous feedback to a person's actions ... made possible because one's awareness is limited to a restricted field of possibilities” (46). A final characteristic of flow, writes Csikszentmihalyi, is its autotelic nature, meaning, it "appears to need no goals of rewards external to itself” (47). In Chapter IV, I will contextualize Delevan’s semiotic remediation project in terms of flow.

In the next chapter I describe the location of my research, the LGBT population at Eagle Hill School, and the Writers’ Workshop I teach with writing studio pedagogy. I then introduce my research methodology and accompanying research methods. 
CHAPTER III

\author{
APPLYING FEMINIST METHODOLOGY, AND THE METHODS OF CASE STUDY, \\ GROUNDED THEORY, AND CULTURAL HISTORICAL ACTIVITY THEORY \\ TO UNDERSTAND HOW STUDENTS RECLAIM THEIR \\ DISABILITIES AND SEXUALITIES
}

\title{
Introduction
}

I have two purposes in this chapter: The first is to present the location of research, the LGBT population at Eagle Hill School and the Writers’ Workshop studio course where I apply writing studio pedagogy; the second purpose is to present the mixed methodologies I apply to my research design. I hope to establish my project as feminist research in addition to computers-and-writing research. I take seriously my "role of caring, emotion, and attachment to [my] research subjects” (Bizzell 2003). My interest in feminist research methodologies is motivated by the understanding that LGBT students are underrepresented in learning disabilities literature, both academic and popular. Only until very recently have connections been made between feminist methodologies and disability studies (though not including learning disability studies). Jay Dolmage and Cynthia Lewiecki-Wilson (2012) recognize that feminism and disability studies ought to be powerful allies in the important scholarly project "unmasking the powers and processes of norming and the construction of normality” (24). While Dolmage and LewieckiWilson do not directly examine learning disabilities in their work, they do use the 
alliance of feminism and disability studies to critique the medical model. The authors argue that "disability history and feminist and disability critiques of science provide important methodological lenses, which help the researcher challenge epistemologies that do not self-reflexively examine their own dispositions toward and assumptions about the subject of study” (29). I will also briefly discuss methodological issues affecting research on LGBT youth. Cianciotto and Cahill write, due to the methodological difficulties in researching hidden populations, "the gaps in research on LGBT people widen to chasms for LGBT youth” and also that “data on LGBT youth and their lives are often difficult to gather or simply not available” (151). Finally, I want to acknowledge that Eagle Hill School is open to my research, as the school is interested in learning more about reaching students with learning disabilities across all races, classes, sexualities, and abilities.

\section{The Research Site}

Eagle Hill School was founded in 1967 by three leading educational experts, Peter Figgie, MD, James Cavanaugh, MD, and Charles Drake, PhD. Having attended the Conference on Exploration into Problems of the Perceptually Handicapped Child in 1963, they were introduced to a new term in what proved to be a seminal moment in the history of education of learning-disabled individuals. "Learning disability,” introduced first by Samuel Kirk, described a group of students whose interests had previously been unrecognized in national education policy and had now been publically acknowledged as an entity that required special attention, Soon afterward, a new division of the Council for Exceptional Children was established to focus on educational practice for students with learning disabilities. Eagle Hill School embraced that work and began by offering the first boarding school program for thirty boys, ages seven through thirteen. These students 
were offered an experience that focused on their academic needs in a setting where they could compete against their own best performance rather than against other students. Eagle Hill School has since developed into the premier independent, coeducational college preparatory boarding school educating students in grades 8-12 with learning disabilities.

\section{LGBT Students in Secondary Education}

There is far more research presently on LGBT teens in secondary education than when I was in high school. I wonder how my life would have been different had the sheer volume of research been accessible to my teachers and residence counselors at Eagle Hill School. According to Cianciotto and Cahill, in their book LGBT Youth in America's Schools, "given the studies indicating that 4 to 6 percent of the U.S. population is homosexual or bisexual, [they] estimate that between 896,000 and 1.34 million students in grades 7 through 12 may identify as LGBT" (14). And, report the authors, "very few studies estimate the transgendered population, because of the complexity associated with defining 'transgender' and what one considers gender variant (14). Cris Mayo ("LGBTQ Youth") asserts "as the cultural climate changes and the rights of gender and sexual minorities are being recognized in state and federal laws, schools must find ways to respect those rights" (17-18). Schools need to "move beyond a simple process where lesbian, gay, bisexual, and transgender issues are added to what is already taught as if such lessons weren't already there, either not fully marked or as if LGBTQ people were not already in schools" (18). Attending to this not-so-simple process "means taking into account how institutions and norms shape such understandings of gender identity and sexual orientation” (Mayo 18). Darla Linville (“Queer Theory”), in a valuable study on 
LGBTQ youth, uses queer theory to interrogate and challenge educational discourse and practice. She points out that "in the larger teen population, the feelings about nonheteronormative sexuality are much healthier" (154-55). She goes on to share, "Although [teenagers] may feel less conflict about sexuality than previous generations, they do not feel that sexuality is a simple choice, nor do they accept that one can feel happy without naming oneself or picking a category” (155). Interestingly, and I think that this was definitely true for me as an LGBT teen, "teens may sense that school is fine and free of homophobia and, at the same time, that the least safe place they find themselves is school, without this being a contradiction” (155). Linville discovers that popular questions amongst LGBT teens are, which expressions of self constitute "real” gender and can you value a person based on his or her sexuality. These conflicts, states Linville, "simply highlight the ways in which teens struggle with the various messages they receive from church, school, after-school activities, family friends, and popular culture as they attempt to understand themselves and gender and sexuality” (162).

Much of the literature about LGBT teens focuses on defining LGBT and queer. The defining of the acronym LGBTQ, and the word "queer" in general, is contentious among scholars and people outside of academia. Kimberly Coiser (Creating Safe Schools) defines queer youth arguing this group "must be conceptualized and theorized quite broadly" (285). Her use of the word "queer” is “... as an umbrella term to encompass all children and youth who are impacted by their own and other people's reactions to lesbian, gay, bisexual, transgender, intersex, and queer/questioning issues” (285). Several groups of students come to mind for Coiser: students who are out as LGBT, students who are perceived to be LGBT by other students and teachers, and 
students whose parents identify as LGBT. “Lesbian, gay, and bisexual may seem like relatively easy concepts to understand,” writes Mayo, "but even with those categories there may be cultural and regional differences, different relationships to normative gender identity, and differing degrees of politicization of sexual orientation” (19). Mayo writes “the Q is LGBTQ usually refers to “queer” although it may also stand for “questioning.” Queer is a concept and identity that works against problematic forms of normalization, troubling the exclusions that any category of identity may enact” (21). Questioning students, or "students who are critically analyzing their sexual orientation, are reminders that the process of having sexuality is just that: a process” (21). Coming to terms with my sexuality and learning disabilities was a process, but my coming out as an academic was an even more challenging process.

\section{The LGBT Population of Eagle Hill School}

Taking Kim Coiser’s (“Creating Safe”) and Cris Mayo’s definitions of queer, the LGBT population at Eagle Hill is substantial. We currently have one present and one past member on our board of trustees who identify as LGBT; we also have several faculty across departments who identify as LGBT. Faculty members who have been teaching at Eagle Hill for thirty years do not recall the campus having a gay student presence until the 1990s beginning with my own coming out, although there were out faculty. Eagle Hill School also has several students who have LGBT parents.

Eagle Hill School does much to bring LGBT culture to our students and the outside community. We have Gay-Straight Alliance (GSA), which was established in 2004 by a group of three students and one faculty with no resistance, but there were some initial concerns that having a GSA on campus would offend parents and lead them to 
imagine the school converting their children. Our GSA has hosted a panel for the school that focuses on being LGBT in school and in society; additionally, a GSA adviser holds meetings on campus once a week. Aside from the GSA, the Eagle Hill community came together to perform The Laramie Project for our school, the town of Hardwick, and the surrounding the local communities. In May of 2014, Eagle Hill School was the home for an exhibit titled "In Our Family: Portraits of all Kinds of Families.” The exhibit included photographs of families with same-sex parents.

\section{Writers' Workshop}

The Writers' Workshop course at Eagle Hill School is a six-term class. The course catalog reads: The units of study are designed sequentially, focusing on the fundamental elements of the writing process and the incremental acquisition of written expressive skills. Instructors focus on a variety of topics and themes in their workshops, as determined by individual student interest and ability. Each student's writing ability is assessed and used in the determination of his or her individual placement in workshop sections. Throughout each of these courses, emphasis is placed on proofreading and selfand peer-editing in order to develop each student's ability to critically assess her or his work and the work of peers in a positive and constructive manner.

Teaching Writers’ Workshop at Eagle Hill School is always my first choice when our department chair asks us to name the courses we would like to teach for the coming year. I take the workshop approach seriously. The workshop, as described by Diane Donnelly, in the introduction to her edited collection, Does the Writing Workshop Still Work?, states it "is a process, and as such, its plasticity conforms to individual manipulation, and its response depends to some degree on the dynamics and preparedness 
of each particular class” (9). Presently, most of the writing workshop scholarship is in creative writing. I believe, however, that the workshop approach is valuable for students who are learning other forms of writing. The value of the workshop can be found in a focus on collaboration, on the writing process, on writing in genres, and on learning how to transfer skills from one project to the next and then, hopefully, to other classes in other disciplines.

The studio space I offer my Writers’ Workshop students is, I hope, a safe space in which students can be themselves and play with language across multiple modes. The studio space and pedagogy I have created is predicated upon several other types of studios, in particular studios that focus on the arts. Studio practitioners have much to learn from artistic studios, regarding both physical space and pedagogy.

Hetland et al. (2013) provides readers with this description of the art studio space: The students look relaxed; sometimes they sit on the floor or music plays softly. After materials are set up students dig in, not concerned about getting clay on their hands or paint on their jeans. ... Students talk among themselves quietly as they begin to work, and the teacher circles around, watching for teachable moments and zeroing in on individual students with a comment, suggestion, question, or critique. The students who originally appeared so casual are actually working hard — they are thinking visually, analytically, critically, and creatively. (13)

Elements of designing the physical space of a studio focus on material stations, walls, light and sound, and social climate. Wall space, write the authors, is a potential teaching tool (15). Jason Green, an art teacher at Walnut Hill School for the Arts in 
Massachusetts, has a ceramic studio that "features a large matrix of tiles that reveals how systematic mixing and layering of glazes produce different effects after firing” (16). Often in art studios, teachers use music to either help calm or energize their students. Social climate, according to Hetland et al., means both teacher-student interactions and peer interactions. In teacher-student interactions, "teachers observe and intervene ..." but “are also aware and thoughtful of students' needs for privacy and at times to develop a relationship with materials, tools, and their own work” (16-17). Peer interactions take place in a structure that recognizes the need for students to feel safe and respected by each other. For example, at the Boston Arts Academy, "teachers ... explicitly instruct students in how to make constructive criticism ..." and "teach peer critique methods such as making appositive comment first and then phrasing suggestions for improvement in neutral terms” (17).

Hetland et al. provide four pedagogical structures for teaching and learning in a studio space. The first is demonstration-lecture. In demonstration-lecture, a teacher provides a brief, visually rich lecture to the class. The themes in this structure are group focus, visual emphasis, immediate relevance, brevity, and connection. Demonstrationlecture "diverges from traditional lectures in that the information presented is intended to be immediately useful for carrying out class work and homework” (21). The second structure is students-at-work, where students work independently on a project, typically one introduced to them during demonstration-lecture. The themes in this structure are a focus on creating, independent work, ongoing assessment, and individualized interventions. In the students-at-work sessions, "students are deeply involved with the materials of the assigned project ... thinking seriously; and making artistic decisions as 
they work" (25). The third structure is critique where "art-making is paused, so that students and teacher can reflect on the work in process of creation” (26). The themes of critique focus on artworks, reflective, verbal, and forward-looking. Critiques, write the authors, “have two distinguishing features: They focus attention on students' work and working process ... and second they are explicitly social ... students share their work with the teacher and get responses from them” (26). The fourth structure is exhibition. Exhibition includes the previous three structures and "often extends beyond class space and time, including into virtual spaces” (30). Exhibition also “contributes to program development because it encourages high standards and to program assessment because it makes artistic efforts visible” and can be “physical or virtual, installed or performed, ephemeral or permanent, and sanctioned or guerrilla” (30). In Chapter IV, I discuss how students in my Writers’ Workshop course plan and execute an exhibit in our classroom for other students and teachers at the school.

I identify as an expressivist/neo-expressivist, although I incorporate collaboration, process, new media, and genre studies into my Writers’ Workshop course. I am invested in creating an optimal workshop course in the emergent writing studio. I take seriously Lucy McCormick Calkins’ vision of the writing workshop, which emphasizes minilessons, work time/time to confer, peer conferring, share sessions, and publication celebrations. I also align myself with Nancy Atwell, author of In the Middle: New Understandings about Writing, Reading, and Learning, who asserts that the writers' workshop must be a place that both teachers and students can inhabit together (4). Atwell creates an image of a writers’ workshop where students “develop their own ideas for writing and [write] for all kinds of audiences, where writers receive responses from their 
friends and the teacher while they were writing” (13). Even though I teach multimodal composition and genre studies, I still argue that teaching the work of Ken Macrorie, particularly his idea of truthtelling, is valuable to students, especially teenagers.

Calling myself an expressivist, I like to think that I mentor and guide students to write about topics that matter to them. Being an expressivist means " 'establishing a pedagogy of equity' in which all can contribute to be heard” (qtd. in Tate et al. 118). Burnham and Powell argue that "expressivists value autonomy as signaled in their concern to empower people through voice, and [we] believe in agency and resistance" (118). Even though I refer to myself as an expressivist and a teacher who is concerned with not only voice and personal writing, but also with equity, I know, as Bronwyn Williams writes:

The wide-spread use of the term "expressivism” as a pejorative has distorted important conversations that should be taking place about the personal position in writing, including questions about the value of individual experience in intellectual work, the purposes of writing beyond the composition classroom, and the ways in which experience and writing combine to help writers compose their identities in print. ("Dancing with Don” n.p.)

So that the term expressivist becomes less pejorative, or even accepted, Williams argues instead that being an expressivist can mean professing "that knowledge can be generated by students exploring and reflecting on the meaning of their experiences and ideas in writing running counter to the epistemological mainstream of the academy” (n.p.). Williams furthers argues that this does not mean simply writing about what 
happened to you and how you feel about it. It requires that writers — and for Don Murray students are writers — must make connections from their experiences that help them come to new knowledge and understanding (“Dancing with Don” n.p.). Growing from one who has been a student at Eagle Hill School to now being a teacher of writing in the same place, it is of paramount importance for me to teach my students the power of writing about the self — an opportunity not likely had before coming to Eagle Hill School — and also the power of using writing to make connections between the self and social justice. Many students come to Eagle Hill needing to write about how they have been treated in other schools, and my colleagues and I invite them to do just that. We also want them to move towards writing about topics bigger than themselves, as Alice with her coming out blog on Tumblr, and Delevan with his invisible theatre project about gay bashing, show us in Chapter IV. Expressivist/neo-expressivist pedagogy helps me — and perhaps other colleagues - help students meet that goal.

Along with being a neo-expressivist, I am also interested in the social processes that impact student writers and how those social processes broaden what it means to write. Prior and Hengst talk about the social processes of writing as the process of semiotic remediation, or the “ 'diverse ways that humans' and 'non humans' semiotic performances are re-represented and reused across modes, media, and chains of activity” (1). For Prior and Hengst:

The notion of remediation focuses attention not only on the laminated heterogeneity of semiotic means that are simultaneously at play in any situated interaction, but also on the location of any interaction — and its convergence of particular tools, people, and environments — within 
historical trajectories that reach from past into present and project forward to near- and long-term futures. (7)

I teach students in the studio that texts are complex and that texts are produced at specific sociocultural moments. I teach students that texts are produced based on the social processes that include activities, technologies, and processes available to writers in specific sociocultural moments and the histories, cultures, and activities that sponsor and maintain a text can never be divorced from one another. Finally, I teach students the value of cultural historical activity theory as a lens to look at their own composing by engaging students in mapping the trajectories of the texts they are producing, as I did with both Alice and Delevan while they were composing their semiotic remediation projects.

In the sections of Writers' Workshop that I teach, the focus is on students learning how to compose multimodally, and with an awareness of rhetoric, literate activity and the possible trajectories of texts; and to support students who desire to make texts that are socially responsible. I always emphasize revision and collaboration as integral to the act of composing. I have used Wysocki and Lynch’s Compose-Design-Advocate to begin discussions on ethos, pathos, and logos in written and visual communication; however, the language of the book proved to be too dense for many of my students. I recently adopted Kristin Arola, Jennifer Sheppard, and Cheryl E. Ball’s Writer/Designer: A Guide to Making Multimodal Projects. This book is ideal for my students. The language is accessible and the examples are relevant, making it relatively simple for students to begin understanding the complexities of composing texts in a combination of visual, aural, spatial, and gestural modes, as well as the traditional linguistic mode. In the first part of 
the class, we grapple with what it might mean to write without writing in the traditional, linguistic mode. For students who are dyslexic and dysgraphic, realizing that they can compose texts in other modes can be life-changing. There are usually a few class periods where students doubt that images, sounds, and movements are texts, but after this doubting period, students go into a renaissance mode where everything is a text and everything is rhetoric, and the projects that they compose are works of art! There is such a difference in the atmosphere of a writing class where students are afraid to write, versus where students are excited to compose.

\section{Methods and Methodologies in Feminist and Computers-and-Writing Studies}

I use Sandra Harding’s work to define method “ 'as a technique for gathering evidence' and methodology as a ‘theory and analysis of how research is done or should proceed” ” (qtd. in Schell and Rawson 2). My position and ethics as a researcher grow from the work of computers-and-writing researchers and feminist researchers. I also focus on methodologies as critical research practices and research as praxis. Sullivan and Porter (“Opening Spaces”) want researchers to come clean about why they research the topics and subjects they do; they advocate a methodological reflexiveness that included “a critical perspective toward one’s research practices” (9). Powell and Takayoshi (Practicing) similarly argue that a central concern of feminist epistemology and methodology has been self-reflexivity (2). Feminist methodologists, write Powell and Takayoshi, "have called on researchers to explicitly reflect on their epistemological, ideological, and subjective commitments about their own positionality” through the “research site, participants, data collection, as well as in the representation” (2). Fonow and Cook suggest that "reflexivity has also come to mean the way researchers write 
themselves into the text, the audience's reactions to and reflections on the meaning of research, the social location of the researcher” (qtd. in Powell and Takayoshi 2). Kirsch (Ethical Dilemmas) analyzes "the methodological and ethical implications of feminist research for composition studies” (x), and I take those implications as I work closely with my own research participants. Kirsch’s seven principles for femi nist research guided me throughout my research project: asking research questions that acknowledge and validate women's experiences; collaborating with participants as much as possible so that growth and learning can be mutually beneficial, interactive, and cooperative; analyzing how social, historical, and cultural factors shape the research site as well as participants' goals, values, and experiences; analyzing how the researcher’s identity, experience, training, and theoretical framework shape the research agenda, data analysis, and findings; correcting androcentric norms by calling into question what has been considered 'normal' and what has been regarded as 'deviant;' taking responsibility for the representations of others in research reports (such as this dissertation) by assessing probable and actual effects on different audiences; and acknowledging the limitations of and contradictions inherent in research data as well as alternative interpretations of that data (Kirsch 4-5).

My research is also guided by Kirsch and Royster ("Feminist Rhetorical”), who weave the idea of critical imagination into feminist methodology. Critical imagination means developing mechanisms "by which listening deeply and respectfully becomes standard practice.” Deep listening, argue the authors:

... is geared toward facilitating a quest for a more richly rendered understanding — listening to and learning from women themselves, going repeatedly, not to our assumptions and expectations, but to women — to 
their writing, their work, and their worlds, seeking to ground our inquiries in the evidence of the women's lives, taking as a given that the women have much to teach us if we develop the practice to pay attention in a more paradigmatic way. (649)

The shift in practice to performing research with critical imagination is what Kirsch and Royster call "a shift in the commitment to engage dialectically and dialogically, to actually use tension, conflicts, balances, and counterbalances more overtly as critical opportunities for inquiry ... to simulate an interactive encounter with women who are not us ... women whom we study” (652). It is this vision of what critical imagination can do to bring forth stories of female and LGBT students who have been diagnosed as learning-disabled that compels me to record their stories. I want there to be clarity and substance to discussions about teaching and learning from students with learning disabilities.

Sullivan and Porter “contend that research practices in computers and composition research are of necessity a praxis” (45) and that methodology needs to be recognized as a heuristic that is constructed from particular situations, not applied to situations before reflection from the researcher. Methodology, argue the authors, "intersects with and is perhaps changed by practice” (46). Sullivan and Porter argue that “once we accept that the methods we use provide powerful filters through which we view the world, then we can adjust to a position of using those filters with at least relative consciousness” (65). What this meant for my research project was that I did not know which methods I would apply to my research project until I met my students in Writers' Workshop. Once I met the students and had a better understanding of who they were as 
writers, technology users, and, as my position at Eagle Hill School affords me, an understanding of who they are outside of the classroom, I recognized that case studies were appropriate to capture their stories and responses to their own work so that I could use those stories and responses to help me interpret my data. As my research continued, I recogni zed that my situation was changing as my data became more complex. I decided that my case studies would need to be explained in a way that would allow me to theorize my writing studio as a space for learning-disabled students to experiment with making multimodal texts with a variety of technologies. This being the case, I applied grounded theory to my study, which is a methodology that privileges reflexiveness and concurrent data collection and analysis.

Research on writing means maintaining a shared understanding of research as situated, systematic, and reflective investigation of literate activity with the goal of deepening our understanding of why, how, when, where, and what writers are writing (Sheridan and Nickoson 1). Further, knowledge-making, writes Haas, Takayoshi, and Carr (“Analytic Strategies”) is “particularly important for the field of writing studies, where the object of study — contemporary writing practice — is not fixed but fluid and changing” (51). This knowledge-making, the authors continue, “depends on what John Dewey calls 'competent inquiries', which [they] understand to be inquiries that are systematic, self-conscious, clearly articulated, and warranted” (51). Researching writing studies also means being interested in blurring approaches to research. Sheridan and Nickoson identify three places of blurring in researching writing studies: in what we consider literate activity, in just how multilayered learning environments are, and being able to overlap qualitative and quantitative methods (2). While I do not overlap 
qualitative and quantitative methods, I do consider my students' literate activities and the writing studio as a multilayered learning environment.

The ability to mix methods and methodologies and also be able to create a methodology that researchers are comfortable using is a key feature in researching writing studies. Haas, Takayoshi, and Carr discuss the importance of researchers creating a homegrown research methodology. One way of creating a homegrown methodology is to "combine research traditions," (60) as I have done in this project pairing case studies with grounded theory. Another way, write the authors, is in the "action-reflection, talktext movement ... an integration of doing, writing, reflecting” (58). This research method they share is much like the memo-writing process in grounded theory, where the researcher actively becomes part of the research project by including his or her own interpretations of the data as data for the project. Selfe and Hawisher ("Exceeding the Bounds”) advocate that the research subject should also become part of the research process and share the importance of engaging research subjects as co-authors. Co-authors not only provide information as data but also help the researchers modify the questions and interpret the data as it is being collected. The authors claim that if researchers depend solely on objective information, "we tend to miss the human and very personal face of social, cultural, economic phenomena that so fundamentally shapes the project of education” (36). Essentially, the writings of Selfe and Hawisher and Kirsch and Royster both call on researchers to embrace critical imagination.

The first time I was encouraged to think about writing and technology and also to write, myself, from a feminist methodology, was in the first semester of my master's program at Michigan Technological University in Cynthia Selfe's graduate course on 
literacy, technology, and education. Selfe gave me an opportunity to do my own research and create a case study for her and Hawisher's edited collection, Gaming Lives in the Twenty-First Century. My case study focused on a gamer named Chris who has diagnosed learning differences. Using the questionnaire that Selfe and Hawisher invented for their research project, my coauthors and I described how Chris played a flight simulator game to strategize his writing practices in his freshman composition course at St. Edward's University. That case study, as well as the case studies I produce in this dissertation, resonate with me, as I, like my subjects, have diagnosed learning disabilities and am openly gay. I hope that my subjects' stories will resonate with readers, creating conversations in learning disabilities studies and LGBT Studies.

\section{The Case Study Strategy}

In this section, I introduce the case study methodology in terms of definition, concerns, the role of theory, and single- and multiple-case designs. Robert Yin (Case Study), a pioneer in case study methodology, defines a case study as an empirical inquiry that investigates a contemporary phenomenon (the case) in depth and within its realworld context, especially when the boundaries between phenomenon and context may not be clearly evident (18). Case studies are appropriate when the research addresses either a descriptive or explanatory question. The case study also "favors the collection of data in natural settings" and is now commonly "used in conducting evaluations" (Yin, Applications). Both Stake (The Art) and Yin base their approaches to case study on a relativist paradigm. One advantage of the constructivist approach, write Crabtree and Miller (Doing Qualitative), is the close collaboration between researcher and the participant, while also enabling participants to tell their stories. Through these stories the 
participants are able to describe their views of reality, and this enables the researcher to better understand the participants’ actions (qtd. in Baxter and Jack “Qualitative Case”). Yin (Applications) points out that although the case study is a distinctive form of empirical inquiry, many researchers nevertheless disdain the method. One concern is that the case study methodology is not as rigorous as other methodologies. There is also much confusion between research case studies and teaching case studies. In teaching, reports Yin, "case study materials may be deliberately altered to demonstrate a particular point more effectively; in research, any such step would be forbidden” (20). A third concern is the perceived inability to generalize from case study findings. The short answer, responds Yin is that "case studies, like experiments, are generalizable to theoretical propositions and not to populations or universes” (21). A fourth concern about case study research is that case studies can take too long and they can result in massive, unreadable documents. Such assumptions “incorrectly confuse case study research with ethnography” (21). In summary, case study methodology has been considered "soft” research, "possibly because researchers have not followed systematic procedures (23).

Theory in case study research is highly desired. In case study methodology the word "theory" has dual meanings. First, theory suggests a cause-and-effect relationship. Second, theory "means the design of the research steps according to some relationship to the literature, policy issues, or some other substantive force” (Yin, Case Study 28). Besides making it easier to design a case study, having theoretical propositions plays a role in helping the researcher generalize the lessons learned from the case study (Yin, “Applications 40). Yin writes that the most useful generalization for qualitative researchers is the analytic generalization, which "may be based on either (a) 
corroborating, modifying, rejecting, or otherwise advancing theoretical concepts the researcher references in designing the case study or (b) new concepts that arose upon the completion of the case study ...” and this generalization will be a conceptual level higher than that of the specific case” (41).

The final difference that I want to discuss regarding the case study strategy is single- and multiple-case designs. For Yin (Applications), there are four designs from which case study researchers can choose: holistic single-case, holistic multiple-case, embedded single-case, and embedded multiple-case. The single-case study, writes Yin, is an appropriate design under several circumstances. There are five rationales for a singlecase study: The subject must be critical, unusual, common, revelatory, or longitudinal. The single-case study, according to Yin, is "analogous to a single experiment and many of the same conditions that justify a single experiment also can justify a single-case study” (51). The multiple-case study is, simply stated, when the study contains more than a single case (56). The logic underlying the use of multiple-case studies is that "each case must be carefully selected so that it either predicts similar results or predicts contrasting results but for anticipatable reasons” (57). Stake uses three terms to describe case study: intrinsic, instrumental, and collective. Intrinsic case study research is for when a researcher is interested in understanding a unique case; if the researcher wants to gain insight and understanding of a particular situation or phenomenon, instrumental is the type of case study that needs to be crafted. Like Yin’s multiple-case study, Stake’s collective case study covers multiple cases in one study. According to Yin (Applications), a benefit to a multiple-case study over a single-case study is that having at least two cases means a researcher will have the possibility of direct replication; also, analytic 
conclusions coming from two cases will be more powerful than those coming from a single case” (64).

\section{Research Design}

I determined early in my planning stages that I knew the unit of analysis, or the case, was going to be an analysis of LGBT students enrolled in my Writers’ Workshop courses. My case study question is a straightforward "how" question, which is most common in case study research: How can practicing writing studio pedagogy transform the writing classroom into a space for students who identify as learning-disabled and LGBT to reclaim their disabilities and sexualities?

Yin and Stake suggest that placing boundaries on a case can prevent too many objectives in one study. Binding a case can include by time and place, time and activity, and by definition and context (Baxter and Jack). I bound my case study research by inviting students who identify as LD and LGBT and who are in my Writers’ Workshop courses to participate in the study, instead of students who only identify as learningdisabled. I also bound my study by limiting the time of data collections between January $20^{\text {th }}$ and May $1^{\text {st }}, 2014$.

I chose to design a descriptive, multiple-case study. A descriptive case study is used to describe an intervention or phenomenon and the real-life context in which it occurred. A multiple-case study enables the researcher to explore differences within and between cases. The goal is to replicate findings. Because comparisons will be drawn, it is imperative that cases are chosen carefully so that the researcher can predict results across cases, or predict contrasting results based on a theory (Yin “Case Study”). 


\section{Data Collection}

Kevin Eric DePew (“Through”) urges digital-writing researchers to “examine more features of the communicative situation rather than merely an artifact it produces” because, he believes incorporating interviews and observations, for example, “into methodological design ... can enrich research findings” (52). By designing such methodological strategies, argues DePew, "researchers insert communicative participants into the process, which gives researchers the opportunity to see both the complex nature of the research site and apertures in the field's tropes” (52). Following DePew's argument for locating more enriching research findings by mimicking the communicative triangle of rhetor, audience, and text, my data collection will include documentation, interviews, and observations of research participants.

Yin (Applications) writes that a researcher may find six sources of evidence, all potentially relevant in doing the same case study. Using multiple sources of evidence helped me triangulate my data. Yin provides an overview of the six primary sources of data that can be collected in case study research. Documentation is stable and can be reviewed repeatedly. Examples of documentation are log notes and award notes from teachers. It is also specific in that it can contain exact names, references, and details of an event. The weaknesses of documentation are that it can be difficult to retrieve and also that there could be biased selectivity if the collection is incomplete. Archival records are precise and usually quantitative, but the researcher could face accessibility issues if the records are deliberatively withheld. Examples of archival records are individualized education plans and neuropsychological evaluations. Interviews are insightful in that they provide explanations as well as personal views, perceptions, attitudes, and meanings. 
However, interviews can be biased due to poorly articulated questions and inaccuracies due to poor recall. I will interview students about their classroom experiences, their literacies, and their projects. Direct observations, as well as participant observation, cover action in real time but can be time consuming, and also actions observed may proceed differently because participants are aware of being observed. Physical artifacts, (in the case of my research, "artifacts" mean the texts research participants compose) are insightful into both cultural features and into technical operations but may be difficult to make available to participants. Yin's overview of the six sources of data that a researcher could possibly triangulate was particularly helpful in my deciding how to collect data from my Writers’ Workshop class.

I chose to analyze documents and archival records about my students whose parents gave me consent to include their child in the research project. As a teacher at Eagle Hill I have already read the files of each of my students. These records provide me insights into a student's verbal comprehension, perceptual reasoning, working memory, and processing speed — test scores such as the ACT and SAT, and report cards from previous schools discuss in depth the students' learning disabilities and how they have learned (or have struggled to learn) how to write in academic situations leading up to their admission to Eagle Hill.

Interviewing is perhaps the most important method of data collection in my study. I interviewed my students about their early and teenage years' literacy acquisition, both traditional and technological, and about their struggles and successes with writing in past and present classrooms, academic, and social situations. I also interviewed students during and after each writing project was completed to see if a particular modality of 
composition appeared to be more accessible for them and also to observe how their sense of what it means to be a writer may have changed. Selfe and Hawisher ("Exceeding”) discovered early in their initial interview sessions the need to "pay attention to the small stories” (38) and that throughout the interview session it is important to recognize that research participants might use "the interview settings and the narratives they told within these settings as their own personal form of social action” (39). I take this to mean that Selfe and Hawisher imagine that the power of storytelling is a form of social activism.

Finally, I directly observed my students in the Writers’ Workshop class playing with the different composing tools and making a variety of multimodal projects in the writing studio. In these observations I was looking at how students familiarize themselves with the studio’s resources and, if they had any problems using the resources, how the students asked for help from either their peers or me. This triangulation of data will help me create a case study that tells a story of how my research participants were documented as writers before Eagle Hill and, most importantly, how these research participants viewed themselves as writers before and after our course.

\section{Using Grounded Theory to Analyze Case Study Data}

Baxter and Jack and Yin all agree that the data collection and analysis occur concurrently. Yin (Applications) notes that one important practice during the analysis phase of any case study is the return to the propositions so that the researcher does not analyze data that is outside the scope of the research questions. Once I completed my data collection, I began to play with the data, searching for patterns, insights, and concepts that seemed promising for me to use in answering my research questions. The strategy I 
implemented to answer my research questions from my data was to work my data from the ground up - also known as grounded theory, a type of inductive analysis.

According to Strauss and Corbin ("Basics”), grounded theory is a systematic approach for the collection and analysis of qualitative data for the purpose of generating explanations that further the understanding of social and psychological phenomena. Farkas and Haas (“Grounded Theory”), who use a grounded theory approach for studying writing and literacy, evoke Donna Haraway’s 1988 quote in the beginning of their essay: The only way to ... a larger vision is to be somewhere particular. For these authors, the goal of "the grounded theory approach is a theory (a vision) that is grounded to that ‘somewhere particular: data from a specific area of human practice” (81). Farkas and Haas define grounded theory:

The goal of grounded theory is not a solution to a problem or the answer to a question, although grounded theory, like all research, is inherently about problems and questions. Rather, the goal of grounded theory is a set of working relations — a theory — a fluid structure built through systematic analysis and writing. (84)

Grounded theory in my research project involves identifying specific concepts in my accumulated data that point to how research participants used the resources in the writing studio to complete projects in multiple modalities and genres and how they acquired learning-disabled and sexual literacies in the writing studio space and the Eagle Hill School campus. The concepts that emerged through the data were labeled and then organized into like categories, using open or initial coding. Initial coding, writes Charmaz, "moves us toward later decisions about defining our core conceptual 
categories” (47). Charmaz and other grounded theory scholars suggest initial coding stick closely to the data — word-by-word, line-by-line, and incident-to-incident. They recommend coding with gerunds and the use of in-vivo coding, which allows participants’ own words to become code names.

The next levels of coding in grounded theory are focused coding, axial coding, and theoretical coding. Focused coding means "using the most significant or frequent earlier codes to sift through large amounts of data" and "requires decisions about which initial codes make the most analytic sense to categorize data incisively and completely" (Charmaz 57). Axial coding relates categories to subcategories, specifies the properties and dimensions of a category, and reassembles the data fractured during initial coding to give coherence to the initial analysis (Charmaz 60). The next type of coding in grounded theory is theoretical coding. Theoretical codes integrate the theory by weaving the fractured concepts into hypotheses that work together in a theory explaining the main concerns of the participants.

The idea of categories is central to grounded theory. Glaser and Strauss described categories as conceptual elements of theory and also as a more effective means of generating theory (qtd. in Dey 168). Categories emerge initially from a close engagement with data, but can achieve a higher level of abstraction through a process of constant comparison, which allows their theoretical elaboration and integration (Dey 168). Originally, Glaser and Strauss cautioned researchers against reading the disciplinary research on their subject in order not to approach their research with preconceptions. However, Dey points out, "it is doubtful that categories emerge in data without prior theory on behalf of the researcher" (176). "In fact, if we want to ground our categories," 
writes Dey, "we need to give as much attention to their theoretical provenance as to their empirical base" (177). Dey advocates for researchers to be more circumspect and "ask which patterns [in the data] are worthy of recognition” (177). Finally, Dey suggests to researchers that "categories can be grounded through a systematic appraisal of the contexts, dynamics, and results of interactive process ...” which means researchers must engage in "connecting categories which have emerged through the initial analysis by a comparative investigation of their various properties and relations” (178).

After this initial open coding, and then throughout the analysis of my data, I engaged in the memo-writing process. Kathy Charmaz (Constructing) writes that memo writing is the "pivotal intermediate step between data collection and writing drafts of papers (73). Memo writing, writes Charmaz, constitutes a crucial method in grounded theory because it prompts the researcher to analyze the data and codes early in the research process” (72). Lora Lex Lempert (“Asking”), another pioneer in the grounded theory methodology, discusses the act of memo writing in great depth. Memo writing, writes Lempert, is the "methodological link, the distillation process, through which the researcher transforms data into theory" and "roots the researcher in the analyses of the data while simultaneously increasing the level of abstraction of analytical ideas” (245). Memos, simply stated, to use a term from Glaser, conceptualize the data in narrative form. Beginning to write memos is challenging, but once the researcher has a routine that is effective, she can write memos from several types of data. Lempert advocates not limiting memos to data collected from respondents only; instead, she encourages researchers to write memos that stem from the disciplinary research. Lempert also discusses the importance of diagramming memos, which she refers to as "the visual 
display of what researchers do and do not know” (258). The visualizations in diagramming, reports Lempert, enable researchers to conceptualize the data in more abstract terms.

Charmaz (Constructing) advocates that researchers engage in theoretical sampling, sorting, and diagramming to support the development of an analysis that links categories. Theoretical sampling means seeking pertinent data to develop an emerging theory. A researcher conducts theoretical sampling by sampling to develop the properties of a category until no new properties emerge. Thus, writes Charmaz, researchers saturate categories with data and subsequently sort and/or diagram them to integrate one's emerging theory (96-97). The purpose of theoretical sampling is to obtain data so a researcher can explicate her categories. Theoretical sampling "pertains only to conceptual and theoretical development; it is not about representing a population or increasing the statistical generalizability of results” (101).

Through sorting, writes Charmaz, the researcher develops the theoretical integration of the found categories. Sorting also gives the researcher a logic for organizing her analysis and a way of refining theoretical links to make comparisons between categories. Therefore, sorting prompts researchers to compare categories at the abstract level. Diagramming provides a visual representation of categories and their relationships. Charmaz writes that many grounded theorists "treat creating visual images of their emerging theories as an intrinsic part of grounded theory methods” (117). Diagramming, Charmaz continues, "enables [researchers] to see the relative power, scope, and direction of the categories in the analysis as well as the connections among them” (118). Examples of diagramming in grounded theory can be seen in the work of 
Clarke (2005) and as far back as Strauss and Corbin (1990). Through mapping situations, Clarke "intends to develop grounded theory methods in ways that preserve empirical realities and complexities without resorting to reductionist analyses" (qtd. in Charmaz 118).

I want to conclude this section on the grounded theory method by looking closely at it as a response to three research dilemmas — the data dilemmas, the theory dilemmas, and the viewpoint dilemmas - and how grounded theory confronts these dilemmas. Here, I use the work of Farkas and Haas, as they have confronted these dilemmas in their own research. These dilemmas are important to confront before the next chapter where I share my case studies and use grounded theory to interpret my research processes and my findings in response to my research questions. Data, analysis, and theory are understood in a particular way in grounded theory. Data "refers to something in the world, something that exists separate from the researcher's subjective viewpoint or rendering ...” and "analysis is at the heart of grounded theory, where data are not rendered or presented, they are analyzed" (83). The data dilemma is that "one is faced with the daunting tasks of rendering [large portions of data] into verbal and graphic form” (84). In grounded theory, "researchers are analyzing preliminary ways from the very beginning — even as data collection proceeds," and the second reason the data dilemma is minimized is "that collection, analysis, and writing co-occur, through memoing, or the writing of theoretical memos" (84). The second dilemma, the theory dilemma, "is the potential mismatch between what a given theory would expect a researcher to find and what her data in fact reveal” (84). In grounded theory the approach is different: because the theory is built from the data — and ideally each theoretical category is traceable to particular data points 
— data do not have to be cut to fit the theory (84). Finally, the viewpoint dilemma "concerns whose perspective — researcher or participant — should be foregrounded" (85). Farkas and Haas respond to this dilemma by recommending, "grounded theory is one way to confront, even upset the theory-practice binary. In grounded theory, the goal is not to fuse the views or voices of participants into a more-or-less authentic narrative" (85). What really stands out to me, as the researcher in this process, is that with grounded theory, "experience is understood in new ways — data are fractured and made strange ... and then reconstructed in new ways ... so neither the viewpoint of the researcher or the participants can remain intact” (85).

\section{Mapping Rhetorical Activities in the Writing Studio}

In Chapter V, as a method to examine my findings, I use cultural historical activity theory to understand how my research participants engage in a variety of rhetorical activities in the writing studio, independent school, and safe space. Cultural historical activity theory, or CHAT, is an attitude and approach to studying texts that acknowledges them as complex and situated in specific histories, cultures, and activities that can never be divorced from one another. I base my knowledge about cultural historical activity theory in the work of Paul Prior, et al. (2007) and also my own research and practice on CHAT during my time at Illinois State University as a graduate assistant in the First-Year Writing program.

Prior et al. claim that there is a need for a new mapping of rhetorical activity because the five canons are not sufficient to examine all of the complex elements that make up rhetorical activity. The authors examine the classical canons and explain how the canons are not useful in investigating rhetorical activities, particularly digital new 
media texts. They claim that it is best to remap rhetorical activity than to try to "retrofit this ancient tool to do varieties of work it was never designed to address” (8). The classical canon and the remapped canon overlooked the role that socialization plays in rhetorical activity. Cultural historical activity theory argues that "mediated activity involves externalization (speech, writing, the manipulation and construction of objects and devices) and co-action (with other people, artifacts, and elements of the socialmaterial environment) as well as internalization (perception, learning)” (17). The primary issue that CHAT explores is "how people, institutions, and artifacts are made in history" (18).

I think of the human and nonhuman actors, activities, formed relationships, madeobjects, and sociohistories that take place in learning space as what Paul Prior and Julie A. Hengst (“Exploring Semiotic”) call a sociogenesis. I think of sociogenesis, in my research project, occurring across three heterotopias — the school, the writing studio and the safe space — as chronotopic laminations, or "the simultaneous layering of multiple activity frames and stances which are relatively foregrounded and backgrounded” (Prior and Shipka, “Chronotopic,” 188). The idea of chronotopic laminations comes from Bakhtin's chronotopes, which are nodes that involve embodied and representational worlds. I think it is productive to consider each of the three heterotopic spaces as independent chronotopes, or nodes, all laminated onto one another to observe they each come together and also collide depending on the actors, activities, and mediated objects interacting in the writing studio.

In the following chapter, I present two case studies. The first case study focuses on a trans gender girl, Alice. Alice utilizes the writing studio to create a rhetorical 
analysis, a semiotic remediation project where she takes fictional work that she has written in another course and repurposes texts as video poems. For her final, multimodal project she composes a coming out project on Tumblr. She looks at the possibilities that come with moving away from relying solely on the linguistic mode of communication in favor of communicating and composing visually, aurally, spatially, and linguistically about her identities as a transgender and learning-disabled teenager. The second case study focuses on Delevan, a junior at Eagle Hill School who identifies as a gay man. Delevan also composes a rhetorical analysis, as well as a semiotic remediation project where he takes a compilation of his own poetry and remediates it into a mural. Delevan also composes a final, multimodal project titled "No Gay Bashing.” In this final project, Delevan looks at the possibilities to make meaning with movement. He uses the work of Augusto Boal and, with his friend Dolores, leads a group of students in an "invisible theatre” project and organizes focus groups of students in each grade level to view and respond to the theatre project as a way to begin a schoolwide dialogue on bullying. 


\section{CHAPTER IV}

\section{ALICE AND DELEVAN}

\section{Introduction}

In this chapter, I introduce two students who are learning-disabled and LGBT at Eagle Hill School, Alice and Delevan. Alice is a senior and Delevan is a junior. Alice and Delevan each share what they did on three different projects composed in the writing studio. Learning a basic rhetorical vocabulary, Alice analyzed a transgender ad campaign and Delevan analyzed three advertisements designed either for or in opposition to the LGBT community. The second project Alice and Delevan share is their semiotic remediation. In these projects, the students learned about literate activity. Alice remediates a series of creative stories she repurposed into video poems and Delevan remediated a set of poems into a mural for the studio. The third project Alice and Delevan share is their final projects. Alice produced a coming out project that she launches on Tumblr. In her case study I discuss teaching a rhetorical genre studies approach in the studio space and, more specifically, teaching critical awareness of genres. Alice offers us a short, but meaningful, genre analysis of coming out narratives online and an equally useful discussion of values, beliefs, ideologies, consequences, and obligations as part of the coming out story narrative genre. To use an idea from Foucault, Alice begins to grasp “modern power” by means of communicating and composing in a 
public genre. Delevan staged an invisible theatre project with his peers and filmed a documentary in the writing studio about gay bashing at our school. He then organized focus groups of students from each grade level and asked them to view and respond to the filmed invisible theatre project. He created his invisible theatre troupe modeled after the critical work of Augusto Boal, who he read in the studio as part of his project. In Delevan's case study I discuss teaching embodiment as an important modality. Alice and Delevan end this chapter by sharing their experiences creating and facilitating an exhibition in the studio space that showcased each student's projects. I have placed each of Alice and Delevan’s projects online at http://kimswritersworkshop.blogspot.com/.

I begin each Writers' Workshop course by having four conversations with my students: classroom design, diet and exercise, recognizing learning strengths, and creating course goals and rules.

The first of these conversations is about redesigning the classroom as a space where they believe they would be able to learn the most. I encourage the class to think about putting themselves first. If they are not comfortable in their learning space, then they won't learn. We begin traditionally with the desks in two rows, three in front and four behind and facing the larger whiteboard. The arrangement has a formal feel, for which no student particularly cares. We start by taking the desks out of rows and putting the desks in a large circle. We stay in the circle for about two weeks, but the students find it hard to get up and move around and stretch. So many students at Eagle Hill School need to stretch and walk around the classroom to take breaks from writing that I wanted to build yoga into the academic day. In order to address students' — and my own — need to move around, we, as a group, decide to arrange the desks in pods. The pods work well, 
as students get to collaborate with one another face-to-face and have enough free space to move around. As luck would have it, the year Alice and Delevan were in the class a teacher in the math department wants to get rid of her two round tables for standard desks. As a class we jump on the offer and move the tables in and the desks out ourselves. Having the round tables, just like the pods, allows students to closely work together and also get up and do yoga. Favorite poses in the studio have been cat and cow (a spinal stretch), shoulder stretch, and hip stretch. The seating arrangement activities are a great way to disturb the power hierarchy of the traditional classroom. I get excited about the prospect of moving away from what Bateson termed the chapel model for the networked model. As I have mentioned, each student at Eagle Hill is required to have a laptop or a tablet. Students notice that having a laptop opened at a traditional desk, in rows, make communication even more difficult, but having laptops opened on the round tables, especially if students are seated at every other seat, leaves lots of room for students to work digitally and also have the space spread out for fidgeting. For a lot of teachers, fidgeting is a sign of not paying attention, but at Eagle Hill we recognize it as a way to help our students pay attention. If a student needs to take some time and knit a scarf in between writing a paper or making a project, then I let that student knit. No questions asked. I am reminded of what Lisa Gerrard wrote in 1993: An ideal computer classroom is a place for readers, writers, and editors to gather in groups and work alone and it is also a place where the daily users are the people most likely to know how to make the classroom a stimulating place to learn (162).

The second conversation that we have is about diet and exercise, or what we at Eagle Hill call the body-brain connection. The dining hall and the gym are directly 
connected to the studio space; I consider both emplacements that surround the studio as a heterotopia. I ask students what they eat and when they eat and in what kinds of exercise they participate. Obesity and diabetes are alarming problems with our nation's teenagers and what and how much students eat does, in fact, effect how they pay attention in class and the work they produce in the studio and in their other courses. Exercise is important to our campus. We have established Spark, named after the book Spark by John Ratey, which is a Monday-through-Thursday exercise initiative for students not enrolled in an interscholastic sport. In a class survey, Delevan and Alice each wrote about their daily diets and exercise. Delevan writes:

My diet consists of plenty of carbs, meats, and vegetables. I try to make sure I eat balanced as much as possible. My diet helps me perform in school because the amount I eat helps me focus usually. My diet also allows me to perform on stage and play ultimate Frisbee for our school's team.

Alice's diet consists mostly of ... ...deli sandwiches, and I think that's because I am a day student. I am picky about the vegetables because they are over-steamed. Although, I like the way the dining hall serves asparagus. I do the required Spark activity which for me is walking on the running track with my friends or participating in Zumba in the multipurpose room.

The third discussion I have with students in Writers’ Workshop is about themselves as learners. Because I come to teach the course with a broad definition of writing, it is valuable for me to know if my students are visual, auditory, or kinesthetic 
learners. I also know that to grow and develop as a writer, it is imperative to have a strong sense of self, so knowing my students better will help me help them grow and develop as thinkers and writers. Therefore, we complete and then discuss two surveys: The Self-Evaluation Checklist and the Learning Strengths Profile. Both surveys come out of Rush Neurobehavioral Center's handbook, Executive Functions: A Blueprint for Success Guide. The Self-Evaluation Checklist is an important indicator of whether or not students see school as a positive experience, whether or not a student believes he or she is a self-advocate and how confident a student believes he or she is in the classroom. The Learning Strengths Profile essentially asks students to indicate with which modalities they learn most effectively. Alice indicates that it is difficult for her to view school as a positive experience and to have confidence in the classroom. Her learning strengths profile indicates she is a visual and spatial learner; she learns best with music either as part of the text or in the background; and she is also logical. The learning strengths profile indicates she does not thrive with linguistic or interpersonal communication. Delevan indicates that he also finds it a bit difficult to see school as a positive experience and that he sees himself as a self-advocate. His learning strengths profile indicates he is also a visual and spatial learner, as well as a learner who thrives when projects focus on the body/kinesthetic. He, like Alice, also learns best when music is part of a project or when music plays in the background. His profile also indicates that Delevan is comfortable with both interpersonal and intrapersonal communication. I call students' learning strengths their "differences" because these strengths empower students to stand out amongst their peers and take ownership of their academic and social futures. 
The fourth discussion students and I have is about our goals for the class, or, put another way, what is it that students want to learn in the course and how we will go about this learning. How much you learn, I tell students, depends on how well you self-monitor your interactions with others in the studio and how well you learn to solve problems that you will inevitably encounter in the studio. I write this statement on the whiteboard: "This studio space is designed to help you reimagine writing and then learn to improve on your writing skills, so most of the classroom rules are designed to help facilitate that learning. I am pretty laid back, but there do need to be a few rules to help manage our class time together. Please observe the following." I then ask students to write down a list of rules that they think are fair and that they will abide by. I then take the list of rules, and add a few of my own that need to be listed, and create a contract that each student has to read and sign. Most of the time students reach a consensus on which rules should be enacted. Rules such as be patient, be kind, no gossiping, and be respectful are the most common. In the studio class with Alice and Delevan I also got “judge others' writing fairly", "food should be allowed in the studio but no begging for food," and "Have fun." Having fun, while not a rule, is certainly a mantra that I present throughout the year. I want students to imagine writing as hard work, rewarding, and fun. I also want students to develop into divergent thinkers and innovative problem-solvers. I ask each student to open up a blank word document and write the following five steps for emergent problemsolving and then save the document on their desktops and refer to it when a problem arises: (a) attempt to understand the problem in the context of people, objects, and internal and/or external influences, (b) communicate with your peers about your understanding of the problem and request suggestions, (c) devise a plan, (d) carry out the 
plan, and (e) look back and reflect. This five-step, problem-solving process is similar to the emergent problem-solving method, a method predicated on the notion that a “collective solution represents a better solution ...” and the solution "emerges iteratively as people, contexts, artifacts, and bureaucracies interact” (Kitalong and Brady 207). As I introduced in Chapter II, I also teach students to value the insights based on problems with which they have dealt in the past. I also teach them the Vincent Ruggerio problemsolving method, where students must identify values, consequences, and obligations of those parties involved in a problem to help students realize the most moral solution.

I liken the purpose of making rules together to the operational and curricular goals for a computer-supported writing facility written about in early computers-and-writing literature. Creating class rules encourages students to engage in convergent thinking, and asking students to commit to a basic problem-solving model encourages students to engage in divergent thinking.

\section{Becoming Familiar with Common Terms and Alice and Delevan's Learning Disabilities}

We began the course reading Arola, Sheppard, and Ball’s Writer/Designer. The premise of the textbook is that students "should take advantage of every possibility that's out there — not just words but also sound, images, movement, and more — so [they] can create communications that perfectly meet [their] goals, [their] situations, and the needs of [their] audience” (xxiii). I think it is important that students think of themselves not only as authors, but as designers, and more generally, as communicators. Communication is a difficult task for a large part of our student population, as many have nonverbal learning disabilities such as Asperger's Syndrome. The first terms that I want students to 
become familiar with are multimodal and text. It is surprising how many students — and colleagues, too — are taken aback when I tell them that a text is any piece of communication in any mode. I attribute my surprise to being a product of a college composition discourse community, meaning I have been studying multimodal composition and its benefits for students' academic, professional and civic lives since I began my master’s degree at Michigan Technological University in 2003. It feels appalling to me that eleven years later what seems so obvious about writing to me is still blowing people away.

I next introduce my students in the studio to the five modes of communication: linguistic, visual, aural, spatial, and gestural. It took me quite some time to persuade my students that four of these five modes of communication were valid means of expression in an academic class. I attribute the difficulty in persuasion to our students being judged strictly on linguistic writing samples, and not multimodal writing activities that allow students to tap into their learning strengths. I next introduce to my Writers’ Workshop students the terms rhetoric, rhetorical situation, audience, purpose, context, and genre. I intentionally choose to focus on this basic vocabulary because in my experience, once students begin to comprehend the basic structure of a rhetorical analysis, they begin to see their roles as writers differently. Having a foundational knowledge about rhetoric and rhetorical analysis transforms passive consumers of text into active prosumers. A prosumer is one who both actively produces and consumes texts. The first time I came in contact with the term prosumer was in Michael Salvo and Thomas Rickert's 2006 Computer and Composition Online Web text “...And They Had Pro Tools.” In the Web text, the authors cite "new media culture is less resonant with interpretation than with 
engagement, and to explain this experiential difference we deploy the concepts of "worlding" and "prosumer." The term prosumer refers to the erosion of the difference between a consumer and a producer” (n.p.). We spent about two terms (a term is three and a half weeks) going over the rhetorical terms and putting those terms into practice with in-class rhetorical analyses, such as an analysis on our school's Web page and student art work that is hanging on the walls of our studio space. It was at this point in the year that I asked my students in which modes they communicated most effectively.

Alice tells me:

My auditory processing problems affect me in class when all sounds mesh together, so it's hard to hear what people are saying. Someone could be saying something but their voice could sound like it’s coming from a fan. I also have dyslexia. I always have to check my grammar and be cautious not to flip letters or spell letters backwards. Given what we have learned about different modes of communication, I would say I communicate more effectively visually, and not linguistically or aurally ... My auditory processing problems affect me in class when all sounds mesh together, so it's hard to hear what people are saying.

Delevan tells me:

I communicate most effectively in visual, spatial, and gestural modes. I have ADD and executive dysfunction. I would not call myself an academic writer. I have struggled my entire life with reading and writing and deciphering texts. I was deaf for a while and I was unable to read or write because I couldn't hear the words and I couldn't say the words. My 
adenoids were swollen [and I had a problem with my Eustachian tube]. I could hear but it was like hearing music in the shower while you are in the living room. Writing was hard because I couldn't sound out the words. I would read a book, and say the words in my head, but I couldn't fully read or write until I was ten. I was afraid to stand out among my peers. I had a late start learning how to properly read and write. I was able to get points across and use big words to embellish, things like a thesis or supporting points fell flat for me. I didn't know how to dig deeper into the text because words didn't have the greatest meaning for me. I wasn't an avid reader. I read comic books because there were pictures and there were not long, drawn out pages of text. As an actor, I have to read but because of the way script is spaced out, I am able to understand it. I have never gotten an A on anything I have felt proud of. Teachers would give me A's because they felt bad for me. I am troubled that I will not be an academic writer. Writing seems like something so basic. It seems like something with just enough work you should be able to do it fluently. While I can speak however I am needed to, I have a time conveying a proper message. I can go pages and pages.

I try to write outside of school. I am bad at academic writing, but I am good at creative writing, particularly poetry and songwriting. I can write it for myself because I know the meaning behind it - no one else needs to. I do social media writing, too. I am a teenager, after all. 
The responses that Alice and Delevan provide could perhaps show that they do not possess a strong understanding of how one learns to write, and they certainly have a narrow understanding of literacy acquisition, or what counts as literacy, but I also wonder if both use their auditory processing problems and other disabilities as defense mechanisms to deny having to take ownership of their writing. I invited Alice and Delevan and other students in the studio to answer twenty questions about their own literacy acquisition early on in the Writers' Workshop course. Not only do their responses to my questions create a stark contrast in opportunities for literacy sponsorship, but also the responses are other examples of how students enact defense mechanisms to deny learning opportunities. Delevan, for example, denies that he has had many meaningful conversations with teachers or friends about reading, writing, disability, or sexuality. The evidence that Delevan provides in his case study contradicts several of his claims about his own literacy acquisition.

\section{A First Foray into Rhetorical Analysis}

As I wrote in the previous section, I teach students how to conduct a rhetorical analysis first because doing so motivates students to move away from being consumers of other peoples' ideas and arguments toward becoming prosumers of their own ideas and arguments. Delevan and Alice each performed a rhetorical analysis, along with the other students in Writers' Workshop. Delevan chose to conduct a neo-Aristotelian analysis of three television commercials that represent how the media has represented LGBT citizens over the last fifty years. Alice conducted a cluster analysis to understand the worldview of a Washington, D.C., ad campaign titled \#transrespect. Delevan used Writer/Designer as a guide to compose his Neo-Aristotelian analysis; Alice referred to Sonja K. Foss’ 
Rhetorical Criticism to compose her cluster analysis. The authors of both textbooks provide students explicit questions to answer about the texts being analyzed. For both Alice and Delevan, this project was their first exposure to thinking about writing as multimodal and writing their own work with a rhetorical vocabulary in mind. Alice and Delevan both vocalized to me that they felt engaged in the project, as I was offering them an opportunity to focus on sexuality issues that matter to them. Delevan told me, "It isn't often that I am allowed to write about a topic that interests me”; Alice echoes Delevan, adding that "talking about transgender issues in class feels forbidden, not that teachers say I can’t talk about being trans but more that if I do talk about trans issues, some teachers and some students become visibly uncomfortable and quickly change the subject.”

Conducting the rhetorical analyses in the studio proved to be a fun and meaningful experience for the class. Each student gave a multimodal presentation on his or her analysis and other students in the studio were allowed to ask questions. Delevan chose to compose a Prezi to showcase his rhetorical analysis "because on Prezi you can watch video and click easily from slide to slide. Plus, it involves the audience more than a PowerPoint because, I think, movement intrigues audiences and keeps their attention whereas slides tend to be static and boring and you risk losing your audience.” Alice chose to deconstruct the individual advertisements and then produce an audio file with her analysis. This rhetorical analysis project was helpful because it supported both individual work and collaboration. Students were pressed by their peers to think about new angles and ideas regarding the texts. Alice, for example, was pressed by a student to think about the overall intention of the \#transrespect project — was it to include 
transgender men and women or was it to exclude transgender men and women who did not fit a certain type?

Delevan, after completing the rhetorical analysis, responded:

Purpose was easy for me to understand and that there can be more than one purpose in one text makes sense. Most texts I come in contact with seem to be persuasive and entertaining or persuasive or informative or expressive, but always persuasive. I had not thought about the possibility of an unintended audience or that there are implied and actual authors: doing this kind of writing makes me second guess a lot of what I see on television and read and see online. Watching ads, I guess, makes me wonder who else is watching this? Am I the unintended audience? Who is the actual author and what are their motives? And, I have definitely not considered design choices in writing before. Design choices on stage, yes. But not writing. I learned the most about the design principles looking at the advertisement titled “Men and Women Shouldn’t Live Together.” The emphasis between what our society considers women's work and men's work was the whole premise of the advertisement. The organization worked to emphasize the surprise in the ad. For example, the constant contrast between the man making the mess and the woman cleaning up after him with Tammy Wynette’s “Stand by Your Man” playing over the film. Country music does not represent LGBT people. And then, bam! It is two men. Amazing. 
Where Delevan's response to the rhetorical analysis focuses more on the actual application of terms to a text, Alice's response focuses much more on the "hidden messages" in the text, or "what is absent from this text and is it on purpose?"

Alice writes:

In my rhetorical analysis, writes Alice, I argue that the \#transrespect ad campaign holds the worldview that it is acceptable to be transgender as long as your outward physical appearance and tastes in cultural experiences do not disturb the cisgender population.” Each of the spokespeople for the campaign embrace activities like walking through a museum, shopping, and wearing nice clothes, eating at food trucks and shopping at farmer's markets. Given this ad campaign, will it be possible to respect and not discriminate against Other trans people - people who do not fit this mold?

This wasn't an awakening for Alice, as she feels discriminated against often at school and in her own home. Having an opportunity to analyze this ad campaign just added more fuel to her desire to make projects that offered opportunities to people, not take them away. I sat down with Alice early on in the year to talk to her about her experiences being transgender. Alice told me:

My friends started helping me dress up in female clothing in freshman year. During sophomore year, I became a boarder at the school. My friend put her jacket on me and her hairband in my hair. Dressing up like a girl made me feel happy. I had no idea how to comprehend what was happening, but it made me happy; however, it still embarrassed me 
because of how society treats people. In junior year I started using temporary words to describe myself: cross dresser, femmeboi, and from there I went to mikoboy (Japanese). I had never until junior year heard of the word transgendered, but that word describes me better than the other words do.

Some students refuse to call me Alice, and some refuse to acknowledge me as a girl and some don't know. Some students just think I like to pull back my hair and put on a dress. Some of them I would like to keep it that way, but there are other students I am scared to tell because the only time they talk to me in the first place is when we are in class. Students who don't understand me ask what I would I do if my parents walked into class right now?

Two teachers call me Alice, and another knows I want to be called Alice but refuses to call me Alice. In the classes where my teachers accept me as transgendered, my work is good. The refusal of the teacher acknowledging me as transgendered has made it so it is hard to do good work in his class. You do not do well in school when you do not feel well yourself. My parents completely reject my being transgendered. My mother thinks it is a phase to get her angry. My brother thinks I do this for attention and popularity. My girlfriend is accepting of my being transgendered. She does not want to call it a lesbian relationship because my being transgendered is not about our having sex. 


\section{Creating an Intimate Relationship between Students and Writing: Teaching Cultural Historical Activity Theory in the Studio Space}

Halfway through the third term, I started talking with students about how interesting and how complex is the act of writing. I introduced the studio to cultural historical activity theory (CHAT). Sharp-Hoskins and Frost (“Cultural”) define CHAT as an attitude and approach to studying texts that acknowledges them as complex and situated in specific histories, cultures, and activities that can never be divorced from one another (n.p.). My argument for teaching students in the studio cultural historical activity theory and offering them opportunities to engage in semiotic remediation is that knowing how social processes impact writers and writing situations will give them an advantage in being prosumers of ideas and information in different, more intimate ways than traditional methods of rhetorical analysis. The principles of CHAT that I teach students in the studio are that texts are complex and are produced at specific sociocultural moments; texts are produced based on the activities, technologies, and processes available to writers in specific sociocultural moments; and the histories, cultures, and activities that sponsor and maintain a text can never be divorced from one another. The intimacy that develops between students and writing occurs when they can see themselves as actors as well as other humans and nonhumans as actors collaborating, talking, fighting, and making up in one moment in time that is impacted by the past, present, and future. Writing potentially moves from being a loathed and arduous academic subject to being a captivating subject, one in which students with all different abilities can participate and produce potentially persuasive texts. 
It was hard for me, at times, to remember that I was introducing a really complex topic to high school students; a topic that was really difficult for my college students to understand four years earlier. Out of our work with rhetoric, design, and literate activity, though, came some really meaningful projects of which my students are proud. Alice composed a series of video poems and Delevan composed a mural. In the next section, Alice shows the studio and tells me about her experience using CHAT to think about remediating her fiction into video poems.

\section{Alice's Video Poem}

Alice came to the Writers' Workshop studio with several texts, short stories she had written in another writing class. The main story is titled "Freak" (http://tinyurl.com/kt7fs52), and it was composed originally for an open assignment in her Reading and Writing: Critical Analysis course. I saw the value of using "Freak" and the other stories to introduce Alice to the ideas of literate activity. I asked Alice if she wanted to remediate "Freak" and her other stories in a new way and for an audience other than her studio peers. After thinking about it for a while, she approached me about taking "Freak" and several other short pieces of writing she has composed and repurposing them all into a digital text. I asked her to think more creatively and get back to me in a few days. Alice thought about how she might repurpose the text and, a week later, she pitched to me and her classmates in a brainstorming session what I think was an excellent idea:

I want to take my stories and remediate them as a series of moving poems, making them accessible for the school's gay-straight alliance so that other LGBT students can learn about what it is like for a boy to come out as a trans gender girl. The rhetorical situation is while I am the first 
openly transgender student at Eagle Hill, I am not going to be the last. There needs to be a collection of video poetry that will help future transgender students feel less alone on our campus and the book needs to be digital so it can be downloaded on students' laptops. And, since the students who will read it — the audience — have all different learning disabled labels, I need to make it accessible for a large number of potential readers. The poems will of course move but they will also be narrated. I need to pitch this project idea to my studio class and Mr. Kim using the CHAT vocabulary so I and the rest of the studio can understand the trajectory of this project. I will create a CHAT map on Inspiration and then give a short presentation and take questions. Since the studio class is fifty-four minutes, I will have about ten minutes to present my map and then five minutes for questions. In order to even get to the point of mapping I need to do a ton of brainstorming.

Over four or five class periods, Alice answered the following two questions, developed by Sharp-Hoskins and Frost, and produced a CHAT map.

1. Why does the video poem take the form that it does?

Videopoetry began to take form in the late 1970s. Tom Konyves was a pioneer in Videopoetry. On the website movingpoems.com, he writes on his web page that Videopoetry is a genre of poetry displayed on a screen, distinguished by its time-based, poetic juxtaposition of text with images and sound. In the measured blending of these 3 elements, it produces in the viewer the realization of a poetic experience. The poetic 
juxtaposition of the elements implies an appreciation of the weight and reach of each element; the method is analogous to the poet's process of selecting just-the-right word or phrase and positioning these in a concentrated "vertical” pattern. It takes the form it does to provide audiences poetry with a cinematic feel — to provide them an opportunity to experience words differently.

2. What activities, social formations, and arrangements of power preceded the emergence of my video poem?

This question made me think a lot about what has come before my wanting to turn "Freak" and other stories into moving poems. The activities of creating "Freak" and other stories come from writing them in class and at home as an assignment in another writing course. My parents do not like that I identify as transgender and some teachers are unsure or uncomfortable, so I have to write these poems and stories in secret. People think the act of writing secretly is daring and exciting but in reality it is exhausting. I don’t know who is going to find me writing poetry or when, so all of my senses are heightened while I am writing these stories. I smell differently when I write poetry about myself. I feel vibrations of other people moving around, and I hear everything from gnats to wind to running toilets and faucets. It seems obvious I don't have the power in this situation. If I did, I wouldn't have to hide everything I write from my parents and most teachers. Most of my composing happens in the dining hall or the activity center where there is not so much surveillance. The 
"where” I compose and why I hide is very much ecological. The idea of social formations, also as ecological, are interesting. Several seem to contribute to my poetry and short fiction. The formation of my family impacts this poem. I have a traditionally masculine father and he plays a role in this poem. His reactions to me anger me and also scare me and also cause arguments from within my family. My mother works hard to fight for me. I also have a younger brother who is athletic, sings well, is attractive — the antithesis of me. The poem "Freak” definitely arrives from that formation. Another social formation is the class in which I am supposed to present this poem. I am the only LGBT person in the class. I accept my peers but I don't necessarily trust the ones in this class. My teacher is nice enough. I know I make her nervous. So, the dynamic in this class is stressful. But, I want my voice to be heard through the stress. Producing the poem began with pencil and paper, and no particular kind of either. I write with what I can find. I don't like to shop poems around with other people generally, especially when they are still developing, but with this one poem I did share it with a few friends to get their feedback on whether or not I should submit it in the class. After I developed the poem on paper, I typed it out. I used MS Word, nothing special. This poem is distributed to only my teacher and it is now being repurposed as a moving poem.

Alice brings to the class a storyboard composed with paper and pen that depicted how she thought she might approach her project. She talks to the class about rhetorical 
situation and audience, as well as context, which I applaud because she is taking terms from the first major project and using them to describe this, her second project. The studio responds to Alice with questions I gave to them that focus on genre. The questions are ones that Sharp-Hoskins and Frost provide in their article "Cultural Historical Activity Theory.” These are also questions that are already familiar to me coming out of a graduate teaching position that emphasized genre. The studio is mostly interested in inviting Alice to think through what technologies are involved in the production of video poetry and how the video poem will be distributed. The CHAT map Alice created, which answered the question what activities, social formations, and arrangements of power are involved in the production of her video poem project, can be read on my blog (http://tinyurl.com/kt7fs52).

Alice continues talking about making her semiotic remediation project:

Remediating ...the word Mr. Kim uses to mean change from one genre to another genre is something that I can relate to ... In a way, I am remediating myself from a boy to a girl. I use technology as a means to remediate myself, and I am definitely impacted by ecology and socialization. The boy who I am biologically right now is a lot like my printed poem, but I want to be as cool and interesting as my video poem ... so I, and the people around me and places I am part of ... are helping me remediate myself. My creative writing into a set of video poems only took about a week. I came into the studio each day and used class time to work on my project, and I also worked on the project during my free time, too. It was difficult for me to work at home because, as I mentioned, my 
parents are not okay with my identifying as trans gender and they actually blame the school, saying that the school influenced me to want to be a girl. The school did not influence me, but, as I have said, some teachers and friends do support me. Anyway, iMovie is really easy to use. I learned it on my own years ago. I just read online tutorials and watched a couple of instructional videos on YouTube. I am not a master at iMovie, but I am good enough to make a video poem, I think. I wanted to keep the red I use in the printed text to emphasize the word freak the same in the video poem. The repetition of the word freak is obviously important and it needs to be contrasted from the rest of the text. The music I chose, Hans Zimmer, has a fast rhythm. I want my audience’s heartbeats to become faster. I want them to feel what it is like to be a freak, to be someone who scares their parents and teachers.

Alice completes the semiotic remediation project, and she indicates that she is satisfied with the outcome of her video poem. She tells me in a short reflection that remediating texts is a new experience for her but one that she finds valuable for producing a new and potentially more relevant text for a different audience. She also found cultural historical activity theory applicable to articulate her own coming out process. 


\section{Alice Comes Out on Tumblr: A Final Project in Rhetorical Genre Studies and Critical Awareness of Genre}

“Over the last two years, I have found a lot of solace from coming out stories. Many of them help me imagine what my own coming out may be like to certain friends and family members. Some scare me. Some make me laugh.”

In the writing studio space, Alice is excited at the prospect of creating her final project as a coming out project on Tumblr, which can be viewed on my blog (http://tinyurl.com/kt7fs52). Alice is not comfortable, as we learned from her video poem project, composing strictly in the linguistic mode of communication, as her dyslexia makes composing in the written word challenging. Being a student in a studio space that offers its users a choice in topic and composing tools, Alice continues to embrace composing visually, spatially, and linguistically. In the studio space, I encourage students to think about their compositions from not only a multimodal approach and CHAT approach but also a rhetorical genre studies approach. Genre, as theorized by Anis Bawarshi and Mary Jo Reiff, in Genre: An Introduction to History, Theory, Research, and Pedagogy, “connects kinds of texts to social action” and can be viewed as "ways of recognizing, responding to, and acting meaningfully within recurrent situation” (3). For Amy Devitt (Writing Genres) genre should be seen “not as a response to a recurring situation but as a nexus between an individual's actions and a socially defined context.” Genre, she argues, “is a reciprocal dynamic within which an individual’s actions construct and are constructed by recurring context of situation, context of culture, and context of genres” (31). 
In a rhetorical genre studies approach to writing, "students learn how to recognize genres as rhetorical responses to and reflections of the situations in which they are used ..." furthermore, "students learn how to use genre analysis to participate and intervene in situations they encounter” (Bawarshi and Reiff 192). Anne Beaufort, in her now-famous study College Writing and Beyond: A New Framework for University Writing Instruction, advocates a genre studies approach to writing, too, responding, "let them practice learning new genres and the ways of new discourse communities ... and challenge them to apply the same tools in every new writing situation” (158). It is so important to Alice to use the writing studio space to learn how to intervene and participate in both online learning-disabled and transgender communities. Learning the genre of coming out narratives provides Alice an inroad into conversations with other learning-disabled and LGBT people she cannot access living at home with parents who reject her sexuality. With Alice, I teach the genre analysis heuristic from "Scenes of Writing: Strategies for Composing with Genres,” which is located in Bawarshi and Reiff's book. The guidelines for Bawarshi, Reiff and Devitt's genre analyses are written in an accessible language for postsecondary and secondary students. The first step is to collect samples of the genre; the second step is to identify the scene and describe the situation in which the genre is used; the third step is to identify and describe patterns in the genre's features; and the fourth step is to analyze what these patterns reveal. I also ask Alice to read shorter essays from the Illinois State University FYC textbook series Grassroots Writing Research. The essays in Grassroots are written mostly by undergraduate and graduate students who are experimenting with genres in their writing classes either as students or teachers. Alice read Sarah M. Lushia’s “Making Pictures Talk: The Journey 
of Learning a New Genre” and Courtney Schoolmaster’s “Follow the Bread Crumbs: Adhering to the Conventions of a Genre.” Both of these essays introduced Alice to learning how to define and look for genres in texts she was already reading and writing. Alex Kim, author of "Speaking Out: Ideologies, Identities, and Individuals in Coming Out Stories," argues "the genre of the coming out story," comprises a definite locus wherein actors create, deconstruct, define, and dissociate their own positions” (239). Alice talks about the genre analysis she prepares to create a site on Tumblr to archive people’s LD/LGBT coming out stories:

"I have been reading coming out stories for two years. I read rucomingout.com, whenicameout.tumblr.com, and comingout.tumblr.com, and emptyclosets.com, and experimentproject.com. My project is to gather stories from other people about their coming out as learning disabled and queer. I chose Tumblr as a space to compose my project because there is a large LGBT following. It is a very open website in terms of its membership. I also chose Tumblr because it has an easy HTML editor, and I can have control over my entire project. Finally, I chose Tumblr because I can add more images and fewer words and have an audience of people that are more my age.

To prepare for this project I collected samples of coming out stories online from the blogs I just mentioned. I also read Am I Blue and Freak Boy, which are popular print books with the social justice and literature teachers at Eagle Hill. The coming out narrative appears mostly in personal blogs and a few LGBTQ organization sites. The genre of coming 
out narratives is used when people want to express themselves to and their feelings to other people who may be struggling to come out. It is a genre that is read and written as a mechanism of support. The genre of the coming out narrative interacts with mostly with the genres of blogs. Lots of teenagers talk about how old they were when they came out and the reactions of their parents and friends. There is also often discussion of gaining and losing friendships. Some coming out stories are also dedicated to specific people in the narrator's life, like moms, dads, and grandparents. The hashtags are sometimes just as interesting as the stories. For example, a few I like are \#inspiring, \#hopeful, \#happy, \#pansexual, \#bisexual, and \#contact me.

It's interesting. The genre of coming out narratives is mostly personal testimony. I guess one way to talk about the structure of this genre is cause and effect. People typically begin a coming out story by writing about how they came out and then spend a considerable amount of time writing about how people reacted — whether they were kept or disowned. Often writers in this genre appeal to the emotions of their readers. I sometimes wonder if some writers' stories are as dramatic in real life as they are represented online. The participants, who appreciate this genre, obviously, I think, are those who have both come out and are struggling to come out. This genre makes it possible for people like me to come out. If there were no coming out narratives, there would not be as much support accessible to teenagers who live in houses where their parents and families reject them.” 
Bawarshi and Reiff write about the significance of teaching critical awareness of genre to students; they argue, recognizing "genres as socially situated and culturally embedded is to recognize that genres carry with them the beliefs, values, and ideologies of particular communities and cultures” (197). Teaching values has been a part of my pedagogy long before I was exposed to genre theory in rhetoric and composition. When I was a student, and then an adjunct instructor of writing and cultural foundations at St. Edward's University, I taught students about values as a foundation for moral reasoning, how to identify values, and how to analyze value conflicts. I teach values as presumed to be good, something worth acquiring or striving for. Values are what we choose or believe to be worthwhile or have merit. It is important that students recognize values should be freely and thoughtfully chosen. There are three categories of values that I teach to students. The first type is instrumental values, or values that are a means to achieve terminal values. These values pertain to modes of conduct, ways of achieving what one wants in the world. The second type is terminal values. Terminal values are considered good in themselves; they are the end goals individuals and societies strive to achieve. The third type is core values. Core values are the values individuals or societies rank as most important. Therefore, values are an explicit part of mentoring Alice in her creating a coming out project.

Reading a sampling of coming out stories in preparation to create my project led me to think about the instrumental, terminal, and core values of us LGBT kids who are coming out. The instrumental values of the LGBT community on Tumblr are helping other people, creating friendships, and being involved in something larger than ourselves — a 
movement of people who are courageous to come out, risking our familial relationships. The core values of the LGBT Tumblr are community security, recognition and stability. These values are important to recognize in the genre of the coming out narrative because each shapes the way rhetorical patterns, such as emotional appeal and personal testimony as credibility are structured in the stories.

Teaching a critical awareness of genres not only allows me to teach values as inherent to genres, but also how one's values are connected to the consequences and obligations one has of creating — or not creating — texts that are connected to social action. Obligations, I teach my students, represent actions that we should take and would be wrong not to take. While we have a number of obligations simply by being human beings, we most frequently deal with obligations that arise from specific roles we inhabit in different contexts and situations. Consequences are the outcomes of a decision-making process that considers what will happen if one chooses one path rather than another. It is critical to teach students that they have to predict the effects of their actions as best they can and attempt to maximize overall good, or at least minimize overall harm when making a decision. Alice writes:

While I don't feel forced to make this page for a group of people, I think that as a transgender girl who is comfortable in her body, I am a good person to make a page available to LD and LGBT teens, like myself, who need an outlet of support. I have found a lot of comfort in coming out pages, so I wanted to create one, too, for people who want to share their 
stories. The consequences of inaction are having one less space online for some confused girl to tell her story.

It is imperative to teach students to consider ideologies as an inherent part of genres that connect texts to social actions. I urge them to consider ideology as "the thing that entices you to forget that meaning always happens in context ... [and] that it leads you to accept each day as a natural fact” (Nealon 100), but their job as ideological critics is to "make the familiar seem a bit more strange and thereby to make us consistently examine the things that we all too often take for granted” (101). Alex Kim (“Speaking Out”) examines in depth the four dominant ideologies that can be experienced in the genre of the coming out story. He writes, "the four major ideological strands immutability, importance, deceit, and liberation — I found in my informants' coming out narratives served as resources for creating coherence within their stories.” Additionally, Kim argues, "the coherence they created did not always affirm and uphold the ideologies positively; sometimes my informants constructed narratives that tactically positioned their claims to a gay or lesbian identity in opposition or negation of these ideologies” (268). Alice and I applied Kim’s ideological categories to her own search in exploring the

coming out story genre in preparation to launch her Tumblr page. Alice became intensely interested in whether or not the coming out stories that would be posted on her Tumblr project would adhere to the genre's already discovered ideological strands.

\section{Alice Launches http://gbtandlearningdisabilities.tumblr.com/}

LGBT identity projects are not new to the computers-and-writing discipline, but the majority of these types of projects were published predominantly in the 1990s and early 2000s, during the first Queer turn in our discipline. In Randal Woodland’s “Queer 
Spaces, Modem Boys and Pagan Statues,” he discussed such coming out in online spaces in the following terms: “These on-line 'queer spaces' ... are 'third places' in ... combining the connected sociality of public space with the anonymity of the closet” (qtd. in Alexander and Banks 280). Scott Lloyd DeWitt mapped uncharted territory in 1997 looking at the ways in which LGBT students constructed their identity/came out on the Web. DeWitt positions his essay as a cautionary tale to teachers "who may be unaware of opposition awaiting students whose identities are being shaped by their experiences on the World Wide Web” (229). And Joanne Addison and Susan Hilligoss’s 1999 “Technological Fronts: Lesbian Lives 'On the Line,' ” analyzed the authors’ experiences participating in an "online study of academic women and computers." Reflecting on their negotiation of lesbian identities in the supposedly liberating realm of cyberspace, Addison and Hilligoss rightly maintained that "to come out online is [to] articulate an identity that our society works to render invisible.” The authors claimed that "coming out online as a lesbian may be harder than doing so in face-to-face interactions” because the "visual cues" of identity that are present in face-to-face performances of teaching no longer exist (qtd. in Alexander and Banks 281).

More recently, in LGBT Studies, Christopher Pullen and Margaret Cooper, in their 2010 edited collection LGBT Identity and Online New Media, argue that LGBT identity is evolving as a community form, at the same time that it is increasingly distanced from the need for a physical social space, in the mediation and evocation of its messages, politics, and textures” (xiii). The editors contextualize their collection in the work of Anthony Giddens, who argues: "Intimacy should not be understood as an interactional description but [as] a cluster of prerogatives and responsibilities that define 
agendas of practical activity” (qtd in. Pullen and Cooper 1). The editors use the Giddens theory of intimacy to explain how new opportunities online for LGBT citizens allow for the showcasing of "sexual diversity" (2). LGBTs have "stimulated opportunities to test their identities within virtual environments, and to make connections previously unimagined” (1). These opportunities are evident, argue the editors, with the number of opportunities people have for virtual coming out, engagement in dating, or sexual encounter, composing self-narratives through blogging, connecting and constructing communities, and the potential to mobilize political ideologies (2). Through online new media, argue Pullen and Cooper, there is an awareness of speaking to a public, offering some sense of democracy” (5). This sense of democracy offers LGBTs “modern power.” As Nancy Fraser tells us, modern power relates to Foucault's ideas:

Modern power is more penetrating than earlier forms of power. It gets hold of its objects at the deepest level — in their gestures, habits, bodies, and desires. ...Taken in combination, these characteristics define the operation of modern power as what Foucault calls 'self-amplifying' (qtd in. Pullen and Cooper 5).

Such potential for modern power, argue Pullen and Moore, “to flow through the varying contexts of social life foregrounds the opportunity of 'self amplification' through online new media ...” and furthermore, "through the connection of intimate storytelling and community identification, transgressive ideas progress” (5). Alice’s coming out project on Tumblr, then, is an example of a teenager taking hold of modern power to amplify herself and those who post their stories. Self-amplification becomes one more important instrumental value learned as part of this powerful genre. Alice produces her 
identity project from a rhetorical genre studies approach, paying careful attention to critical genre awareness and the opportunity to research and compose in a public genre. Alice and I spent some time discussing her reactions to the launch of her coming out project. We specifically discussed how the stories posted on her Tumblr page adhered to the conventions, values, and ideologies she has discovered while in the research phase of her project:

The coming out stories Tumblr users posted on my wall do follow the genre conventions I established early on in my project. They are of a similar length and focus on similar topics as the coming out stories I have been reading for years. The values the authors bring to their narratives seem obvious, influencing others, leadership, and openness and honesty. There are no value conflicts among the coming out stories; however, I imagine, there would be several value conflicts, if, say, I were to juxtapose these stories to the diatribes that evangelical, right-wing Christians post on their blogs. Ideology is a hard concept for me to think about. It's not something that I have ever been asked to think about. The first and second stories definitely could be categorized as having a liberatory ideology. In the first story, the author writes about the acceptance he or she found in the death rocker friend named Lisa. In the second story, the author tells a friend he or she is LGBT, and the friend gets excited, saying "that's so cool!” Both accounts show freeing and, maybe even empowering, instances of coming out. I really wanted to spend more time communicating with the authors, although I am shy, so I didn't. I am 
curious about the ideological strand of immutability. Like, did things change or remain the same for the authors after they came out? It seems, most likely, that nothing really changed for the first author — I mean, he/she and the death rocker hugged and went back into the club. The second author, too, seems unchanged by coming out to his/her friends. The third author seems really lost, and there is not enough of a story posted to decipher an ideology.

Alice tells me that she may, at some point, reach out to the authors on her blog. But for now, she will be a quiet observer, providing an online space for other LGBT Tumblr users to tell their stories. Alice believes she has changed as a writer being involved in Writers' Workshop in this emergent studio space. She writes that she has not ever had an opportunity to write as a transgendered girl in a formal space. I would argue that the writing studio, with a motivated student and teacher, can be a liberating space.

Having Alice compose in and study the genre of coming out stories provided her an opportunity to write in a public genre and think about writing in public contexts. Public genres, point out Bawarshi and Reiff, "allow teachers to focus on academic objectives of analysis and critique while bringing into the classroom [or studio] genres that function as sites of intervention in public spheres" (205-206). Alice, as a member of the writing studio, has taught me, the teacher, the value of teaching the coming out genre to other studio groups. Studying and composing in the coming out genre offers students opportunities to meet several academic objectives. 


\section{Delevan Conrad}

Delevan's work in the studio space is very much a new experience for him. As I showed earlier in the chapter, Delevan, like Alice, is exposed to a new rhetorical vocabulary to help analyze texts. Delevan also pitches and creates a semiotic remediation project and develops a final, multimodal project that he will share and discuss in this chapter.

Before coming to Eagle Hill School, Delevan was educated at Seabury Hall in Makawao, Hawaii. A private school affiliated with the Episcopal church for grades 6-12, Seabury Hall is not a school designed specifically for students with learning disabilities. Enrollment in the 2012-2013 school year was 443 students and the student-to-teacher ratio was 10:1. At Seabury Hall, Delevan's grades ranged from excellent in dance and music to failing in literature, history, and chemistry. Delevan briefly talks about a previous school experience in which he was taken out of classes where he thrived because of his academic struggles:

School in other places before Eagle Hill was difficult. At Seabury Hall if you get a $\mathrm{C}$ or below you are put in academic probation. In my sophomore year, I got A's in all my dance, art, and theater classes. However, I earned nothing above a C in my academic classes. My first year, they allowed me to stay in art classes, but my second year they took me out of all my theater projects.

Upon coming to Eagle Hill School in 2012, Delevan’s parents were asked to describe his strengths and needs, why they think Delevan would be an asset at Eagle Hill, and in which types of situations Delevan's self-esteem would be the strongest. Delevan, 
his parents write candidly, "is creative, enthusiastic, and competitive and these qualities show in almost everything he does in life. He is high energy and wants to do well in all things he touches. Delevan, wherever he is, brings high energy and more than a little flare to all around him. Delevan will have a strong self-esteem and be confident in anything that involves theatre, dance, and the performing arts.”

\section{Delevan's Semiotic Remediation Project: Making a Mural}

Similarly to Alice, Delevan brings some creative writing of his own into the studio for the semiotic remediation project which can be found on my blog at (http://tinyurl.com/owmnd7h). Delevan wrote a short book of poems simply titled “Poetry Collection.” Delevan tells me:

I have had these poems saved to my laptop for a couple of years, at least since Seabury Hall and maybe I wrote a few even before I went there. Certainly having them stay stagnant on my laptop isn't doing me any favors. I want people to know about me. I want them to know about my coming out process, which several of these poems represent. I want to create a mural. I have always been intrigued by murals. So much work goes into making one, whether it is a joint effort or a crazy or politically motivated artist working alone. Murals are important pieces of ours and many other cultures because they have inspiration and awe-inspiring beauty, and they have important social messages hidden in the images, shapes and colors.

My pitch to the studio class was to create a mural in the classroom, using the larger of two whiteboards. I want to use a variety of dry-erase markers 
and illustrate both images and words — but more images, actually. The rhetorical situation is there is an absence of discussion of LGBT issues at our school, so by doing this project out loud, I am providing an opportunity for people to come face to face with LGBT issues and other issues that affect teenagers like me — like divorce, alcoholism, crushes, and bullying.

I asked Delevan what activities, social formations, and arrangements of power preceded the emergence of his mural?

The writing began in 2010 to my senior year 2014. I wrote these poems to cope with several frameworks. The first is family: My alcoholic father, surprise step-father, and mother who is a step-monster. The second is sickness: I also wrote to cope with depression and loneliness - I wrote to keep myself company. These poems are heavily influenced by my sexuality and music, as well as my conflicts with religion. I am constantly stuck in a state of limbo with religion. I would write on my laptop, always in my bedroom, after midnight, on my MacBook pro. I contemplated distributing my poetry as a pamphlet a few years ago but I just didn’t have the desire to be let down with rejection.

In the studio, Delevan provides us his idea, roughly on paper. Before he begins his semiotic remediation project, his peers in the studio want him to address the values he sees as important in this project, i.e., what values will come through this project to your audience? And, will your audiences appreciate this possibly offensive piece of art? Delevan’s CHAT map can be viewed on my blog (http://tinyurl.com/kt7fs52). 
The week that Delevan spends composing his mural is intense. There is no other way to describe Delevan than in a state of flow. I am tempted to photograph him in this state of flow, but did not want to risk interrupting him. I asked him one day after the project was completed if he had felt anxious or bored during the actual drawing. He replied that he felt neither anxious nor bored. In fact, he responded that he just felt happy and that he was in his element. Drawing illustrations that represented aspects of his life was cathartic. Before the mural was completed, however, several incidences occurred that ripped him out of a state of flow and into a state of upheaval. Delevan explains:

Halfway through my composing the mural several students from other classes came into the space and became visibly and vocally upset at the rosary that reads "RIP homo" and the vagina spewing into a can of grape soda and the penis that is dripping semen. I became intensely interested in the socialization surrounding my mural displayed in the studio after a series of visible and vocal upsets. My peers and I had discussed before I began that the mural may be more accepted in an art classroom than in the writing studio space, but I still felt taken aback by the controversy that stirred around my project. The debate that ensued with my peers was not foreseen by me. So that I could capture each person's ideas and concerns, too, I created a game where my peers would role play, choosing to be students from Mr. Kim's other classes, other teachers who stop into the studio, and admissions counselors taking tours with prospective families. I wanted to weigh each argument to consider whether or not I should finish the project. Pictures of the mural project 
before the role-playing game can be found on my Web page. This is a transcript of the roundtable discussion I had in the studio with my peers about the mural.

Tina role-played a student:

I find this piece mindful and stimulated. I find the pieces controversial but appropriate in a writing classroom. As a student I think it is important to be immersed in worldly events and be prepared for what's to come in the world post-Eagle Hill.

Roberto role-played a student:

I like the artwork Delevan produced. The only thing I would suggest is that he to put it on a poster board because the artwork not only resembles a knock at religion thing but it also has some graphic sexual materials that will be disturbing to tours, kids like underclassman, and it could potentially freak them out and even traumatize them.

\section{Edwin role-played the admissions counselors}

In order to fulfill the goals of a college preparatory academy, one must first consider that the students entering a classroom here are not yet at a college level. It is our goal to assist them so that they will become able to handle college level classes, not to expose them to materials that they should see during their postsecondary education. How am I supposed to explain to a prospective student and parent why they are being confronted with a potentially uncomfortable situation in a classroom that it was not our job to show them? How does making a mockery of religion fit in with 
our school's guidelines, how do we advertise insult art on our Web site?

Eagle Hill is already a statement; we help children with learning disabilities. We cultivate a good relationship with the public, we have never seen our role as an agitator. A very interesting, creative, and valuable piece of work unfortunately placed in a difficult environment. Perhaps at the wrong time in the academic lives of our students as well. Josh role-played a teacher

I think that expression through art is an important resource for a developing mind. However, the context of the art, especially controversial or (what could be considered as) vulgar art, is important. In a classroom setting for high school students of many ages, displaying such art without clear educational purpose is distracting offensive.

Delevan continues:

Roberto and Edwin's comments resonate the most with me. I considered whether or not to finish the mural, and I decided to not finish it. It was a hard decision for me to come to because now I am not sure that the safe space is as ... well ... safe as I thought it was. Is the studio space or the academic space unsafe, or are my choices in production and distribution not appropriate for this space ... I am still unsure. Erasing the mural was painful. Perhaps I could draw it again on poster board but, honestly, I like that people had to confront my ideas because I think that my ideas are common themes of a lot of people here, LGBT or straight. 
The CHAT project provided me an outlet to rethink the relationships I have with my friends and teachers and also the values I have and the ones I did not know I had until I started this project. I was asked to focus on how people talk about texts, and having an opportunity to actually sit in on a discussion about the different possible reactions to my mural got me thinking about how far-reaching a text can be ... the power that unintended audiences can have over the production and distribution of a text is terrifying, actually.

The CHAT project also got me thinking about other texts I have written and how I might be able to repurpose them to new audiences, such as repurposing some of my movement pieces into printed pieces. I think that often we think that print has to be repurposed to something more multimodal, but what if I took a multimodal text and repurposed it into a linguistic text?

I see Delevan’s mural project as an opportunity to incorporate grit, which I discuss in Chapter V, into the writing studio. Delevan "felt like a failure" after he decides to stop production on the mural. I use this powerful moment in the writing studio to teach grit, which is firmness in character embodied with virtues of tenacity, perseverance, and the ability to not give up. Shortly after Delevan begins a new project, I come into the studio and explain that frustration is a given when one writes for an audiences, intended and unintended, especially when that audience has opposing beliefs and values. It is important for students to be resilient and self-confident in the face of adversity and then move forward with their personal, professional, and civic activities. We watch Angela 
Lee Duckworth’s 2013 short Ted talk titled “The Key to Success? Grit.” Duckworth defines grit as the passion and perseverance to meet long-term goals. Grit, she says, is about sticking with your future and making your future a reality. Duckworth argues that the grittier students are more likely to complete school. Talent does not make one gritty; grit is usually unrelated or inversely related to measures of talent. Duckworth advocates for growth mindset to build grit, an idea of Carol Dweck of Stanford University, which is that the ability to learn is not fixed; it can change with one's effort. When kids read and learn about the brain and how it grows in response to challenge, they are more likely to persevere when they fail because failure is not a permanent condition. We have to be willing to fail, to be wrong, to start over again with lessons learned. Duckworth’s talk causes a stir in the studio. Delevan remembers responses to the studio after the Duckworth talk: "I wanted to completely redo the project with a new, more insightful CHAT map. I remember wanting to research my audiences more; I wanted to talk about the text more with the actual stakeholders than produce it first and then be distressed at the fallout.” I admired Delevan's renewed, grittier sense of purpose but there are other projects to complete and, besides that, I tell him and the rest of the studio that I am not sure it is always the best idea to get every person’s approval before you begin producing a text. Sometimes the writer just has to wait and see what different reactions will be toward his or her work.

Delevan poses really important connections to the writing he does and the relationships he has with people and spaces after completing his CHAT project. Delevan explains: 
I have an understanding of cultural historical activity theory that allows me to look at and understand my relationships with other people across at the school and in the studio. I also have a new understanding of how CHAT can bring me into conversations about my values and beliefs and how those values and beliefs are impact me as a writer and also impact my writing situations.

Delevan in a previous interview labeled himself as a poor writer. Now, after completing and reflecting on the semiotic remediation project, he wants to experiment with remediating a spatial and gestural text to a linguistic, traditional text and, even more interestingly, he is referring to himself as a writer.

\section{Delevan's Final Project: No More Gay Bashing}

For Delevan’s final project, which can be accessed at http://tinyurl.com/kt7fs52, he wants to compose something about gay bashing at our school. Delevan talked to me a lot about being a target for bullying because of his learning disabilities and sexuality, especially in Hawaii where he said the campus communities were generally safe but his experiences in public spaces around Makawao were anything but safe. He talked specifically about being jumped and knifed at a mall for dressing effeminately. He also

told me that here, at Eagle Hill, students are not immune to bullying. Students frequently harass each other for being learning disabled. He has even been harassed by a teacher on campus for being gay; Delevan suspects that teacher ridiculed him for being gay because the other students in the class identified as heterosexuals and athletes and the teacher wanted to make them feel more comfortable having Delevan in their class.

Delevan is concerned greatly with the bullying that occurs at our school: 
It happens in the lunchrooms, in classrooms, and in the dining hall frequently enough to cause me to want to alert people in positions of power that it is (bullying) that not enough is being done (to prevent other students from being bullied). In Writers’ Workshop, using our textbook and having discussions with each other and the teacher, we learned a lot about rhetoric and how it is possible to move people to action by composing persuasive texts. I had never heard the word "rhetoric" before the class, but it makes sense that the more persuasive a speech or movie or new article is the more likely it is that people will act for change. Performing on stage is a strength of mine. I live it. I breathe it. I eat it. It is in my blood. I can do both serious and comic roles. For example, I was the cat in the hat in Suessical the Musical and I was also in The Laramie Project as Jedidiah Schultz, a gay student at the University of Wyoming. I know I can make kids laugh and adults think about what it means to be a gay teenager in Wyoming or really anywhere else in the country. I wanted to compose a project about gay bashing in my Writers' Workshop course. I did not want to write a paper. I wanted to compose a project that highlighted my love of theatre and celebrated bodies as mediums for messages. Mr. Kim suggested I read the work of Augusto Boal, who was an advocate for social justice and discussing oppression in instances of live theatre. I read parts of Boal's Games for Actors and NonActors and also parts of Boal's biography in order to brainstorm for my 
project. I decided to begin an invisible theatre troupe with my friends to tackle the issue of bullying at school.

Writing studio spaces can be locations for students to engage in storytelling and theatre to learn about and teach each other about local and global problems they face at school, work, and home. I argue that writing studio spaces in theory and practice should not exist apart from the bodies of the teachers and students who experiment in it. So much of Delevan's — and other students' — strengths are in theatre and movement; therefore, it is necessary to create a studio space that privileges bodies. With this in mind, I begin teaching and discussing with the students in the studio theories of embodiment and movement. Ideas of embodiment, movement, and theatre go hand in hand, particularly in the writing studio with Delevan's specific focus on imitating the social justice theatre work of Augusto Boal.

\section{A Brief Introduction to Augusto Boal and Theatre of the Oppressed}

In 1971, for political reasons, Augusto Boal was forced to leave Brazil and went to live in other countries in Latin America, from which he was also exiled due to the political regimes of these countries. At the beginning of the 1980s, the political situation became more liberal and Boal returned several times, until he finally decided to settle back in his homeland. He worked on different projects until he established the Centre of Theatre of the Oppressed in Rio de Janeiro, with five other people. Boal began with the principle that theatre, like language, can be appropriate to anybody so long as the methods are passed on to them. Through series of exercises, games, techniques, and drama forms the aim is to understand social reality, and to then be able to change it. 
The three main categories of Theatre of the Oppressed are image theatre, invisible theatre, and forum theatre. Image theatre is a "set of exercises to uncover truths about societies and cultures without resort to spoken language.” Groups involved in image theatre "suggest themes and then individuals shape themselves into different poses, using their own and others' bodies like clay.” Invisible theatre is public theatre that involves the public as participants in the action without their knowing it. The public is called "spectactors." Finally, forum theatre is "a game in which a problem is shown in an unsolved form, to which the audience, again spect-actors, is invited to suggest and enact solutions." After one showing of the scene, which is known as the model, "it is shown again slightly speeded up, and follows exactly the same course until a member of the audience shouts "stop," takes the place of the protagonist and tries to defeat the oppressors" (Boal xx-xxi). Critical spatial theory is central to Augusto Boal's Theater of the Oppressed (TO). Shari Popen, author of “Aesthetic Spaces/Imaginative Geographies” argues in TO, the space of theatre is brought out of abstraction and reclaimed as an embodiment of human imagination ... a space where humans are actively engaged in multiple ways of problem solving” (125). These spaces, continues Popen, "make possible imaginative geographies, in which opportunities for transitive knowing are freed up, rather than over-determined by highly structured contexts and places” (126). Boal combines three epistemological properties to make aesthetic spaces transitive: plasticity, telemicroscopic, and selfreflexivity. Plasticity allows time and space to become flexible, manipulatible. According to Boal, in The Rainbow of Desire, "all combinations [of space and time] are possible, because aesthetic space is but doesn't exist" (qtd. in Popel 126). The property of the telemicroscopic simply means that the stage brings things closer "where they can be 
better observed and known” (126). Finally, on self-reflexivity, TO is a mirror that we can penetrate to modify our image, not only the image that we carry of ourselves, but also the images that we have constructed of the world (126).

Boal writes only a small amount about invisible theatre, in comparison to image theatre and forum theatre. Invisible theatre deals with a subject "that must be of burning importance, something known to be a matter of profound and genuine concern for the future spect-actors.” A small play is constructed and will be played in a place that is not a theatre and for an audience which is not an audience” (6). The genre of invisible theatre can studied both in Boal's book Games for Actors and Non-Actors and on YouTube in a series of videos uploaded by both high school and college drama classes. A compelling example that Boal provides readers is titled "Picnic in the Streets of Stockholm." In the first action, a family sets up a picnic in a busy area of the city and is greeted by two actors in the role of passers-by. In the second action, the passers-by argue that the "pavement was meant for people to walk on and not for people to set up tables and have tea on. The family gives in and says since we can't have a picnic on the table, let's have it in the middle of the road” (14). In the third action, three actors in cars begin to "remonstrate with the family because as far as they are concerned the road was made for cars, not for a family to have tea." In the fourth action, a contest develops between the family and the drivers. Boal reports that the arguments raged on for almost fifteen minutes before the arrival of the police, "which is unusual for such a theatrical piece" (15). Boal reminds readers that "invisible theatre offers scenes of fiction. But without the mitigating effects of the rites of conventional theatre, this fiction becomes a reality” (15). The conventions of invisible theatre become clear to me, Delevan, and his friends: One 
must have a problem of burning importance, one must have actors willing to be involved in writing and performing a script, one must have a designated space to perform the script; and, importantly, all performers involved must be prepared for unrehearsed action. Forum theatre is like a game, and, as with any game there are rules, which must be addressed for the game to be successful (18). There are many, many rules for forum theatre. Delevan cites these rules in his final project, which can be found online through the appendix.

Delevan originally wants to engage himself and his friends in an invisible theatre project where they will perform an act of bullying in the dining hall or outside the student activity center to see how other faculty and students will react and whether a spect-actor will put him or herself in the middle of the scene, but that idea is met with concerns from our school's principal. The principal does not approve of having students and teachers not know that an act of bullying is an act and not real. Delevan and his friends continue reading Boal's Games for Actors and Non-Actors and eventually plan a project that combines elements of invisible theatre with elements of forum theatre:

So that we could combine invisible theatre with forum theatre into a performance project that would hopefully start a dialogue on bullying at the school, my friends and I staged and filmed a classroom performance where I was being gay bashed by another student. We knew we could not involve people in even a scripted act of bullying without telling them what was going on, so we filmed our performance in a classroom with an iPhone to make it look like another students was "secretly" shooting an act of bullying. The script was short and purposefully left with no cathartic 
moment for the bully or the other students in the class. The problem was intentionally not solved. We then held focus groups for students in each grade, eighth through twelfth. Students were read the rules for forum theatre. We did have a student as the joker. The students in the focus group had no idea that the scene they were watching was scripted. They really thought another student shot the footage with a phone. The students in the focus group could yell freeze and take on the role of any of the students filmed.

Delevan chose to keep the footage of the focus groups unedited. Delevan and I read about human vibe, an aspect of body rhetoric. Jason Del Gandio, in Rhetoric for Radicals, defines human vibe as "a form of energy felt between people” (171). Del Gandio briefly offers three clarifications to help readers understand human vibe. The first clarification is that vibe is a bodily phenomenon. We are, writes Del Gandio, "embodied beings who transmit and feel vibrations” meaning “our bodies emanate feeling” (171). The second clarification is the vibe is a communicative phenomenon. Del Gandio writes that we use vibe to "express emotions and feelings, to gain the attention to others, to attract people or to push people away ...” (171). His third clarification is that vibe is rhetorical. Del Gandio is particularly interested in charisma, pointing out that a person can feel "speakers' embodied vibrations, which makes [them] look and listen” (172). The right vibe can be persuasive, while the wrong vibe can hurt your credibility. Delevan discusses the vibes in each group:

The vibe in the eighth grade was both energized — they were excited to be part of the project — and one of intrigue. The students 
clearly wanted to be there and had a lot to say. I did have to intervene all the time to get them tal king at the beginning of each new question. Charisma was emanating from the group and also from me as the moderator. I also was excited to have them in the group.

The vibe in the ninth grade focus group was harmonious and, I guess polite. My peers took turns, waited for each other to finish speaking. Elyse, the first student to speak, definitely brought a thoughtful vibe to the group. She spoke softly but said important things about bullying here on campus. The boys in the group are actually two of the most hyperactive on the campus, but I attribute the vibe Elyse encouraged to keep them calm. Conversely, the vibe Elyse brought, I think, had an adverse effect on the girls. Elyse has a large personality and it seems as though the vibe, while fun typically emanates from her, the energy she brought with her to the focus group, kept the other two girls quiet. She had a dampening effect. Overall, the focus group, I think, went well. There was a lot of important information relayed to the faculty, too. At one point a student asked us to turn off the camera because she wanted to say something confidential. That air of confidentiality set another vibe in the room. The charisma seemed to have disappeared, and it was all business. What the students had to say about faculty bullying on campus was sobering. The room got quiet, and then the bell rang signaling the end of lunch.

The vibe of the eleventh and twelfth grade focus group was the most mature and complex. The group remained on topic. They tried their 
hardest to be empathetic. Their honesty was candid. There was focused conversation about how to define bullying. The silences in the room were just as important as the speaking. There was one known homophobic student in the group, who said nothing for the entire time the group was together. Based on the histories I have with these students, as they are in my peer group, they were able to take me and our friends out of the video, and put themselves in the same situation. They watched the video and participated in the focus group unbiasedly. Whereas the eighth and ninth grade did at times push other people out of a speaking role, the $11^{\text {th }}$ and $12^{\text {th }}$ grade did well to give each person a chance to speak. We also met in the Leigh Conference Room, and not the classroom, which may have put a more formal tone on the focus group. Students typically are only in the conference room for junior and senior meetings or school presentations. Where the classroom was more relaxed, the conference room was seen as more formal.

Delevan completes his project as our time together ends. The project gains interest amongst the faculty and other students at Eagle Hill School. Delevan's adviser requests that Delevan and I retroactively turn the bullying project into an honors project.

\section{The Exhibition}

One of the first discussions the studio has in the beginning of the year is whether or not we should create and host an exhibition of our projects toward the end of the year. This year's class agrees that we should have an exhibition and at first we all agreed that we should hold it on Family Weekend in the spring. However, as Alice remembers: 
I wanted to hold the exhibition on Family Weekend, but during the course of the year my projects — and I, too — were becoming bolder. I wasn't just writing papers; I was making video poems and launching a web page for transgender people who are coming out. My parents, hardworking middle-class Americans, were not going to be happy. As it was already, they blamed the school for "making" me transgender. I knew they were going to be uncomfortable at the very least and furious at the very most. I felt compelled to bring this to the attention of the studio, and I was met with nothing but support from my peers.

Delevan also remembers:

When Alice approached the studio about wanting to keep the exhibition in house, I had no objections. After all, my mural had been ... shall we say ... decommissioned. I was eager to show my bullying project and my Prezi but knew that parents are always more conservative than their children so the mural wouldn't make the cut. We did agree — as a class, though — to photograph what I had illustrated and put it in an album for a private showing to those who were interested in seeing what this project was all about ... the art teacher was interested, as was the voice teacher and a few of my friends, too.

Another student, Edwin, becomes frustrated at Alice's request to not invite the public if it means inviting parents and Edwin does vocalize those frustrations in uncivil verbal exchanges. In his exchanges to Alice, he berates her for not being stronger toward her parents and even says that "her fears are ruining our experience in the studio" and, 
"Sorry I'm not trans. I have problems with my parents, too but I am not going to NOT invite them.” At the point Edwin becomes uncivil toward Alice the writing studio as a playground, as a site of limited perfection, collapses. Edwin becomes what Huizinga terms "a spoilsport."

I intervene after that exchange and use it as a teachable moment to introduce the idea of empathy. I listen to Edwin and the other students and model reflective listening. I also attempt to show Edwin and other students empathy and validate their concerns, and then ask them to think through their frustrations and try and validate Alice’s fears. It takes about a week, but Edwin comes back and makes a good effort to empathize with Alice.

As I am helping my students plan for the exhibition, I rely a lot on Jody Shipka’s scholarship (“On the Many Parts”) where she describes inviting her students to engineer multipart rhetorical events. This exhibition is not simply about the texts that students produce, but rather about, to quote John Trimbur, "the complex cycles of activity that link production, distribution, exchange, consumption, and valuation of writing” (qtd. in Shipka 52). Shipka cites Nancy Sommers, who "stresses the importance of theoretical and pedagogical frameworks that provide us with opportunities for 'bringing life and writing together' and suggests 'what happens between the drafts may well be 'one of the great secrets' of the profession” (53). For Shipka, and this is something I continuously stress to my students, as well, "writing functions as a stream within a broader flow of semiotic activity” (54). The classroom becomes an activity system and the students take on the role of "heterogeneous engineers," engineering an exhibit. The role of heterogeneous engineers is an important one for my students creating the exhibition, and 
one that they willingly embrace. Given the turbulence in the studio coming from oppressive actors like parents and others in positions of power, I read to my students this meaningful passage on heterogeneous engineers from Shipka’s text: “Heterogeneous engineers' efforts are successful if the resulting assemblages of human and nonhuman entities maintains some degree of stability in the face of the attempts of other entities or systems to dissociate them into their component parts” (56). In other words, the students in the studio building the exhibition were tested by actors and therefore, the students, as engineers, had to engage in collaborative and creative problem-solving to ensure there would, in fact, be an exhibit in the spring. The ability to problem-solve creatively and effectively hinges on how the students as engineers play. Play, argues Shipka, is the stuff of life; the ability to look at the world from a different angle. Learning disabled-labeled students find their strength in play. It is the LD student who must look at the world from a different angle to survive an education system that does not work to teach them on their level.

As Lois Hetland et al. reminds us, “creating exhibitions is an authentic practice in which artists regularly engage, and thus it is a key part of a studio education” (30). The exhibition is important in the writing studio because the event shows students that their intellectual, artistic work does not stop at the teacher's desk. Early on the studio decides we will have a physical exhibition, but it would also be filmed so that we can have a virtual exhibit, too. The studio arranges the exhibition in four phases: a planning phase, an installation phase, a public phase, and an aftermath phase. Alice and Delevan talked about each of these phases. I summarize and combine their remarks: 


\section{Planning phase}

We all felt that the focus of the exhibition needed to focus on how being proud of being different is a form of risk-taking. Being out as LGBT is a risk that we thought was worth sharing with the attendees. Other students could use the risk-taking theme to talk about coming out as having a particular learning-disabled label. And, we all agreed that experimenting with new forms of writing and thinking about writing differently was definitely a kind of risk-taking, as we were leaving the comfort zone of being uncomfortable with writing in the traditional sense. We did struggle to determine a date to hold the event, and we also struggled with whether or not the event should span a couple of evenings. In the end, we agreed to have the exhibition be one afternoon from 3:30 to 5:00, so right after school until dinner. Mr. Kim agreed to be the moderator, and we each agreed to stay at our stations and introduce our projects and answer questions from attendees. We decided that we would have index cards by our stations, so that attendees can write something about each project, and then after the show we can read them together as a class. We decided on an email invitation and also a Facebook invitation. Both methods of delivery will reach our intended audience, the EHS community.

\section{Installation phase}

The class decided that we would keep the two tables in our studio, using both for studio members' laptops, so attendees could move from one 
station to the next looking at different projects. Our lighting options were unfortunately nonexistent, as we have fluorescent overhead lights, but we decided that wasn't too big of a deal. We asked Mr. Kim if he could remove a lot of his classroom decorations, so they did not take away from the seriousness of our exhibit, and he agreed. Finally, we utilized the small whiteboard in the room to list the projects, and the large whiteboard in the room was to alternately showcase Delevan's Prezi project and Edwin's documentary on dance.

\section{Public Phase}

This phase of the exhibit was the most exciting but also the most rattling. We washed down the tables and vacuumed the studio space. So that we did not have to contend with the fluorescent lights, we decided at the last minute to leave the blinds open to bring in natural light and leave the windows open to bring in natural air. During the intermission when Mr. Kim spoke briefly about the work we were doing in class, we went around and organized the note cards and wiped down the tables just to keep the space looking professional.

\section{Aftermath phase}

De-installing the exhibit was easy because really it was not that big. I think the best part of this final phase was going through the note cards. Some of the cards had basic comments like "nice job” and "cool," but other cards had more profound statements and even some had questions. For me, Alice, one that stood out read "you are brave to create 
this type of video poem for an online crowd.” For me, Delevan, the one that stood out was about the Prezi production of the rhetorical analysis. It read "way to make the conversation about same sex relationships interesting" and another read "I have never seen a Prezi before. I think I will have my students try it out” and the bullying project garnered some intriguing note cards, too. One read, "you are so right on. Bullying a huge problem here and you are the first to really do something about it,” and another said, "the focus groups really caught my attention. Perhaps there should be more student focus groups and on other campus problems.” Another part of the aftermath phase that proved to be vital for judging our performance was going over some of the malfunctions that we had to problem-solve. For starters, the laptop connected to the project kept going to black during Delevan and Edwin's presentation. That problem was easy to solve, though, because it just meant getting a student to sit over at Mr. Kim's desk and move the mouse. Another more serious problem we had to solve was the flow of traffic in the studio. At one point it got really congested and attendees were stepping on each other's feet. We decided rather quickly to open up an adjoining classroom and move two stations into that other room so that people could come into two classrooms and circulate calmly from project to project.

Finally, we all agreed during the aftermath phase that the exhibition really helped make us confident. Having the exhibit prepared us to tal $k$ about how several members of the studio went from being unsure 
of or even disliking writing to being sure and liking writing when the selection of topic and mode was on our terms, which are two aspects in previous writing classes that were not on our terms.

I was proud of my students’ performance before, during, and after the exhibition. They demonstrated they could be creative, professional, and personable under pressure. Specifically, they demonstrated to their audience what some at the exhibition knew and some were not yet aware: Students who are given opportunities to compose in modes that work with and not against their learning styles will develop meaningful texts and also develop their self-confidence as writers. In the next chapter I first present my grounded theory analysis of these cases and then discuss in depth each category that helped me arrive at my theory. I end the chapter with a discussion of what my saturated categories bring to composition studies. 


\section{CHAPTER V \\ GROUNDED THEORY AND ANALYSIS}

\section{Introduction}

I came to this project looking to answer my research question: How can the writing studio be a space for LD and LGBT students to reclaim their disabilities and sexualities? I worked with Alice and Delevan for four months. I interviewed each of them several times with both general and specific questions pertaining to their learning disabilities, their learning strengths, their experiences at school, their families and friends, and their literacy practices; I closely observed them interacting with their peers, and I closely observed both Alice and Delevan compose several projects. Before I began collecting "on stage” data, I closely read reports written on them by experts in the medical and academic disciplines, and I also read notes from their current teachers and parents. I began to play with my accumulated data, searching for patterns, insights, and concepts that seemed promising for me to use in answering my research questions. I began reading data and simultaneously making data in the form of memos. I looked closely at each of their projects, too. Beginning with initial coding and moving toward a more focused coding and then applying the same coding processes to my memos, I was able to visualize similar patterns in words, lines, and entire documents in the data that revealed several categories, such as "difficult to have confidence about traditional, linear 
writing", "being in small classrooms is helpful”, "moments where writing is reimagined", "moments of failure”, "moments of pressure”, "moments of pride”, "having good teachers that always complement students”, and “opportunities to compose texts of interest.” These categories were evident throughout the data, which led me to eventually saturate my categories, or sort my findings into several distinct categories or frameworks that can help form a theory: relearning differences as strengths, empathy and grit, selfefficacy, interest, and rhetorical agency. What makes this study grounded theory and not a traditional qualitative analysis is I went into my research project not knowing these frameworks would serve me in better understanding my students' writing activities. The theory I am presenting to answer my research question is:

Students who identify as learning-disabled and LGBT can reclaim their disabilities and sexualities when they are empowered, by others and themselves, to relearn their differences into strengths and use those strengths to become agents of social change by means of composing activist texts for their schools and their communities. By becoming agents of social change at school and in their communities, LD and LGBT students can motivate their teachers and peers to unlearn accommodations and stereotypes.

In the following pages, I will explore each of the saturated categories that led me to my theory.

\section{Relearning Differences as Strengths}

Looking closely at the rhetorical activities in which Alice and Delevan engaged at the writing studio, I was able to observe them relearning their differences as strengths by ways of conversation, problem-solving, creative thinking, and play. As I explained in 
Chapter IV, I name students' “differences” their learning strengths because these strengths empower students to stand out amongst their peers and take ownership of their academic and social futures. Alice’s “differences” are she is a visual and spatial learner; she learns best with music either as part of the text or in the background; and she is also logical. The learning strengths profile indicates she does not thrive with linguistic communication or interpersonal communications. Delevan's “differences” are he is a visual and spatial learner, as well as a learner who thrives when projects focus on the body/kinesthetic; he learns best when music is part of a project or when music plays in the background. Delevan is comfortable with both interpersonal and intrapersonal communication. He also does not thrive as a linguistic communicator. A CHAT analysis will reveal ways in which Alice and Delevan relearned their differences as strengths in laminated heterotopias. Recall that in the introduction, I wanted to identify ways in which students use their space to engage in a variety of rhetorical activities in the writing studio, which I consider a heterotopic space, or an Other space that mirrors real space. I think it is also important to acknowledge not only the writing studio as a heterotopic space, but also Eagle Hill School itself.

Writing studio spaces are heterotopic spaces in that they continuously accumulate articulations of otherness with each new group of students to use the space. The studio space has the power to juxtapose in a single real place several spaces, several emplacements that are in themselves incompatible. For example, students composing texts in the studio space often utilize the graphic arts studio, the general art studio, the multipurpose room in the gym, the conference room, and the dormitories to complete their projects. The studio space is linked to what Foucault calls slices of time. The studio 
space is a heterotopia that is "linked ... to time in its most futile, most transitory, most precarious aspect and this is the festive mode” (Foucault, “Of Other Spaces” 20). The writing studio is emergent and by nature of being emergent is transitory, meaning its function changes as students' writing needs change. The studio’s purpose not only changes over time due to technological innovation and more local, curricular changes, but it also changes class period to class period depending on who is using it.

A heterotopia must have, in relation to the rest of space, a function. I argue that the studio space I offer students enrolled in Writers’ Workshop is “another real space, as perfect, as meticulous, as well arranged as ours is disorderly, ill constructed and sketchy” (21). The studio space is perfect because in it students are allowed to be messy. While this sounds like a contradiction, I invite readers to think about the ways in which public school classrooms embrace (or are forced to embrace) policies that hold some students back and not others; and from a design perspective, these classrooms often have desks in rows making communication difficult. These ill-constructed spaces push students toward clean, straight, and cohesive products; whereas my studio space encourages students to make mistakes and reflect on what they learned without consequence. In a messy space, the focus is on "allowing students to recognize within the 'products' of writing the interplay of their own voices with others, of their own words with the means of communicating them, of the politics of each and every writerly choice they make” (Dolmage “Writing Against” 115).

Students enter Eagle Hill School, one heterotopic space and the writing studio space, another heterotopic space, in a state of crisis, having come from situations where they were oppressed by public schools and bullied by teachers and other students for 
being different. Students come to our school with an array of defense mechanisms that prevent them from participating to their fullest potential in academic classes. After hiding behind these defense mechanisms for such a long period of time, our students usually lack confidence in their academic abilities and are unaware that they have anything valuable to offer to their teacher and peers. Before arriving at Eagle Hill, students are not encouraged or inspired to use their differences, or, put another way, students are not afforded opportunities to figure out their learning strengths, nor are they provided opportunities to put those strengths into action. I suspect that is because "differences" are not qualities that help students fall in lockstep with popular policies in American education, such as standardized testing.

When Alice and Delevan entered the writing studio, they began a dialogue, or entered into the process of socialization, with their teacher and their peers that focused on sharing the activities in which they engaged during writing. Alice and Delevan began to view conversation in the classroom as a way to express themselves and get to know themselves as writers, instead of as something which could lead to being reprimanded. Delevan told us he danced and sang, drank a ton of Polar seltzer, and called his friends to bounce ideas off of them, and those answers were not treated as comical. Alice responded that she did yoga and blogged, listened to music and also talked her two close friends, and she was not chastised by the studio for going online while she was supposed to be writing. These discussions allowed Delevan, for example, to utilize his interpersonal skills and for Alice to develop her interpersonal skills. After such powerful conversations, each student drew maps or composed a collage of their writing activities and in the process recognized that they shared more in common than any of them had realized. 
When students compared similarities amongst their "bizarre”, “not traditional” writing activities, I observed the writing studio as a heterotopia, mirroring the reflection of the traditional writing classroom in our embrace of writing as messy. The writing studio is laminated on the safe space where presumably it is acceptable and expected to speak one's mind and be oneself without negative repercussions. These two chronotopes are laminated on the independent school, whose mission it is to provide students in crisis with equal resources to succeed academically and socially.

Alice and Delevan also relearned their “differences” into strengths as their understanding of production, distribution, and reception was developed. Alice and Delevan entered the writing studio space already possessing knowledge of how to use a variety of writing tools for a variety of contexts; for example, Alice, producing her cluster criticism, knew how to download images into Photoshop and repurpose each photo as a different page of her analysis; she also already knew how to compose and edit texts in iMovie, and she knew how to develop and upload content for her blog. Delevan knew how to illustrate using markers, as well as how to choose effective placement on the board for images and the color of images. He also knew how to use his mobile phone as a video camera and download the video capture from the focus groups on bullying onto iMovie. Another tool that Delevan, particularly, used to compose and remediate text was his body.

Jay Dolmage argues that in the discipline of rhetoric and composition, we "have not acknowledged that we have a body, bodies; we cannot admit that our prevailing metaphors and tropes should be read across the body, or that our work has material, corporeal bases, effects, and affects” (“Writing against Normal” 110). It is imperative 
then that in Writers’ Workshop, I teach students that their bodies create rhetorical messages or, in other words, that their "physical enactments materialize [their] political views and beliefs” (Del Gandio 145). When I teach body rhetoric, or embodiment, in Writers’ Workshop, I focus on three areas: the body, the message, and the audience. I mentor students toward an understanding that the way they move — sit, walk, stand — “aligns their internal politics with their exterior communication” (Del Gandio 147). I teach students that their bodies are always on display; therefore, they are always communicating messages. I share with students in Writers' Workshop that the way they use their bodies to communicate with one audience will not be the way they use their bodies to communicate with all audiences. Jennifer Rowsell, in Working with Multimodality: Rethinking Literacy in a Digital Age, reminds us "whereas video, animation, and designed text can be replayed in the absence of a performer, movement needs the performer present in the midst of practice to communicate” (110) and, argues Rowsell, "unlike the interactivity of digital, designed modes, movement is fundamentally about drawing an audience's attention to aspects of performance that the performer/mover wants them to focus on in that moment” (111).

The tools and mediated contexts in which students use these tools to create meaningful communication is another way students relearn their "differences" as strengths. What Alice and Delevan were not aware of was that these popular tools and contexts in which to use these tools are just as academic as Microsoft Word and a traditional research paper. It is difficult to see yourself as an academic writer when your learning strengths only allow you opportunities to use popular composing tools in contexts that are not privileged as academic. Alice, Delevan, and other students in the 
studio were able to relearn their "differences" into strengths when their preferred medium for distribution and their strategies for reception were counted as academic writing, and not simply as writing for fun. Alice distributed her video poems and her blog potentially to thousands of people. Online publishing for Alice was "no big deal" and something she does "regularly." What she did not realize in the beginning of the course is that those texts she produced were remediated from texts she has come in contact with in her everyday life, such as coming out stories and LGBT fiction. Alice took up years of coming out stories that she has read online and remediated those stories as poetry and a blog. Delevan had seen and heard a number of public service announcements on bullying over the years and had also read a number of newspaper and magazine articles on gay bashing in high school. Delevan took up those texts with an important message to treat people with respect and dignity and produced an innovative theatre project in the studio for our school.

The activities of distribution and reception that Alice and Delevan took up are another strong example of both engaging in rhetorical activities amongst the three laminated heterotopia. The writing studio space, by nature of being emergent, is transitory; meaning its function changes as students’ writing needs change. Alice needed the studio to compose a coming out blog and Delevan needed the space to compose an invisible theatre project, and the studio space was able to accommodate two different students who each had different projects for different audiences that needed different technologies. However, Alice and Delevan needed the space to be safe from judgment. Both students were composing projects for audiences of oppressed groups of people. In these particular situations, the safe space, a third heterotopic space, was actually safe in 
that neither Alice nor Delevan were judged on their values and beliefs. One reason Alice, Delevan, and other students were able to produce, distribute and respond to texts so freely was because the studio and the safe space were laminated with a closed space. The public could only enter Eagle Hill if those with the power invited them in.

Ecology also plays a role in the ways that students can relearn their "differences" into strengths. I understand physical ecology to mean the design of the space, and — as I have argued in previous chapters — how spaces are designed, in the way of placement of workstations, lighting, flow of traffic, and technology and in the way of the emplacements surrounding a space. Spatial design makes all the difference in how students learn. Alice and Delevan, both of whom are spatial learners, were provided opportunities to make changes to all of those areas in the studio. They traded the desks for tables and tables became workstations. These small movements made large impacts as they brought students closer together as colleagues sharing advice on projects and as heterogeneous engineers creating an exhibition. The biological factors that exist beyond the boundaries of the texts the students in the studio produced proved to also be differences that were relearned into strengths. These differences impacted the students as writers but also impacted the writing situations in which they found themselves.

Alice, transitioning from a male to a female, is aware that her biological makeup is different from her gender, and she admits that does have an impact on the way she composes:

Knowing that the audience is not a passive body of people but, instead a co-producing — to use a word from class — body of actors makes me hyperaware of who I am and who I might have to be or not be 
to communicate effectively. For example, my being transgendered was an asset in my cluster criticism because I have a stake in the argument to include trans gender citizens in community activities; however, my being trans gender negatively (maybe I am being too hard on myself) impacted how the studio put together the exhibition.

Alice and Delevan were also afforded opportunities to question their differences as strengths learning in the laminated heterotopia. Alice, Delevan, and even I, as their teacher, were aware of the stigma that being learning-disabled has on us as writers and on our writing situations.

Alice and Delevan learned that being afforded the opportunity to be part of a group that makes decisions is hard work and does not always lead to a happy ending. Alice and her parents and Delevan and members of our Eagle Hill community have different cultural beliefs on gender and sexuality, and in the instance of the exhibition being public and the mural being part of the exhibit, those with opposing cultural beliefs impacted both the writer and the writing situation. I would argue that Alice's fears about opening the exhibition to families and Delevan's realizing that his art can be decommissioned based on outside (of the studio) influences with opposing cultural beliefs shows a crease in the laminated heterotopia. Opening the exhibition up to families would force the studio to be an open system temporarily, not the closed system in which we composed with confidence. The fear that Alice possessed of her parents seeing her transgender-focused work and the frustration and anger Delevan feels because he could not finish his mural exposed our safe space to be an illusion. 
Teachers need to be prepared to confront students who are in denial that they do have academic and social strengths and that they can offer valuable insights in the writing studio or classroom. Convincing LD/LGBT students that they have worth can be a tough sell, and sometimes their convincing us of their worth can be equally challenging. These confrontations are unnerving and hard, but the result will be liberating. However, students are only going to recognize their differences as strengths if teachers offer inclass assignments and long-term projects that require students to utilize those strengths. If the student is a visual or spatial learner, then the teacher needs make that discovery and then create a visual and spatial project. If a student is interested in exploring themselves as a queer writer or their potential roles in queer communities, then the teacher needs to support that student. The teacher and confident peers need to nurture students to a level of confidence that they have strengths and can use those strengths to engage in meaningful dialogue about writing and compose articulate, even powerful texts. As Alice and Delevan showed us, powerful texts can reveal safe spaces to be unsafe, and being in an unsafe place can make students feel like they failed. These are the moments teachers have to teach students two of their most important strengths, grit and empathy. Modeling grit and empathy are crucial components in the teaching of writing in secondary school, and that was determined in my grounded theory study.

\section{Grit and Empathy}

Teaching students that writing is social and takes place in social environments, and teaching students that one of the most important parts of writing is socialization, or coming together with diverse groups of people to talk about the production, distribution, representation, and reception of their writing, opens up students to a public which they 
may not be ready to address. I want my students to embrace writing and I want them to embrace the activities that impact writers and writing situations, but I also need them to be aware of the possibility of frustration and even sometimes failure and embrace those, as well. Because frustration and failure happen to each of us in the classroom or studio or after school, at work, and even at home, teaching grit needs to become a component of teaching writing. Along with grit, I also want my students to learn the importance of unity, to find a likeness between themselves and their classmates and outside audiences. This means teaching empathy.

Teaching grit is more of an attitude than a strategy. We have to be comfortable putting students in a position where they have to struggle, show tenacity, and exhibit resilience. The importance of grit is indicated in a 2013 report from the U.S. Department of Education titled Promoting Grit, Tenacity, and Perseverance: Critical Factors for Success in the $21^{\text {st }}$ Century, which expresses concern for students who are learning "to do school but are not developing life skills to persevere in the face of challenges they will face in the real world" (18). Education stakeholders "should consider how to give priority to grit, tenacity, and perseverance in curriculum, teaching practices, and out-of-school support” (xii). Grit is also known as resilience, and the resilience movement is picking up steam at Eagle Hill School and other schools in the United States, too. Kenneth Ginsburg (Building Resilience) writes that "resilient people see challenges as opportunities" and that "rather than engaging in self-doubt, catastrophic thinking, or a mindset of victimization, [resilient people] seek solutions” (4).

Ginsburg shares with his readers his 7C's model of resistance: competence, confidence, connection, character, contribution, coping, and control. Competence is the 
"ability to know how to handle situations effectively" and is "acquired through actual experience” (25). Confidence is “the solid belief in one’s own abilities” and is rooted in competence. Ginsburg writes that "Children who experience their own competence and know they are safe and protected develop a deep-seated security that promotes confidence to face and cope with challenges” (25). On the notion of connection, Ginsburg argues that "family is the central force in any child's life, but connections to civic, educational, religious, and athletic groups can increase [a person's] sense of belonging” (26). As Eagle Hill School is a residential school, academic and residential faculty act as family to our students and, therefore, the relationships we have with our students are often the central force in their lives. Building character in students helps them "enjoy a strong sense of self-worth and confidence” (27). Some ways that I help my students build character are helping them understand how their behaviors affect other people in different ways; helping them clarify their values; and helping them consider right versus wrong and to look beyond immediate satisfaction or selfish needs. One way that my students, particularly Alice, had an opportunity to clarify her values was when she was composing her final, multimodal project — her coming out blog on Tumblr. Recall that during this project, she was thinking critically about her values and beliefs. Contribution is letting students "realize that the world is a better place because they are in it" (27). Ginsburg writes that children "who understand the importance of personal contribution gain a sense of purpose that can motivate them. They will not only take actions and make choices that improve the world, but they will also enhance their own competence, character, and sense of connection” (27). I cannot think of a better example of character building than Delevan and his multimodal bullying project. Not only did he bring students together on an 
important social justice topic, but he has begun to enact real change at our school. Ginsburg advocates that children "who learn to cope effectively with stress are better prepared to overcome life's challenges” (28). As a teacher to secondary students it is important to model positive coping strategies and teach them the difference between a real crisis and something that just feels like an emergency. I think that one of the benefits of focusing on problem-solving strategies in the writing studio is that once these strategies are learned they can be applied outside of the writing studio to uncomfortable situations like crises and emergencies. Control, the seventh of Ginsburg's Cs focuses on children realizing that they can control outcomes of decisions and actions" and because they possess the ability to control these outcomes, they are "more likely to know that they have the ability to do what it takes to bounce back” (29). Writing studio pedagogy affords students opportunities to take control of their decisions and actions. The example that comes to my mind first is Delevan's semiotic remediation project. Delevan really wanted to finish composing his provocative mural that was remediated from his poetry collection. However, his peers role-played different stakeholders at our school. Delevan could have made a different decision and taken a different action, but instead he listened to his peers, which was uncomfortable. He was upset, but I do believe that his figuring out that he could take control of his decisions and actions made him work harder and more rhetorically with his next project, the bullying project.

Along with Ginsburg's seven C’s of resilience, there are Thomas Hoerr's (Fostering Grit) six steps for teaching grit in the classroom, and they tie in nicely with how I assigned projects in the studio. The first step is to establish the environment; the second step is to set the expectations; the third step is to teach the vocabulary; the fourth 
step is to create the frustration; the fifth step is to monitor the experience; and the sixth step is to reflect and learn. The mural project is a strong example of teaching grit to Delevan and other classmates. The environment established is, of course, the studio environment and the expectations were created by both me (I created the project) and Delevan (he chose the means of production, distribution, the intended audience). Delevan and the studio experienced the fourth step before the third in that before I sat down with the studio to talk about grit, the frustration had already been created when the group of students in the studio role-played stakeholders at the school resulting in Delevan stopping the project. As the teacher, I monitored the situation, as well as Delevan's mood, and finally, a few days after our discussion on grit, I asked the studio to reflect on the whole event in a journal entry that could be visual or linguistic. We then moved forward to the next project. While empathy may seem unrelated to grit, a student who possesses both as strengths will be able to address his or her audience better than those students who are neither empathetic nor gritty.

Empathy is the ability to recognize and respond to another's emotional plight or experience beyond background or differences in beliefs. Empathy involves connecting, building relationships, listening, and caring for others. Like grit, empathy too needs to be a goal of the writing studio or writing classroom. Students should leave the classroom or school environment equipped with skills to build meaningful relationships with their peers. Kimberly Hunter, author of Empathy in Education, points out that “developing positive relationships requires empathy skills like listening to others, understanding verbal and nonverbal cues, and learning to understand, and appreciate, the differences in others” (n.p.). As Alice and Delevan revealed in their case studies, students bring their 
lives into the classroom; they do not leave their problems and feelings at the door, and when "classmates do not have the skills to understand and work with their diverse classmates, problems can arise” (Hunter n.p.). Teaching students in the studio empathy as one of their strengths to understand writers and writing situations is critical and should, if possible, be taught alongside grit. The studio was left in a state of confusion and hurt when Alice argued for the exhibit to be in-house instead of public. Other students wanted a public exhibition, but Alice's parents would show up; after all, they are supportive of their son and ignore that they have a daughter. The other students were not angry at Alice, but not all of them understood Alice's fears. Empathy is intrinsic, but there are steps teachers can take to help students learn to be more empathetic. The first step is to practice reflective listening with students. Repeat back to them what they said and see if you listened correctly. The second step is to show empathy and validation. Doing this means accepting the other person's feelings regardless of whether or not you agree with them. You do have to mean what you say to the other person; in other words, empathy cannot be faked. The third step is to express understanding. This means to indicate an understanding of what the other person is experiencing. When Edwin, another student in the studio, became frustrated with Alice for not wanting to publicize the exhibition, it was important that I intervened in this teachable moment. Remember, in Chapter IV, after the conversation between Alice and her peers was finished, I came over and asked them each to participate in reflective listening and then did validate Edwin's feelings about being frustrated and asked Edwin in turn to think about validating Alice’s feelings. Edwin did eventually, the next day, validate Alice’s fears about having her parents attend the exhibit. Does this mean that Edwin learned how to be empathetic? I suspect not. I do, 
however, suspect that Edwin will be more prone to being empathetic the next time a situation with another person or group of people frustrates him.

I know so many students who are learning- disabled and are not students at Eagle Hill School. These students are frustrated, will fail several classes in high school, and may even not complete school. These students need to become gritty. Like Angela Duckworth in her Ted Talk and Paul Tough in his bestseller, How Children Succeed: Grit, Curiosity, and the Hidden Power of Character, I am asking myself and asking you to ask yourself, how? How can we teach grit to our students? How can we teach empathy? I am comfortable waiting for teachable moments during which I can help students learn to be optimistic and help students build their strengths. I am comfortable waiting for those teachable moments where my students and I can practice reflective listening, validating others' feelings, and trying to understand others' experiences. The next grounded theory category that contributed to my theory is self-efficacy.

\section{Self-Efficacy}

I want to put forth the argument that students who use the studio as a space to unlearn their differences as strengths and who are provided opportunities to show their strengths develop self-efficacy, or the strength of one's belief in one's own ability to complete tasks and reach goals. Much of my understanding of self-efficacy comes from the important work of cognitive and social psychologist Albert Bandura. Self-efficacy beliefs, posits Bandura, "regulate human functioning through four major processes: cognitive, motivational, affective, and selection ("Perceived” 133). I will briefly go through each of these four processes (though not to the extent that Bandura does) and connect these processes to the writing students were achieving in the 
writing studio. Bandura writes that "self beliefs of efficacy affect thought patterns that can enhance or undermine performance” and that "people’s beliefs about their efficacy influences the types of anticipatory scenarios they construct and reiterate.” Therefore, "those who judge themselves as inefficacious are more inclined to visualize failure scenarios which undermine performance by dwelling on how things go wrong” (133). In our initial interviews both Alice and Delevan were inefficacious toward their writing; neither believed that they were strong academic writers. Both students constructed at an early age and reiterated constantly that they are not good academic writers, so therefore they would always have problems writing in traditional school genres. What changed their cognitive process in the studio was being afforded opportunities to write in modes in which they felt comfortable and even were emboldened by and, as they composed more, the bar of their own expectations was set higher. My ultimate expectation as the teacher was that they would set their own expectations higher than when they began Writers’ Workshop. An example of a student setting his or her expectations higher than when he or she began Writers' Workshop would be learning a new genre and then seeking out opportunities to create a project in that genre that serves a purpose beyond getting a good grade. Self-beliefs of efficacy, argues Bandura, "play a central role in the self-regulation of motivation" (141). Bandura writes that "the capacity to exercise self-influence by personal challenge and evaluative reaction to one's own attainments provides a major cognitive mechanism of motivation and self-directedness” (142). I read this statement as when students find value in the work they do, i.e., composing a project, they will challenge themselves to compose the best project they can, and when they do not reach their own expectations, they will problem-solve to figure out why they did not meet their 
goal and try again, i.e., revise the current project or aim higher on the next project. Delevan's experience with the mural was a lesson in motivation for him. Remember, he was pleased with the progress he had made on his mural when, unexpectedly, a conversation ensued where students in the studio role-played different stakeholders. Ultimately, Delevan decided to discontinue his project and did not reach his goal of making a piece of art that would engage people, willing or otherwise, to confront LGBT issues. At first Delevan was upset, but then he got gritty and wanted to set the bar for success even higher on the next project. Bandura would respond perhaps by arguing Delevan was "seeking self-satisfaction from fulfilling valued goals and [was] prompted to intensify [his] efforts by discontent with substandard performances” (142). Delevan's unfinished semiotic remediation project left him feeling incomplete, even though I think he learned some valuable lessons. The feeling of incompleteness, though, pushed him to be more ambitious with his next project, the bullying project. Not only did he create a project where the topic meant a lot to him, but also he took on a topic that was important to our students and many of the faculty. Other students and faculty caught wind of his project and inquired to him what it was all about. I think that the positive reactions Delevan received from across campus made him even more ambitious, as he selected students to form a focus group representing each grade level on campus in order to get to the root of the perceived bullying problem on campus.

The affective process has to do with people's beliefs in their capabilities affecting how much stress and depression they experience and how they cope with that stress, as well as their level of motivation. It stands to reason that "people who believe they can exercise control over potential threats ... are not perturbed by them. But those who 
believe they cannot manage the potential threats experience high levels of anxiety arousal.” People, argues Bandura, “display little affective arousal while coping with potential threats they regard with high efficacy. But as they cope with threats for which they distrust their coping efficacy, their stress mounts” (146). This affective process can be witnessed more with Edwin, the student who became uncivil with Alice. Edwin became distressed in the writing studio with Alice because he desired to have a public exhibition but Alice and Delevan argued well for having the exhibition in-house. Edwin, perhaps perceiving a lack of control in the studio’s debate, began to distrust his coping efficacy and his stress mounted to the point of his making uncivil comments to Alice. Because I redirected the conversation stemming from the debate amongst studio peers to a lesson in empathy, I was able to avert either Edwin or Alice from further anxiety.

The fourth process of self-efficacy Bandura examines is the selection process. He argues, “judgments of personal efficacy also shape developmental trajectories by influencing selection of activities and environments" (151), which means "any factor that influences choice behavior can profoundly affect the direction of personal development” as "social influences operating in selected environments continue to promote certain competencies, values, and interests” (152). Students in the writing studio interact with several factors uncommon to a traditional writing classroom experience. Students in the studio are being influenced and influencing their peers each day by the technologies and the mediums they select to compose their projects. Students in the studio are also influenced positively and negatively by socializing about their writing — talking about their projects, their audiences, and their desired outcomes from their projects. The writing studio environment promotes to students new interests and the opportunity to discover a 
value and belief system that motivates them to compose projects that are meaningful to them and the communities to which they belong. For example, Delevan, in his mural project, identified and developed his value system to include leadership, involvement, and accountability, and these are values that will most likely motivate Delevan to do other, more complex projects for the LGBT community as he grows older.

\section{Interest}

In both the writing studio and across the campus we value students' interests and abilities to create, and we also support students' sense of individual agency. In the writing studio space, we are genuinely interested in the variety of topics and choices in resources and designs toward which our students gravitate. Across campus, we are genuinely interested in the fine arts students want to perform, the sports students want to play, and the community service projects that students want to experience. Gunther Kress predicates his theory of multimodality on the idea of interest as a motivating factor in representation and communication. Interest prompts the making of signs. Kress, in Before Writing: Rethinking the Paths to Literacy, argues that "signs arise out of interest at a given moment” and that interest is "always complex and has physiological, psychological, emotional, cultural and social origins; and this interest "gets its focus from factors in the environment in which the sign is being made” (11). Kress (Multimodality) describes the importance of interest in creating instances of communication: A message, intended as a prompt, engages the attention of a participant in the interaction. Attention derives in the first instance from the participant's interest — where interest names the momentary focusing of a 'social history', a sense of who I am in this social situation now, as well as a clear sense of the social environment in which the prompt occurred" (35-36). 
"Makers of signs," writes Kress, "no matter their age, live in a world shaped by the histories of the work of their societies. Inevitably, what has been and is 'around' and available, has shaped and does shape the interest and the attention of the maker of the sign” (74). It is not enough for teachers to simply provide students composing tools like video cameras, tripods, iPads and apps; teachers need to be role models that help students find and hone their interests. The spark of interest is where multimodal and embodied compositions begin. That kind of interest is almost impossible to hone in classrooms where the teacher-student ratio is unbalanced and where the spaces do not permit active learning and play. Kress writes that interest comes from attention, but what brings us to focus our attention on an idea? I argue that our memories bring us to focus our attention on an idea and, from there our interest leads us to begin composing communication.

The memory as a source of invention is rooted in classical rhetoric and, more recently, in neo-expressionism, another reason that expressivist pedagogy is appealing to me. The ad herennium author calls memory the "treasury of things invented." Crowley and Hawhee remind us that in ancient times memory "held a central place within rhetorical theory” (331). "Whenever the need arose to speak or write,” tell Crowley and Hawhee, [ancients] "simply retrieved any relevant topics or commentary from their ordered places within memory ... and added their own interpretations of the traditional material” (332). The authors also connect memory and kairos: "both require a kind of 'attunement' in that the rhetor who is gathering items for reserve in the memory must be thinking simultaneously about what's available now that might be useful later” and, secondly, "memory requires an attunement during the moment of speaking or composing, a recognition of the right time for recalling an illustrative example, an argument, and so 
on” (317). As well, reminds Gideon Burton, “the canon of Memory also suggests that one consider the psychological aspects of preparing to communicate and the performance of communicating itself” (n.p.). George Campbell believed "the human psyche can be divided into the understanding, the will, the affections, the memory, and the imagination," also known as the faculties of the mind and places "the faculties of the mind into a new logical sequence running from memory to understanding, understanding to imagination, imagination to affections, and affections to the will (qtd. in Smith 22425).

Early expressivist Ken Macrorie suggests “go back to your rooms and try harder than ever before in your life to write truths — not the truth — whatever that is, but your truthful memory of a life event you can’t forget” (5). Peter Elbow argues, in Writing with Power, that "the writer might begin with first thoughts, asking us to write from memory (qtd. in Hilst n.p.). Joshua Hilst, a neo-expressivist, argues that memories as a source of invention can best be understood in what he terms "Deleuzian expressivism.” Deleuzian expressivism means, "to be is to express oneself, to express something else, or to be expressed” (Hilst n.p.). For Deleuze, the past and memory are a virtual field, and particular memories are expressions (modes) of this field. Hilst elaborates Deleuze's explanations of memories:

When we recall a memory, it involves a leap into ontological memory. From the virtual field of the past, of ontological memory, a recollection-image is differentiated into an actual psychological memory. When I have a psychological memory, unfolded from ontological memory, I have a recollection-image. (n.p.) 
This recollection-image is important to the invention process because the image is not necessarily what we want to express but, instead, is what it (the memory) wants expressed to us, the inventor. And, in this recollection-image are "multiple unique voices that might emerge through us.” Neo-expressivism, as introduced by Hawk (“A CounterHistory”) and explored both by Williams (“Dancing”) and Hilst, privileges memory over voice. This move away from voice is what Deleuze terms “becoming-imperceptible,” which means "allowing certain other forces to flow" and can be viewed as "an externalization of an impulse which, when released into the world, takes on an exuberant life of its own” (qtd. in Hilst n.p.).

In Chapter IV both Alice and Delevan indicated that entering our writing studio space offered their first opportunity to compose a text that was interesting to them. Kress' insight into interest is valuable to understand why Alice and Delevan have composed the texts they did in the writing studio space. Kress tells us that our interests are shaped both by our lived histories, as well as the tools — and I would argue the spaces, too — that are available to makers of signs. Alice and Delevan’s lived histories are being shaped by their experiences identifying as learning-disabled and also as LGBT. Alice’s life, academic and social, focuses on her coming out as a transgender woman to her parents and peers. It makes sense, then, that her interest in the genre of the coming out narrative is the primary theme in her projects. Delevan is very much interested in beginning a dialogue about bullying and that interest is apparent in his final, multimodal project as he creates focus groups that actually begin the dialogue Delevan desires to take place at our school. I cannot discount that their memories of what it has meant to be LD and LGBT at home and in school and in public — have risen to the surface conscious and have, 
therefore, led them to "new forms of testimony and expression." These memories wanted to be expressed, and they were expressed through whatever recollection-images showed themselves to Alice and Delevan. I am now going to take up the idea of rhetorical agency, as it is another saturated category from my grounded theory analysis. Interest and agency are connected because students are not going to seek out opportunities to become agents of social change unless they feel they can do so by composing projects that are of interest to them.

\section{Rhetorical Agency}

Rhetorical agency is a popular term in discourses of public rhetorics (Cushman 1996; Stevens 2009; Cooper 2011). Linda Flower, in her essay “Going Public,” defines rhetorical agency as "the reflective power to interpret [oneself] to a public and to draw that public into deliberative dialogue” (147). In her essay "How Ought We to Understand the Concept of Rhetorical Agency?” Cheryl Geisler argues that studies of rhetorical agency in specific contexts seem to show that members of subaltern groups, though circumscribed in terms of their agency, are not without agency altogether; that a number of unacknowledged resources — body, space, and so on — allow for the exercise of agency” (15). In conducting a grounded theory analysis, I argue that the writing studio space is a resource to help students develop a sense of rhetorical agency, as it can be a space where students find and further develop learning strengths and practice those strengths as part of their writing processes. As Karlyn Kohrs Campbell points out in her 2004 American Rhetoric Society paper, "only a select few have enjoyed the traditional sense of public rhetorical agency, and this is less of a problem with the idea of agency per se and more of a problem of understanding the varieties of agency and of the available 
means of achieving a hearing” (qtd. in Geisler 10). Campbell's argument about the need to accept other, nontraditional varieties of agency and means of achieving agency is critical if Alice and Delevan and other students in similar positions are going to be heard publically in their personal, professional, and civic lives.

Flower, in a project she sponsors with learning-disabled students and adults at Carnegie Mellon University, and which gave me a great amount of clarity in how I examined rhetorical agency in the writing studio space, writes that rhetorical agency can be developed into three "significantly different” rhetorical moves: expressive, interpretive, and dialogic. Analyzing Alice and Delevan’s final projects, I observed Alice relying on expressive moves in launching her Tumblr project, prompting Tumblr users to post their stories and then, in certain situations, feeling comfortable enough to respond to several of those stories. Delevan, on the other hand, relied on dialogic moves to interpret the reactions of speakers but also adapted his focus group to the needs of the members in the focus group, interpreting students' responses, qualifying his questions for clarity, and justifying his reasons for involving certain students and not other students in the focus groups. My analysis of Alice and Delevan’s work suggests a fourth rhetorical move, which is activity. Alice and Delevan both relied on activity as a rhetorical move to be heard in the ways they utilized composing tools to persuade their intended audiences, in the ways they each chose to distribute their projects to audiences, and in the ways each socialized with their peers in the studio about their projects. What I mean is that students are using cultural historical activity theory purposefully to make a connection with their intended audiences. If teachers are really interested in the work students compose, then activity needs to be considered a rhetorical move. 
I argue that what made these projects successful is that Alice and Delevan got a public hearing for their work because they were able to produce writing in a space that afforded them opportunities to relearn their differences as strengths, and in that process of relearning their differences as strengths, Alice and Delevan grew into a self-efficacy role. While I introduced the concept of self-efficacy in answering my second research question, it is worth discussing again here because self-efficacy and agency appear to be interdependent. Bandura (“Perceived”) writes that "among the mechanisms of agency, none is more central or pervasive than people's beliefs about their capabilities to exercise control over events that affect their lives” (128). The interdependent role between agency and self-efficacy could not be made clearer than in Alice's projects. Her projects were a rhetorical strategy of exercising control of her life by coming out as transgender and of being courageous enough to write about the trauma involved in her coming out process, so far so that other students, in turn, would not feel alone as they come out to their own families and friends. Had she relied on traditional available means of achieving a hearing, I do not believe she would have been heard so loudly by so many people. Instead, she composed a text that incorporated media and affordances that resonated with not only a tech-savvy audience, but an audience that, when persuaded, can carry her message to a larger group of online activists who take seriously their role in helping to deliver important messages.

\section{Acquiring Literacies in Laminated Heterotopia}

Early in Chapter IV, I briefly inquired why Alice and Delevan have a narrow understanding of literacy acquisition, or what counts as literacy. I want to delve deeper into Alice and Delevan’s learning-disabled and sexual literacy acquisitions. I invited 
Alice and Delevan and other students in the studio to answer questions about their own literacy acquisition early in the Writers' Workshop course. I am particularly interested in learning about the secondary discourses that LD LGBT students have acquired at Eagle Hill School and how students perceive those literacies as being helpful in their negotiating the world after high school and into college. Put another way, I am interested in how the learning-disabled and sexual literacies that they acquired in high school will affect their engagements in academic and social situations after their graduation this year. Brian Street, James Paul Gee, and the New London Group offer arguments on literacy acquisition from a New Literacies Studies perspective.

Brian Street argues that literacy is neither natural nor neutral:

Researchers dissatisfied with the autonomous model of literacy ... have come to view literacy practices as inextricably linked to cultural and power structures in society and to recognize the variety of cultural practices associated with reading and writing in different contexts. ... A number of researchers in the new literacies studies have also paid greater attention to the role of literacy practices in reproducing or challenging structures of power and domination. Their recognition of the ideological character of processes of acquisition and of the meanings and uses of different literacies led me to characterize this approach as an 'ideological' model (2001, 433-34).

James Paul Gee distinguishes between what he calls primary and secondary discourses: 
After our initial socialization in our home community, each of us interacts with various non-home based social institutions — institutions in the public sphere, beyond the family and immediate kin and peer group.... Each of these social institutions commands and demands one or more Discourses and we acquire these fluently to the extent that we are given access to these institutions and are allowed apprenticeships with them $(2001,527)$.

And, finally, the New London Group offers us their argument for Multiliteracies, one aspect of the New Literacies Studies:

The term "Multiliteracies" immediately shifts us from the dominant written print text to acknowledge the many varied ways that literacy is practiced in the new millennium. The New London Group came together in 1996 concerned about how literacy pedagogy might address the rapid change in literacy due to globalisation, technology and increasing cultural and social diversity. The result was "Pedagogy of Multiliteracies" (Cope \& Kalantzis 1996). They introduce a framework consisting of three elements of design to describe the activities of an individual as they identify, read and create new text using varying semiotic codes. The identification of semiotic codes forms part of a new literacies metalanguage. (“New Literacies and Classroom Practices”)

Both Alice and Delevan claim to have been exposed to a wide variety of multimodal texts and genres since their arrival at Eagle Hill School and since their time in the Writers' Workshop class in the writing studio space. Alice has experimented not 
only in academic writing and social media writing, but also with creative writing, pinhole photography, and drawing. Delevan, too, has experimented with academic writing; he has also experimented with dance, theatre, and film. Alice tells me that she had little exposure to any type of writing other than grammar worksheets and artificial prompts before coming to Eagle Hill; Delevan claims Eagle Hill "has not exposed me to any new texts that I was not exposed to at other schools, although Eagle Hill has a much more comforting vibe that goes with their approach to literature, mainly because the teachers are all laid back about the topics.” Their similarities in literacy acquisition — both learning-disabled and LGBT — start and stop there. Both Alice and Delevan were provided the same questions about literacy acquisition but their responses create a stark contrast in opportunities for literacy sponsorship.

Even to the researcher without much background in literacy studies, the literacy narratives of Alice and Delevan appear in stark contrast. Alice appears to have acquired many more learning-disabled and sexual literacy practices than Delevan. Alice responds that that she has talked a lot with her adviser about learning disabilities: "My adviser has helped me talk about being trans and about academics. I had one reading and writing class with her and I learned a lot about reading and writing strategies. We have talked about going to college being LD in almost of my senior courses.” Alice also talks openly about her role models. Her learning-disabled role model is Albert Einstein: He was a man of science who had dyslexia along with other disabilities, yet he did amazing things. Alice's trans role model is Kim Petris: "She had an amazing transition but is targeted by other genderqueers because she has had it so much easier than most. They love her 
because she is a symbolic trans woman, but at the same time she is hated because she has not had to be the guy in a skirt with hairy arms and a beard.”

Delevan, as I wrote, appears to have had fewer opportunities at Eagle Hill School to acquire learning-disabled and sexual literacies. When I asked Delevan what types of conversations he has had with teachers about learning disabilities, he responded: “At my previous school not a single conversation was had other than the ones that were about my struggles. Here at EHS I have only talked about learning disabilities in the context of this project. It is not a topic that I think is worth talking about.” Delevan also responded that he has no learning-disabled role models, for "role models do not define us."

There were several factors for me to consider when I juxtaposed these literacy accounts. First, Alice is a senior who has been a student at Eagle Hill since she was a freshman; Delevan came here as a sophomore and is now finishing his junior year. Second, all students, LD and LGBT or not, have different learning styles and have had totally different experiences at school and home. I will finish the discussion of literacy acquisition sharing Alice and Delevan's class reflections. These reflections are modeled after Gloria Anzaldua’s powerful essay Speaking in Tongues: A Letter to $3^{\text {rd }}$ World Women Writers. Alice, Delevan, and other students wrote these letters to other learningdisabled labeled students who are not students at Eagle Hill School. Alice and Delevan both voiced that they would like to send these letters to friends at their former schools and communities who are still struggling to be heard. 


\section{Delevan's Letter}

Dear LD students,

Don't just sit in class paralyzed by the labels people who don't understand you place upon you. Those teachers and people in your community who label you are just afraid of what they do not yet understand. Learning disabilities are still largely misunderstood. People call us retarded or slow or unteachable because we don't adhere to a standardized test or because we ask more questions than are typical of a student, or perhaps we just ask more questions than a teacher cares to or knows how to answer. I would argue that in order to break free from the bondage of your label, you must write yourself out of the chains.

I am fortunate that I was able to move away from a public school and into a private school for students just like us. I am fortunate my parents had the means. I am sure your parents have the desire, even if they do not have the means. I mean it. At my school, I learned how to not only write but to compose with words, images, sounds, and — of particular importance to me — movement. You need to do yourself a favor and discover which modes of communication you can best express yourself and then let yourself go crazy, wild, and free on the page, the screen, the wave. Dabble in every different mode at least twice. You need to start composing to audiences with the purpose of making it known to others that you will not continue to be oppressed by an education system that views you as less than what you really are, which is a rock star in your own right. Make a 
movie. Record a soundscape. Write a hidden poem out of a document that characterizes you as lost, hopeless, or a minority. Write an article for your school paper or even a blog or put together a collage. And, then, after you have composed your piece, after you have put it all out there for an audience to see, submit it, send it, upload it. Reveal your writing as a persuasive text that will move people to action.

I have learned this year that even the safest spaces are not completely safe. Our school, a safe haven for LD students, accepts LGBT students. That does not mean that every teacher and every student at the school accepts me — or others — for who they are. No! It means that I am in a space where I can feel safe to speak out for myself as a gay man but I still have to be aware of to whom I am speaking or even to whom I present my ideas.

I want you to begin writing a little every day. I want you to compose to reveal your emotions or, better, to understand your emotions and why you have them and how to temper them or at least regulate them so you will be taken seriously when you are in a room full of people who don't already take you seriously. I also want you to compose to get your thoughts down on paper. I was told that we don’t understand what we truly think or know until we write it down. I don't know if that's true, but it makes a lot of sense. You also need to write so you can make arguments. You need to be able to argue schools to meet your learning needs. You need to compose to self-advocate. Remember, you can use your body as a text, too. Just craft 
it well. Pay attention to your facial expressions and your hand gestures and your stage presence even if your stage is a classroom or a meeting room or an office or your parents' living room.

There are many distractions for students to carry the learning disabled label, especially for those of us with attention deficit attention disorder and executive functioning problems. We get distracted by other students' talking and movements in the classroom; we get distracted by our own thoughts; and often we get distracted by things such as rain on the window pane, birds chirping outside, and other peoples' phones going off. It is impossible for me to say don't be distracted. I am distracted now, as I am writing this letter, by other students loitering in the hallway in the dorm. My best advice to you is each time you are distracted think about how much you need to focus on your writing. How your writing will get you heard and getting yourself heard could, possibly, hopefully, free you from the bondage of a label.

In closing, write multimodally and write often. Write to make a change in yourself and those people around you. Write constantly to make your school and your community safer spaces. Don’t get caught up in distractions and do not, whatever you do, be complacent in bearing the burden of your learning disabled label.

Delevan 


\section{Alice's Letter}

Dear Learning Disabled Students,

I know what it is like to be discriminated against for simply being who I am. The other day I applied for a job at Six Flags amusement park, and they hired me as a boy and told me that I would have to cut my hair. I told them I am trans gendered and I do not feel comfortable cutting my hair, and they decided on the spot not to hire me. I could choose to be angry or I could choose to lament my situation of being a young transgender girl in a straight world, but instead I choose to write texts that speak to trans gender and straight people about trans gender issues. The mission I am giving you today is to compose yourself into existence. Become what my writing teacher calls an agent of change.

Growing up dyslexic I always doubted by abilities to write because I couldn't spell or see how letters came together to form words, and I struggled all through school. I have failed many times as a linguistic writer, but I learned my senior year in high school that writing isn’t necessarily about putting pen to paper. Writing can be producing your thoughts and also your experiences using images, sounds, and video. My advice to you is not to let the word writing get you down. Let the word composition raise you up. Composition, not writing, focuses on communicating in ways where your own learning differences can be assets. For example, I am a strong spatial and visual communicator, so I took stories that I wrote about my fears being transgender and I 
remediated them into digital poems that can be enjoyed by students, like me, who are struggling to come out. Remediation is another word for taking one text and repurposing it into another type of text for a new audience and maybe even with a new intention in mind. Making a text that leaves a lasting impression on an audience, like getting people to empathize with transgender issues, makes me an agent of social change. The last thing I want to write to you about is not getting distracted by people who want to bring you down. I have allowed myself over the many years I have been in school to let people bother me, harass me, call me names both for being learning disabled labeled and for being transgender. Peoples' taunting is a distraction from your mission to compose yourself into existence.

Or is it? I want to believe that peoples' taunting is a call to action for me. Their bullying motivates me now to do something - to compose something creative and brilliant and powerful. I intend to stand up for myself and other transgender teenagers in my position and compose a response to Six Flags that argues hiring transgender teenagers is just as important as hiring straight or gay teenagers because we, like them, are just as valuable. What will you stand up for today?

Alice

\section{Reflection on the Letters}

These letters are, in my estimation, simply brilliant and perhaps the best examples of thought-provoking, smart, and powerful student writing I have seen in eleven years of 
teaching writing in college and high school. Both Alice and Delevan are showing readers of this project exactly what it means to be agents of social change and embrace grit and empathy. They each have been so thoroughly oppressed by ableist and heteronormative culture both at school and in public, and also by perfect strangers, as well as people they love, and yet both of them have walked away from these scary, potentially scarring situations as stronger people. Alice and Delevan have failed in their lives and have decided, instead of hiding in the shadows, to come out loudly at school, home, and work and help other teenagers do the same. Both students possess an understanding of what it means to be an activist teenager in a relentless, unforgiving world. I have changed as a teacher because I know Alice and Delevan, and I hope, upon reading their stories and these letters, that other teachers will gain an interest in providing teenagers with whom they work a space and a reason to write. 


\section{CHAPTER VI \\ UNLEARNING ACCOMMODATIONS AND STEREOTYPES}

\section{Introduction}

This chapter introduces scholarship in composition studies for unlearning both accommodations and stereotypes for students and colleagues who identify as learningdisabled and LGBT. I have learned firsthand that those colleagues and students deeply entrenched in both ableist and heteronormative cultures are not going to unlearn by themselves. At the same time, it cannot be our responsibility to teach them and guide them every step of the way until they are at a place where they can teach us as students and work with us as colleagues without fear and trepidation. Coming out or, as Simi Linton argues, “claiming” will “necessarily disrupt the social order as disabled people come out to demand an inclusive society” (Claiming). It is only when a social order is disrupted that there is a space to begin a teacher or peer or cow orker on their path to unlearning. Therefore, we have to be courageous enough to come out — to claim ourselves as learning-disabled and as LGBT — for others' unlearning to begin.

I begin the chapter defining "unlearning” and then discussing unlearning from the framework of organizational behavior. Next I examine the scholarship in composition studies and computers-and-writing studies that seeks to make people aware of the need to unlearn stereotypes and accommodations for LD and LGBT students. 


\section{A Framework for Unlearning}

Some of the earliest research on unlearning was performed by Brian Hedberg (“How Organizations”) who argued that unlearning was the conscious discarding of obsolete memories. Hedberg maintained that "the acquisition of new practices was often obstructed by the persisting knowledge of past practices" and that "old practices needed to be unlearned to create a space in the individual's memory for new practices to adhere" (18). John Newstrom ("The Management”) defined unlearning as "the process of reducing or eliminating pre-existing knowledge or habits that would otherwise represent formidable barriers to new learning” (36). Paul Nystrom and William Starbuck (“To Avoid") defined unlearning as a process of "discovering the inadequacies of old ideas and discarding them" (53). Nystrom and Starbuck identified the individual's unlearning process as requiring humility, objectivity, and the self-confidence to face errors; an organization's unlearning process would require a manager's entertaining dissent and fostering a culture of experimentation. The authors go as far as suggesting that a successful process of unlearning may even include the removal of individuals in leadership roles from an organization. An important criticism of unlearning comes from J.I. Klein ("Parenthetical Learning"), who calls into question the physiological possibility of discarding knowledge (293). Klein does not believe that it is possible for memories to be lost but that with new knowledge created, an older memory will be a less available resource.

Newer research on unlearning has been published by Juan Gabriel CegarraNavarro, of Universidad Politécnica de Cartagena, and his colleagues. Cegarra-Navarro and Dewhurst ("Linking Shared”) focused specifically on individual unlearning, arguing 
that it consists of three phases: recognition of problems, alteration of established cognitive patterns, and development of new assessment frameworks to be used in the future. In 2005, Cegarra-Navarro and Moya (“Business Performance”) linked individual unlearning to organizational performance. In this study, the authors discovered that “individual and group unlearning could occur in either sequential or parallel processes” (168). Most recently in the literature of unlearning, Feza Tabassum Azmi (Mapping) proposes that organizations adopt a learn-unlearn-relearn strategy as a means of “maintaining an organization’s culture of flexibility, agility, steadfastness, and tactfulness” (240). The significance of Azmi’s work is that it is one of the first pieces that emphasizes the importance of relearning. In 2010, John Howell and Nathtalie Mitev (“A Skeptical Look”) argued that individuals cannot unlearn in the literal sense of the word. For the authors, there is not enough evidence that existing knowledge can be deleted. Instead of focusing on unlearning, argue the authors, individuals and organizations need to instead achieve a greater understanding of their environment.

\section{Re-conceptualizing Unlearning}

Njoke Thomas (Towards) writes that “a deeper investigation of Hedberg’s and others' ideas ... raise some serious reservations about the concept of unlearning as presently defined” (4). It is Thomas' intention to reconceptualize how organizations approach unlearning with individuals and within organizations. She strives for a less literal application of unlearning and instead redefines it as “a form of learning in which the individual engages in intentional evaluation of the self, task, and environment to determine that a change of practice is necessary and possible.” Many individuals become "stuck due to desensitization to key changes in their environment and therefore, 
unlearning is contingent on an element of surprise, events that violate expectations” (26). An essential step in unlearning, then, "is the ability to recognize the unique aspects of the situation at hand" (26). Juxtaposing the literature review on unlearning with the LD and LGBT scholarship that follows has allowed me to think through more creatively how a writing studio pedagogy can best afford LD and LGBT students opportunities to reclaim their disabilities and sexualities. These ideas will be examined later in this chapter.

\section{Unlearning Heteronormativity in the Composition Classroom}

LGBT compositionists, myself included, demand to reclaim our sexualities and to do so desire students and colleagues to unlearn heteronormativity as it is experienced in the writing classroom and in English departments more generally, and in its place have students and colleagues treat us with respect. We also want our sexualities unaccommodated in the writing classroom. Unlearning heteronormativity would result in not only being included in conversations but also being heard by our heterosexual peers and colleagues. Being included and heard means that students who make contributions in class and colleagues who make contributions to their departments are taken seriously and that their ideas are not judged by their peers as fringe. Being included and heard also means that if I, as a researcher, submit an article in a disciplinary journal, I do not want my work being relegated to a special issue.

Johnathan Alexander and David Wallace (“The Queer Turn”) write that “the particular critical power of queerness remains an under-explored and under-utilized modality in composition studies" and "rhetoric and composition needs a better understanding of how heteronormativity operates in society at large, in our classrooms and in the pages of our books and journals” (301). The authors argue that queer has not 
had nearly enough attention in composition's social turn and that "paying attention to queerness provides opportunities to engage with students in challenging discussions about how personal parts of our lives are wrapped in social and political narratives” (303). I agree with Alexander and Wallace and want to interject that unlearning heteronormativity in the writing classroom by introducing in-class assignments and longterm projects that focus on queering texts, such as the queer-themed rhetorical analysis work done by my students in Chapter IV, can begin for some or continue for others the process of unlearning heteronormativity.

Alexander and Wallace organize our queer disciplinary literature into three categories that I find useful for thinking about my own teaching space and how I communicate with students of all sexualities: confronting homophobia, becoming inclusive, and queering the hetero/homo binary. In the "earliest of the queer composition work, the main concerns were primarily about dealing with overt homophobia in students’ writing and the presence (or absence) of openly queer writing teachers” (305306). Alexander and Wallace and Alexander and Banks ("Sexualities”) both cite Richard E. Miller’s 1994 “Fault Lines in the Contact Zone,” in which he examines responding to homophobic writing, noting "how little professional training in English Studies prepares teachers to read and respond to the kind of critical ... opposition ... transgressive and regressive writing ... that gets produced by students writing in the contact zone of the classroom” (qtd. in Alexander and Wallace 306). For LGBT people, write Alexander and Wallace, the personal and academic are rarely separable (308). Alexander and Banks also examine the movement in terms of dealing with overt homophobia and the presence of out writing teachers, arguing that "both sexuality and technology studies are concerned 
with the intertwined issues of space and identity” (274). They cite Malinowitz' Textual Orientations and Spurlin's Lesbian and Gay Studies in the Teaching of English as texts that "demonstrated how acknowledging queerness undermines the assumption of a family-centered heterosexuality and opens up a space for discussing ... lives outside of the heteronormative paradigm” (274). Homophobia must be challenged in composition — and all — classes, and composition teachers and students should not hide normative sexual identities.

The second movement that Alexander and Wallace examine is that of inclusion. The authors argue that queer people need to have their lives represented substantively and on our own terms (309). Harriet Malinowitz, in Textual Orientations, “demonstrated that writing courses focused on queer topics were not only 'inclusive' but 'critical' in that students had the chance to examine how dominant cultural norms about sexual orientation shape our sense of self" (qtd. in Alexander and Wallace 309). Alexander and Banks are specifically interested in what gets included and excluded in print and online texts developed by, for, and about LGBT people. They, too, cite Malinowitz who, in Textual Orientations, “concludes her study by noting ‘that mere inclusion’ renders impossibly simple the experience of the margin, which is a site both of annihilation and actualization, of disempowerment and electrifying resistance” (277). Alexander and Banks argue that inclusion should itself not be the reward because, if it is, "we end up merely reifying the centrality of a White, class-privileged heteronormativity” (277). I argue that a reward for unlearning heteronormativity would be the opportunity to unlearn other stereotypes cast upon other groups of people and then, hopefully, people, having 
relearned acceptance, can pay it forward to someone else with the same misguided beliefs and values.

The third move in composition's queer social turn "attends directly to the tension between the need to make queer people and issues more visible in our classrooms and culture and the potential that doing so has to reinscribe the very homo/hetero binary it works to unseat” (Alexander and Wallace 311). Alexander and Wallace alert us that special issues of JAC and Computers and Composition "offer a spate of essays examining how queer theory might prompt us to re-examine what we do as compositionists and how it might create a new critical foothold for us in providing sustained reflection on the ideologically driven narratives ... that condition so much of our experience” (311). It is in this third move where composition studies and computers-and-writing studies come together to make queer people more visible than we have been in the other two movements. It is in this third movement, in online and offline spaces, where we can clearly see the social construction of identities. Alexander and Banks remind us that "queer theorists start from the assumption that identities are socially constructed" and "much of what [they're] seeing from youth cultures, particularly on the Web, is suggesting that the coming generation will be much more comfortable with the social construction of identity" (283). In the special issue of Computers and Composition that Alexander and Banks introduce, Heidi McKee argues that students easily compose and express opinions that reify very binary ways of thinking about sexuality, claiming that when we "continue deployment of such binaries, we not only overlook the lives of others, such as bisexuals and the transgendered, but we also run the risk of reifying biases within the existing binaries” (qtd. in Alexander and Wallace 313). The queer scholarship that 
Alexander and Wallace, Alexander and Banks, Malinowitz and others have brought into our academic discourse discussions on confronting homophobia, inclusion, and blurring binaries are all important conversations to have with students and colleagues on the long road to unlearning heteronormativity, or as I like to call it, equality.

\section{Unlearning Learning-Disabled Accommodations}

The question in learning disabilities studies that is important to me as someone who identifies as LD, and most relevant to me as a faculty member developing and implementing a writing studio pedagogy at my school, is how we can teach ourselves first and then teach others to unlearn accommodations. In other words, what are the best, most innovative ways to inspire teachers to practice pedagogies and create projects that are accessible to students of all abilities, focusing on students' individual strengths, skills, and talents. Along with creating accessible lessons, in-class assignments, and long-term projects, unlearning accommodation also means recognizing and respecting disability. Brenda Jo Brueggemann argues that composition classrooms have "a long, proud history of making the invisible visible and of examining how language both reflects and supports notions of Other” (Brueggemann et al. 370). Jay Dolmage, in the same vein as Brueggemann, writes "for all students to have access to those things composition has to offer — literate skills, a voice, and the words to write the world — we must ensure that disability is recognized and respected” (15). Brueggemann's reminder and Dolmage’s call to action are typed out and tacked to the wall near my desk so that I can remember to keep trying to meet what have become personal and professional goals.

Perhaps no other disability studies theorist has done more for promoting unaccommodating classrooms in the last twenty years than Patricia Dunn. In 1995, Dunn, 
in her book Learning Re-Abled: The Learning Disability Controversy and Composition Studies, approached LD students from a paradigm of unlearning accommodations. Dunn's now well-known and well-respected argument is that all students should have opportunities to learn writing multimodally. Dunn argues that "any pedagogical changes that might arise from a study of LD issues are perhaps less important than attitudinal changes on the part of the students and especially on the part of the instructors” (154). In her 2001 book Talking, Sketching, Writing: Multiple Literacies in the Teaching of Writing, Dunn calls for composition teachers to "investigate and use whatever intellectual pathways we can to help writers generate, organize, reconceptualize, and revise thoughts and texts" and that all writers would benefit from "multiple intellectual pathways to generate knowledge, and the world in general would benefit from the intellectual contributions of people traditionally excluded by print-loving pedagogies” (1). She cites Paulo Freire as a revolutionary in multimodal thinking as he engages his students in "visual, tactile, and other literacies to help them develop language-based literacies" (58). Dunn also cites Patricia Bizzell as arguing, "If learning to write can be seen as a process to think about one's own thinking” then "it suggests that other ways to represent thinking about one's thinking could also be useful” (59). From that line of reasoning, which engages teachers to think of introducing multiple representations in their pedagogies, Dunn suggests that teachers include visual activities and also sketching activities in students' strategies for composing. Sketching, she argues, is an “unconventional mode for both experienced and novice writers" and "can work with or against their customary thinking patterns, producing valuable insights regarding overall purpose, structure, and use of evidence” (66). Dunn's call for teachers to introduce unconventional modes of 
learning to experienced and novice writers is a challenge to teach writing to students of all abilities.

Later in 2001, Brenda Jo Brueggemann, Linda Feldmeier White, Patricia Dunn, Barbara Heifferon, and Johnson Cheu, in their College Composition and Communication article "Becoming Visible: Lessons in Disability," advocate for an increased awareness of disability in composition studies and that such an awareness can "disrupt notions of writing and challenge normal/not normal binaries in the field" (238). Particularly important to my own work building case studies of LD/LGBT students is White's section of the article because she examines how learning disabilities are constructed. "A commitment to social justice," White argues, "demands that we examine the way learning disability is constructed" (373). She discusses how being shamed is a "prominent feature in the autobiographical essays written by people with LD, whose stories provide vivid accounts of the way impairments become disabilities” (373). The LD movement argues against constructing disability as impairment, too. White writes that "LD autobiographies testify to the positive impact [of being learning disabled] ... and that "being diagnosed as learning disabled is described as an epiphany, the turning point of the story” (374). No matter how many epiphanies LD students have about having certain abilities, "learning-disabled students will remain vulnerable as long as schools are reorganized less to educate than to sort, a function that requires the convenient fictions of standardized testing in order to make some children Others” (375). Sorting students by ability is a function of neoliberal education. In 2002, in a single-authored article, White again examines how learning disability is constructed by other the medical profession. She suggests that professional discourse, i.e., the medical model, largely ignores 
composition studies' scholarship on learning disabilities because of "a lot of uncertainty" (709). White argues that if LD specialists "looked at research in other fields" they would "find a richer and more useful picture of language and learners" (718), and that the medical model "allows education to frame disability as an unexpected failure that doesn't require systemic change” (726). Dunn and White, two pioneers in composition-LD studies, although they do not expressly write this, argue for unlearning accommodations. Barber-Fendley and Hamel (“A New Visibility”) argue that instead of leveling the playing field to accommodate LD students, teachers should get rid of the field altogether. The authors discuss how accommodations rarely apply to writing classes. First, accommodations attend predominantly to product-based change; second, they are topdown policies that are the same nationwide, which means they often can't take particular student needs into consideration; third, they do not explicitly support the work promoted within composition classrooms; and fourth, accommodations require student-initiated change - emphasizing that disability is an individual matter (528-29). As well, write the authors, "accommodations divide because they are often indicators of unnecessary teaching practices” (533). Melanie Yergeau agrees, arguing, “The very idea of a playing field suggests that accommodation is both immediate and idiosyncratic; it suggests that accommodating is a matter of tinkering with people and places until they fit just right” ("Multimodality in Motion” n.p.). In her most recent Computers and Writing keynote lecture at Washington State University, Yergeau explores digital activism in several disabled communities arguing that we need to disable all the things:

... disabling all the things involves toppling myriad oppressive structures. It involves more than retrofitting, or applying metaphorical 
Band-Aids: It involves catapulting like a velociraptor through a Lego tower. Knock all that shit over, and then maybe melt it in your backyard with a blowtorch. (4)

For Yergeau, "disabling all the things need not only be a metaphor of/in destruction. While destroying ableist structures and segregatory practices is necessary, disabling all the things likewise involves forward-movement” (5). Listening to Yergeau in the early morning of the first day of the conference, I had time to reflect on her words throughout the remainder of the conference and make this connection: Disabling all the things is a grassroots unlearning. Unlearning, like disabling all the things, involves forward movement. It isn’t enough to only unlearn a practice, like accommodation, but there must be an idea learned in its place. The idea that I want to have my colleagues and students relearn is acceptance, and I am not opposed to that acceptance being learned through grassroots activities at my school and in my community should the kairotic moment be present to conduct them. The exhibition that my students talk about in Chapter IV is a grassroots activity that also enacts the element of surprise for which Njoke Thomas (Towards) argues.

\section{Unlearning pedagogy: The Significance of My Grounded Theory Categories to}

\section{Composition Studies}

Kelly Ritter and Paul Kei Matsuda's introduction to their edited collection Exploring Composition Studies: Sites, Issues, and Perspectives serves as an anchor for my concluding section of this chapter, as I look at the significance of the grounded theory categories in my project to composition studies. In their introduction, "How Did We Get Here?” Ritter and Matsuda explore the different perspectives of composition’s history. 
Composition studies is "an intellectual formation that draws insights from various related fields in order to address issues in the teaching of writing” and "draws its students and prospective scholars from many areas inside and outside English Studies” (1). The grounded theory categories, specifically grit, empathy and self-efficacy that I found in my analysis, show the close connection between composition studies and disability studies, sexuality studies, art, and educational psychology. Educational psychology can provide writing teachers with insights into not only how but also why it is important to construct assignments and projects with opportunities built in to discuss the significance of resilience in the face of frustration and even failure. This related field can also help writing teachers teach students why it is critical that they be able to relate to one another both on writing matters but also on other matters, such as disabilities and sexualities.

Another important aspect of my grounded theory categories to composition studies is the first category, relearning learning differences as strengths, attends to learning-disabled students, a newer and quickly growing population in our writing classrooms both at secondary and postsecondary institutions. Ritter and Matsuda write about how different social movements "affect higher education in general and writing education in particular" and throughout these social movements "composition studies has gone through various waves of pedagogical theory, each providing a view of the student, his or her audience, and the written product in different relation to one another” (4). Writing studio pedagogy is showing up in our disciplinary literature more, and I argue that is because this pedagogy has the potential to empower students with different abilities together in the writing classroom relearning their differences as strengths, engaging them in creating texts that can further develop relationships amongst abled and 
disabled and heterosexual and LGBT students, as was the case in Delevan’s bullying project and Alice’s coming out blog.

Ritter and Matsuda suggest that composition studies is a "dynamic field that, perhaps more than any other area of academic study, [which] mirrors the institutional and noninstitutional forces within which it operates” (6). I read their use of the word mirror in a Foucauldian sense, where to mirror is to use an Other space to see a space's flaws. The grounded theory category of interest gives me the opportunity to mirror other spaces, such as other writing classrooms and classrooms that are a part of other disciplines, where students are not typically afforded opportunities or not allowed at all to make connections between what they are learning and the projects they want to make or the papers they want to write. In other words, seeing how the category of interest plays a role in my students' development as writers and thinkers allows me to see more critically other spaces where the same students might have trouble developing, for example, as writers or social scientists.

The category of rhetorical agency as it is taken up in my classroom as a means for students to be heard by their peers and also by more public audiences mirrors spaces where students are not provided opportunities to be heard, such as in classrooms where the papers students write or the projects students compose are not for an audience other than the teacher or at most a whole class of peers. Perhaps in other classrooms and in other disciplines rhetorical agency is taken up, but I imagine it to be taken up in traditional ways. As I wrote in the section on rhetorical agency, Karlyn Kohrs Campbell argues, "Only a select few have enjoyed the traditional sense of public rhetorical agency, and this is less of a problem with the idea of agency per se and more of a problem of 
understanding the varieties of agency and of the available means of achieving a hearing” (qtd. in Geisler 10). Composition studies and some writing classrooms mirror what those varieties of agency can do to achieve being heard and that is why so many writing teacher-scholars place value on multimodal composition, genre studies, and activity theory. These six grounded theory categories contribute to the first part of my theory of students becoming empowered and composing activist texts for their schools and communities. I will discuss the latter part of my grounded theory, which is that LD and LGBT students can persuade their teachers and peers to unlearn accommodations and stereotypes. I will end the chapter with my concluding reflections on writing this dissertation.

\section{A Creative and Collaborative Approach to Unlearning Accommodations and Confronting Stereotypes}

The framework on unlearning has engaged me in thinking through creative and collaborative solutions for how teachers and students can work and play toward persuading their colleagues, teachers, and peers to unlearn accommodations and confront stereotypes. I contemplated how I could help students self-advocate to other teachers and their peers, and then it dawned on me that the writing studio pedagogy I outline in the introduction and explore in depth in Chapter II is the most creative and collaborative method for persuading teachers and other students to unlearn accommodations and confront stereotypes. I see the challenge as incorporating the different principles of writing studio pedagogy into the different, useful unlearning processes offered by Cegarra-Navarro and Dewhurst and Moya and Njoke Thomas, all of whom outline valuable strategies for assisting individuals and organizations in their unlearning. 
I advocate for teachers and students to take up teaching the unlearning process from the work of Cegarra-Navarro and Dewhurst and Cegarra-Navarro and Moya, who argue that unlearning consists of three phases — recognition of problems, alteration of established cognitive patterns, and development of new assessment frameworks, as well as the work of Njoke Thomas, who advocates for unlearning being contingent on the element of surprise. This mixed process of unlearning would be collaborative because it involves an ongoing conversation among students, teachers, and administrators. It is creative because involved in each of the three stages is room for conversations, problemsolving, creative thinking, and play. Often teachers recognize when a student has a learning disability before school administrators and sometimes even before parents. This moment of recognition of a student's learning challenges is critical because teachers are required to report to school administrators and parents when they believe a student might have a learning disability. If that teacher were to embrace composition as a social process and the writing classroom as a social environment, the chances are good that that teacher would learn about the student in question — and the other students' — learning strengths and use that knowledge to craft projects and assignments that engage and challenge that student and the rest of the class. Teachers can persuade students to unlearn accommodations and stereotypes of themselves when the students understand the strengths they possess. Of course, sexuality is another matter altogether. If a teacher suspects a student is LGBT, she should not inform administrators or parents without that student's consent.

Students, too, can persuade teachers and peers to unlearn accommodations and confront stereotypes by altering cognitive patterns. Disability and LGBT stereotypes are 
learned and therefore can be unlearned, and in place of the stereotypes, acceptance can be taught. Students and teachers in a writing studio are in a good place to usher in an unlearning process that alters cognitive patterns of teachers and peers and colleagues because of the many tools at their disposal and the many creative processes present among them. Depending on students' learning strengths, they can, for example, compose visual texts such as collages or compose one-act plays about confronting stereotypes, or similar projects to the ones Alice and Delevan composed in our writing studio. Students can show off to their teachers and peers the different, valuable divergent, convergent, and lateral thinking that they possess and can even teach teachers and students how to approach problems with these types of thinking. Obviously one composition alone will not make too much of a difference, but several students composing several different texts about confronting stereotypes will probably make waves. The idea of an exhibition like the one my students engineered would also help others unlearn some stereotypes about what students with LD can accomplish. The exhibit is also a strong example of the surprise for which Njoke Thomas advocates to bring individuals and organizations out of their environments in which they are desensitized to people and problems. Another example of a surprise that perhaps triggered the unlearning process for people is Delevan’s bullying project. The surprise is not that Delevan created an invisible theater troupe but that he organized and facilitated (with the help of myself and the pragmatics teacher) a focus group for each grade at the school. The surprise is that Delevan, through his project, was able to bring so many people together to talk about a serious issue at our school and from those focus groups make meaningful change as students in the focus 
groups pledged to do more to prevent gay bashing and other forms of bullying on campus.

As teachers learn more about the learning strengths and capabilities of learningdisabled and LGBT students, and as their cognitive patterns change, they can create a new framework for understanding their students, beginning with what Njoke Thomas calls the evaluation of the self, task, and environment. What I hope teachers and students begin to build is a framework where they recognize that they have been misunderstanding how to teach and communicate with disabled and LGBT students, but take up new practices of teaching and communication, including teaching in a variety of modes, talking about writing, and privileging each student's own creative process, while not allowing stereotypes to dictate their interactions with students. The task is to embrace writing pedagogy in the environment, the writing classroom. However, I argue writing studio pedagogy can also be useful in other, non-writing, courses. After all, students should be able to talk openly about how they approach learning math, science, history, and government. Learning equations, scientific theories, timelines, and amendments involves a lot of different, creative thought processes and problem-solving strategies. The writing studio does not need to be the only site of resistance at school. In other words, school, not just the writing studio or classroom, can be a playground of temporary perfect moments where our students are completely invested in what they are learning without boredom and without anxiety. Writing studio pedagogy stands the chance to bring students of all abilities and sexualities into a state of flow.

Unlearning accommodations and stereotypes are not easy or even comfortable or enjoyable processes. Unlearning is a hard process, a slow process, and may not always be 
a workable process the first or second time such an opportunity to unlearn is presented. For these reasons, the unlearning process needs to be a collaborative approach created by teachers who are already practicing a writing studio pedagogy and by their students, but sustained by several education stakeholders, including teachers, students, administrators, and parents. Parents need to be impassioned in supporting their children, finding the energy and the love to fight for the rights of their children to become empowered writers and creative thinkers. Administrators need to be tough and stand up to federal and state legislation, crafting effective arguments that all students should be afforded opportunities to learn in ways that work toward their being successful. In order for parents and school administrators to fight these fights with us, teachers need to inspire students to talk about the ways they learn best and let them compose meaningful texts with a variety of tools and in multiple modes and tell them to embrace their own creative thinking processes and, of course, let them play. My solution is overwhelming. I am overwhelmed writing it because I know at Eagle Hill School I am fortunate. My colleagues in other high schools and in some university English departments are not so fortunate. I do think, though, that the unlearning process is critical because only when colleagues, teachers, parents, and students unlearn can we, the LD and LGBT students, come out, or reclaim, our disabilities and sexualities as our own.

\section{Final Thoughts: How Researching and Writing the Dissertation Impacted Me}

I am sitting at a coffeehouse in Pullman, Washington, as I write this section. The end of Computers and Writing always leaves me energized. I got to spend all week with some of my best friends. I am trying to find some peace so I can sleep tonight in preparation for my long flight home tomorrow, so I pick up Malcolm Gladwell’s David 
and Goliath. It was recommended to me by my chair, Jim Kalmbach. Jim gets me. Not a lot of people do, so when he recommends a book to me, I will certainly read it. The premise of Gladwell's book is that the underdogs, those who are seemingly at a disadvantage, are actually capable of being leaders and of doing remarkable things with their lives. In the chapter on dyslexia, Gladwell introduces his readers to the term "desirable difficulty" — the difficulties that challenge us to think harder and work harder to achieve our goals. Gladwell gives as his example two psychologists administering a Cognitive Reflection Test (CRT) test to groups of students from the United States' top universities. The test questions are hard and most students at these universities do poorly. Then, the psychologists did something completely opposite of what the students were prepared for. They printed the questions in ten-point italics and in the color gray. The questions were hard to read, and students had to work hard to read them. In working harder to read the questions more students produced the correct answers. Gladwell attributes this change to the questions becoming "disfluent”, causing people to "think more deeply about what they come across” (105). Gladwell continues with his argument about desirable difficulties, writing that they have an opposite logic. The opposite logic that Gladwell shares with his readers is that dyslexic people, as an example, "work harder because they have to compensate for something that is missing" and "compensation learning ... requires you to overcome your insecurity and humiliation” (112-113). I take what Gladwell writes to heart, as compensation learning is the type of learning in which both my students and I engage. Compensation learning is an outcome from acquiring learning-disabled literacies. When a student learns what she is good at, where she has her strengths, then she can begin compensating in the classroom. When Alice and Delevan 
compensated for their auditory processing disabilities they began compensating with visual, spatial, and gestural communication both before and during their time in the writing studio class. I, too, recognized in my youth that my weakness is linguistic writing, and I began compensating by listening and using my body to tell stories. I am a people person. I love talking to people and telling stories.

Attending conferences and meeting colleagues from other institutions, I hear a common story. The story is about students who do poorly in school on assignments that should be basic, such as modal papers like cause and effect, or compare and contrast. The teachers I meet are stumped as to why their students are not succeeding with gusto. I interject in these conversations with remarks like "Interesting. My students are doing a rhetorical analysis project, and they really love it," or "Wow, that's too bad. My students are making their own podcasts and then they're uploading them to the Web.” I am always met with the most peculiar looks. I don't usually interject anymore. After conducting my research and writing this dissertation, I am beginning to think I should interject more often. My students are thinking about complicated ideas. They are using complicated terms like rhetoric, remediation, mode, text, etc. They are reading the work of scholars in our disciplines like Cheryl Ball, Kristin Arola, Jennifer Sheppard, and Jody Shipka. And, most importantly, they are making complicated social justice projects, like a coming out blog of transgender Tumblr users and a multimodal bullying project that captivated a lot of stakeholders at our school. The connection between my students' development as writers and thinkers and Gladwell's observation about students with learning disabilities rising to challenges and succeeding in thinking through complex material as a desirable difficulty appears clear. Students don't want to write a compare-and-contrast paper about 
the differences between how TV programs were distributed ten years ago and today or a cause-and-effect paper on global warming. What my students desire — and what your students desire, too — is to go out into their communities and make a documentary about what people are watching on TV. How many people are watching reruns of The Big Bang Theory on TBS and who's watching Orange is the New Black on Netflix? Who gets their news from Democracy Now! and who still watches ABC news during supper? Students will find out all of the necessary information and create a documentary that indicates how our communities are changing the way they receive entertainment. The lesson here is that students want to do well for their teachers and they want to learn about composing, but they want to do it on their own terms and we need to let them show us what they are good at. At the same time we need to share with them our knowledge about rhetoric and composition. Students and teachers can be a great team. The other lesson is that students want to learn complicated material. They do not want to be coddled with narrative writing. They do want to remediate texts and make projects that can impact positive change in their communities.

Looking back on Delevan and Alice’s projects, and also their literacy interviews (appendix C), I am struck by how far each has come as a writer and as a thinker since the beginning of the year. Delevan started off resistant to the idea that he had learned almost anything at all at Eagle Hill that he did not already know from his past lived experiences. Delevan reclaimed his learning disabilities through visual and gestural texts that struck a chord with some and a nerve with others, and I think garnering those varied emotions from different audiences, intended and unintended, helped him to develop further as a writer instead of a student who writes. Alice, too, has grown a lot in the course of a year. 
She has come into her own as a transgender teenager, certainly not all on account of being in my Writers’ Workshop course, but being able to reclaim her sexuality through video poems and then being strong enough to compose a coming out blog for her online community to submit their own stories is, to me, remarkable. I have no doubt that her video poems will help other LGBT students for many years to come, and the writing skills she learned in our class will hopefully be useful as she will want to make herself heard clearly, loudly, and proudly wherever her life takes her. The learning-disabled and sexual literacies each is going to bring with them to college will prepare them to face the academic and social challenges that are waiting for them. I could not be prouder of both of them. Now that I have realized all of this and have typed it up, I will probably not be able to sleep tonight. My teaching life excites me. 


\section{REFERENCES}

Alexander, Jonathan. Literacy, Sexuality, Pedagogy: Theory and Practice for Composition Studies. Logan, UT: Utah State UP, 2008. Print.

Alexander, Jonathan. "Trans gender Rhetorics: (Re) Composing Narratives of the Gendered Body.” 57.1 (Sept. 2005) 45-82. Print.

Alexander, Jonathan, and David Wallace. "The Queer Turn in Composition Studies: Reviewing and Assessing an Emerging Scholarship.” College Composition and Communication 61.1 (2009): 300-320. Print.

Alexander, Jonathan, and William P. Banks. "Sexualities, Technologies, and the Teaching of Writing: A Critical Overview.” Computers and Composition 21 (2004): 273-293. Print.

Arola, Kristin L, Jennifer Sheppard, and Cheryl E. Ball. Writer/Designer: A Guide to Making Multimodal Projects. Boston: Bedford, 2014. Print.

Atwell, Nancie. In the Middle: New Understandings about Writing, Reading, and Learning. $2^{\text {nd }}$ ed. Portsmouth: Heinemann, 1998. Print.

Azmi, Feza Tabassum. Mapping the learn-unlearn-relearn model: Imperatives for strategic management. European Business Review 20.3 (2008): 240-259. Print.

Bandura, Albert. "Self-efficacy: Toward a Unifying Theory of Behavior Change.” Psychological Review 84 (1977): 191-215. Print.

Barber-Fendley, Kimber, and Chris Hamel. “A New Visibility: An Argument for Alternative Assistance Writing Programs for Students with Learning Disabilities.” College Composition and Communication 55.3 (2004): 504-535. Print.

Barrios, Barclay. "Of Flags: Online Queer Identities, Writing Classrooms, and Action Horizons.” Computers and Composition 21.3 (2004): 341-61. Print.

Batson, Trent. "Historical Barriers to Intelligent Classroom Design.” Approaches to Computer Writing Classrooms. Ed. Linda Myers. Albany: SUNY Press, 1993. 118. Print.

Bawarshi, Anis, and Mary Jo Reiff. Genre: An Introduction to History, Theory, Research, and Pedagogy. Lafayette: Parlor Press, 2010. Print. 
Bakhtin, M.M. The Dialogic Imagination: Four Essays. Austin: U of Texas P, 1981. Print.

Baxter, Pamela, and Susan Jack. "Qualitative Case Study Methodology: Study Design and Implementation for Novice Researchers.” The Qualitative Report 13.4 (2008): 544-559. Print.

Beaufort, Anne. College Writing and Beyond: A New Framework for University Writing Instruction. Logan, UT: Utah State UP, 2007. Print.

Bemer, Amanda Metz, Ryan M. Moller, and Cheryl E. Ball. "Designing Collaborative Learning Spaces: Where Material Culture Meets Mobile Writing Processes.” Programmatic Perspectives: Journal of the Council for Programs in Technical and Scientific Communication 1.2 (2009): 139-166. PDF.

Blair, Erik. “A Further Education College as a Heterotopia.” Research in PostCompulsory Education. 14.1 (2009): 93-101. Print.

Boal, Augusto. Games for Actors and Non-Actors. Trans. Adrian Jackson. $2^{\text {nd }}$ ed. New York: Routledge, 1992. Print.

Boden, Margaret A. “What Is Creativity?” Dimensions of Creativity. Ed. Margaret A. Boden. 75-118. Cambridge: MIT Press, 1994. 75-118. Print.

Bowers, John W, et al. The Rhetoric of Agitation and Control. $3^{\text {rd }}$ ed. Long Grove, IL: Waveland Press, 2010. Print.

Brady, M. Ann \& Kitalong, Karla Saari. "Users, Not Solutions, First: Problem-solving for Program Administrators.” Sharing Our Intellectual Traces: Narrative Reflections from Administrators of Professional, Technical, and Scientific, Communication Programs. Eds. Bridgeford, Tracy, Karla Saari Kitalong, and William J. Williamson. Amityville, NY: Baywood, in press. 204-227. Print.

Brandt, Deborah. "Sponsors of Literacy.” College Composition and Communication 49.2 (1998): 165-185. Print.

Brueggemann, Brenda Jo, et al. "Becoming Visible: Lessons in Disability.” College Composition and Communication 52.3 (2001): 368-397. Print.

Burnham, Christopher, and Rebecca Powell. "Expressive Pedagogy: Practice/Theory, Theory/Practice.” A Guide to Composition Pedagogies. $2^{\text {nd }}$ ed. Eds. Gary Tate, Amy Rupiper Taggart, Kurt Schick, and H. Brooke Hessler. New York: Oxford UP, 2014. 111-127. Print.

Burton, Gideon. Silva Rhetoricae, http://rhetoric.byu.edu/ n.p. Web. 
Calkins, Lucy McCormick. The Art of Teaching Writing. Portsmouth, NH: Heinemann, 1986. Print.

Cannon Design, VS Furniture, and Bruce Mau Design. The Third Teacher: 79 Ways You Can Use Design to Transform Teaching and Learning. New York: Abrams, 2010. Print.

Carpenter, Russell, et al. "Studio Pedagogy: A Model for Collaboration, Innovation, and Space Design.” Cases on Higher Education Spaces: Innovation, Collaboration, and Technology. Ed. Russell Carpenter. 313-329. Hershey, PA: IGI Global, 2012. 313-329. Print.

Carrier, John G. Learning Disability: Social Class and the Construction of Inequality in American Education. New York: Greenwood Press, 1986. Print.

Carrier, John G. "The Politics of Early Learning Disability Theory.” Learning Disability: Dissenting Essays. Ed. Barry M. Franklin. Philadelphia: The Falmer Press, 1987. 47-66. Print.

Cegarra-Navarro, Juan Gabriel, and Frank Dewhurst. "Linking Shared Organizational Context and Relational Capital through Unlearning: An Initial Empirical Investigation in SMEs.” Learning Organization 13 (2006): 49-62. Print.

Cegarra-Navarro, Juan Gabriel, and Beatriz Rodrigo-Moya. "Business Performance Management and Unlearning Process” Knowledge and Process Management 12. 3 (2005): 161-170.

Charmaz, Kathy. Constructing Grounded Theory: A Practical Guide Through Qualitative Analysis. Los Angeles: Sage, 2006. Print.

Cianciotto, Jason, and Sean Cahill. LGBTQ Youth in America's Schools. Ann Arbor: U of Michigan P, 2012. Print.

Cloud, Dana. "The Only Conceivable Thing To Do: Reflections on Academics and Activism." Activism and Rhetoric: Theories and Contexts For Political Engagement. Eds. Seth Kahn and JongHwa Lee. New York: Routledge, 2011. 1124. Print.

Coiser, Kimberly. “Creating Safe Schools for Queer Youth.” Handbook of Social Justice in Education. Eds. William Ayers, Therese Quinn, and David Stovall. New York: Routledge, 2009. 285-303. Print.

Cooper, Marilyn M. "Rhetorical Agency as Emergent and Enacted." College Composition and Communication 62.3 (2011): 420-449. Print.

Corbin, Juliet, and Anselm Strauss. Basics of Qualitative Research: Techniques and 206 
Procedures for Developing Grounded Theory. $3^{\text {rd }}$ ed. Thousand Oaks, CA: Sage Publications, 2007. Print.

Crabtree, Benjamin F., and William L. Miller. Doing Qualitative Research. $2^{\text {nd }}$ ed. Thousand Oaks, CA: Sage Publications, 1999. Print.

Cropley, Arthur. “In Praise of Convergent Thinking.” Creativity Research Journal 18.3 (2006): 391-404. Print.

Crowley, Sharon, and Debra Hawhee. "Ancient Rhetorics for Contemporary Students.” $5^{\text {th }}$ ed. Boston: Pearson, 2012. Print.

Crowley, Sharon, and Debra Hawhee. "Ancient Rhetorics for Contemporary Students.” $3^{\text {rd }}$ ed. Boston: Pearson, 2004. Print.

Csikszentmi halyi, Mihaly. Flow. New York: Harper Perennial, 1990. Print.

Csikszentmi halyi, Mihaly. Beyond Boredom and Anxiety: Experiencing Flow in Work and Play. San Francisco: Josey-Bass, 1975. Print.

Cushman, Ellen. "Rhetorician as an Agent of Social Change.” College Composition and Communication 47.1 (1996): 7-28. Print.

Danforth, Scott. The Incomplete Child: An Intellectual History of Learning Disabilities. New York: Peter Lang, 2009. Print.

De Bono, Edward. Lateral Thinking: Creativity Step by Step. New York: Harper Perennial, 1973. Print.

Del Gandio, Jason. Rhetoric for Radicals: A Handbook for $21^{\text {st }}$ Century Activists. Gabriola Island, BC: New Society Publishers, 2008. Print.

DePew, Kevin Eric. “Through The Eyes of Researchers, Rhetors, and Audiences: Triangulating Data from the Digital Writing Situation. Digital Writing Research: Technologies, Methodologies, and Ethical Issues. Eds. Heidi A. McKee and Danielle Nicole DeVoss. Creskill, NJ: Hampton Press, 2007. 49-70. Print.

Devitt, Amy. Writing Genres. Carbondale: Southern Illinois UP, 2008. Print.

DeWitt, Scott Lloyd. "Out There on the Web: Pedagogy and Identity in the Face of Opposition.” Computers and Composition 14.2 (1997): 229-44. Print.

Dey, Ian. "Grounding Categories.” The Sage Handbook of Grounded Theory. Eds. Antony Bryant and Kathy Charmaz. 167-190. Thousand Oaks, CA: Sage Publications, 2007. 167-190. Print. 
Dolmage, Jay. "Writing against Normal: Navigating a Corporeal Turn.” Composing $($ media $)=$ composing $($ embodiment $)$. Eds. Kristin L. Arola and Anne Frances Wysocki. Logan, UT: Utah State UP, 2012. 110-126. Print.

Dolmage, Jay, and Cynthia Lewiecki-Wilson. "Refiguring Rhetorica: Linking Feminist Rhetoric and Disability Studies." Rhetorica in Motion: Feminist Rhetorical Methods and Methodologies. Eds. Eileen Schell and K.J. Rawson. Pittsburgh: U of Pittsburgh P, 2010. 23-38. Print.

Dolmage, Jay. “Mapping Composition: Inviting Disability in the Front Door.” Disability and the Teaching of Writing: A Critical Sourcebook. Eds. Cynthia LewieckiWilson and Brenda Jo Brueggemann. 14-27. Boston: Bedford St. Martins, 2008. 14-27. Print.

Donnelly, Diane, ed. Does the Writing Workshop Still Work? Bristol, UK: Multilingual Matters, 2010. Print.

Dunn, Patricia A. Talking, Sketching, Moving: Multiple Literacies in the Teaching of Writing. Portsmouth, NH: Heinemann, 2001. Print.

Dunn, Patricia A. Learning Re-Abled: The Learning Disability Controversy and Composition Studies. Portsmouth, NH: Heinemann, 1995. Print.

dyspraxiafoundation.org, 2014. Web.

Ellis, Michael J. Why People Play. Englewood-Cliffs, NJ: Prentice-Hall, 1973. Print.

Farkas, Kerrie R.H., and Christina Haas. "A Grounded Theory Approach For Studying Writing and Literacy.” Eds. Katrina M. Powell and Pamela Takayoshi. Practicing Research in Writing Studies: Reflexive and Ethically Responsible Research. New York: Hampton Press, 2012. 81-96. Print.

Fernald, Grace, and Helen Keller. "The Effect of Kinesthetic Factors in the Development of Word Recognition in the Case of Non-Readers.” Journal of Educational Research 4, (1921): 355-377. Web.

Flower, Linda. “Going Public — In A Disabling Discourse.” The Public Work of Rhetoric: Citizen-Scholars and Civic Engagement. Eds. John M. Ackerman and David J. Coogan. Columbia: The U of South Carolina P, 2010. 137-156. Print. Foss, Sonja K. Rhetorical Criticism: Exploration and Practice. $3^{\text {rd }}$ ed. Long Grove, IL: Waveland Press, 2009. Print.

Foucault, Michel. The Birth of the Clinic. New York: Vintage, 1973. Print.

Foucault, Michel. Discipline and Punish. New York: Vintage, 1977. Print. 
Foucault, Michel. “Of Other Spaces: Utopias and Heterotopias.” Trans. Jay Miskowiec. Heterotopia and the City: Public Space in a Postcivil Society. Eds. Michiel Dehaene and Lieven De Cauter. London: Routledge, 2008. 13-30. Print.

Franklin, Barry M., ed. Learning Disabilities: Dissenting Essays. Philadelphia: The Falmer Press, 1987. Print.

Gallan, Ben. “Night Lives: Heterotopia, Youth Transitions and Cultural Infrastructure in the Urban Night.” Urban Studies (September 2012): 1-16. PDF.

Garland-Thomson, Rosemarie. "Staring at the Other.” Disability Studies Quarterly 25.4 (2005): n.p. Web.

Gay, Lesbian, and Straight Education Network. The 2011 National School Climate Survey. Washington, DC: GLSEN, 2012. Web.

Gee, James Paul. “Literacy, Discourse, and Linguistics.” Literacy: A Critical Sourcebook. Eds. Ellen Cushman et al. Boston: Bedford, 2001. 525-544. Print.

Geisler, Cheryl. "How Ought We to Understand the Concept of Rhetorical Agency? A Report from the ARS.” Rhetoric Society Quarterly 34.3 (2004): 9-17. Print.

Gerrard, Lisa. “Designing Computerized Writing Classrooms.” Approaches to Computer Writing Classrooms. Ed. Linda Myers. Albany: SUNY Press, 1993. 149-164. Print.

Ginsburg, Kenneth R. Building Resilience in Children and Teens: Giving Kids Roots and Wings. $2^{\text {nd }}$ ed. Elk Grove Village, IL: American Academy of Pediatrics, 2011. Print.

Giroux, Henry A. Disposable Youth: Racialized Memories and the Culture of Cruelty. New York: Routledge, 2012. Print.

Gladwell, Malcolm. David and Goliath: Underdogs, Misfits, and the Art of Battling Giants. New York: Little, Brown and Company, 2013. Print.

Goncalves, Zan Meyer. Sexuality and the Politics of Ethos in the Writing Classroom. Carbondale: Southern Illinois UP, 2005. Print.

Grego, Rhonda C., and Nancy S. Thompson. Teaching Writing in Thirdspaces: The Studio Approach. Urbana, IL: National Council of Teachers of English, 2008. Print.

Gresham, Morgan. “Composing Multiple Spaces.” Multiliteracies Centers: Writing Center Work, New Media, and Multimodal Rhetoric. Eds. David M. Sheridan and James A. Inman. Creskill, NJ: Hampton Press, 2010. 33-55. Print. 
Gresham, Morgan, and Kathleen Blake Yancey. "New Studio Composition: New Sites for Writing, New Forms of Composition, New Cultures of Learning.” WPA 28.1/2 (2004): 9-28. PDF.

Grover, Susan, and Anne Hendricks. "Accommodating Specific Learning Disorders in the Classroom: Minor Effort, Major Benefits.” Kairos: A Journal of Rhetoric, Technology, and Pedagogy, 7.1 (2002). Web. 25 February 2014.

Guilford, J.P. “Creativity.” American Psychologist 5. 444-454. Print.

Haas, Christina, Pamela Takayoshi, and Brandon Carr. “Analytic Strategies, Competent Inquiries and Methodological Tensions in the Study of Writing.” Writing Studies Research in Practice: Methods and Methodologies. Eds. Lee Nickoson and Mary P. Sheridan Carbondale: SIUP, 2012. 51-62. Print.

Halbritter, Bump. Mics, Cameras, Symbolic Action: Audio-Visual Rhetoric for Writing Teachers. Lafayette, IN: Parlor Press, 2012. Print.

Hallahan, Daniel P., and Devery R. Mock. “A Brief History of the Field of Learning Disabilities.” Handbook of Learning Disabilities. Eds. H. Lee Swanson, Karen R. Harris, and Steve Graham. New York: The Guilford Press, 2003. 16-29. Print. Handa, Carolyn. "Designing A Computer Classroom: Pedagogy, Nuts, and Bolts.” Approaches to Computer Writing Classrooms. Ed. Linda Myers. Albany: SUNY Press, 1993. 103-118. Print.

Harvey, David. A Brief History of Neoliberalism. Oxford: Oxford University Press, 2005. Print.

Hawisher, Gail E., and Cynthia L. Selfe. "Becoming Literate in the Information Age: Cultural Ecologies and the Literacies of Technology.” College Composition and Communication 55.4 (2004): 642-692. Print.

Hawk, Byron. A Counter-History of Composition: Toward Methodologies of Complexity. Pittsburgh: University of Pittsburgh Press, 2007. Print.

Hedberg, Brian. “How Organizations Learn and Unlearn.” Handbook of Organizational Design. Eds. Paul Nystrom and William H. Starbuck. London: Cambridge UP, 1981. Print.

Hehir, Thomas. "Eliminating Ableism in Education.” Special Education for a New Century. Eds. Lauren I. Katzman et al. Cambridge: Harvard Educational Review, 2005. 11-38. Print.

Hetherington, Kevin. The Badlands of Modernity: Heterotopia and Social Ordering. New York: Routledge, 1997. Print. 
Hetland, Lois, et al. Studio Thinking2. $2^{\text {nd }}$ ed. New York: Teacher’s College, 2013. Print.

Hilst, Joshua “Deleuze: (Neo) Expressivism in Composition.” Enculturation. 13 (2012). n.p. Web. 15 April. 2014.

Hoerr, Thomas R. Fostering Grit. Alexandria, VA: ASCD, 2013. Print.

Hook, Derek and Michele Vrdoljak. "Gated Communities, Heterotopia and a 'Rights' of Privilege: a 'Heterotopology' of the South African Security-Park. Geoforum 33 (2002): 195-219. Print.

Howell, John, and Nathtalie Mitev. A Skeptical Look at the Use of the Concept of Unlearning on Organizational Analysis. Web. April 29, 2014.

Huizinga, Johan. Homo Ludens: A Study of the Play-Element in Culture. Boston: Beacon Press, 1950. Print.

Hunter, Kimberly. Empathy in Education. Web. 15 May 2014.

Hursh, David. "Beyond the Justice of the Market: Combating Neoliberal Educational Discourse and Promoting Deliberative Democracy and Economic Equality." Handbook of Social Justice in Education. Eds. William Ayers, Therese Quinn, and David Stovall. New York: Routledge, 2009. 152-164. Print.

Iacoboni, Marco. Mirroring People: The Science of Empathy and How We Connect with Others. New York: Picador, 2009. Print.

Kim, Alex. " 'Speaking Out': Ideologies, Identities, and Individuals in Coming Out Stories.” Intersections 10.1 (2009): 239-278. Web.

Kirsch, Gesa E., and Jacqueline J. Royster. "Feminist Rhetorical Practices: In Search of Excellence.” College Composition and Communication 61.4 (2010): 640-672. Print.

Kirsch, Gesa E. Ethical Dilemmas in Feminist Research: The Politics of Location, Interpretation, and Publication.” Albany: SUNY, 1999. Print.

Klein, J.I. "Parenthetical Learning in Organizations: Toward the Unlearning of the Unlearning Model.” The Journal of Management Studies 26.3 (1989): 291-309. Print.

Kress, Gunther. Multimodality: A Social Semiotic Approach to Contemporary Communication. New York: Routledge, 2010. Print.

Kress, Gunther. Before Writing: Rethinking the Paths to Literacy. London: Routledge, 
1997. Print.

Latour, Bruno. Reassembling the Social: An Introduction to Actor-Network Theory. New York: Oxford University Press, 2005. Print.

Latour, Bruno. “On Technical Mediation - Philosophy, Sociology, Geneology.” Common Knowledge 3.2 (1994): 29-64. Print.

Lee, Virginia S. "Unlearning: A Critical Element in the Learning Process.” Essays on Teaching Excellence Toward the Best in the Academy 14.2 (2002): n.p. Web.

Lees, L.H. “Ageographia, Heterotopia, and Vancouver’s New Public Library.” Environment and Planning D: Society and Space 15 (1997): 321-347). Print.

Lempert, Lora Lex. “Asking Questions of the Data: Memo Writing in the Grounded Theory Tradition." The Sage Handbook of Grounded Theory. Eds. Antony Bryant and Kathy Charmaz. Thousand Oaks, CA: Sage Publications, 2007. 245-264. Print.

Levine, Mel. Keeping A Head in School. Cambridge, MA: Educators Publishing Service, 1990. Print.

Linton, Simi. Claiming Disability: Knowledge and Identity. New York: NYU Press, 1998. Print.

Linville, Darla. "Queer Theory and Teen Sexuality: Unclear Lines.” Theory and Educational Research: Toward Critical Social Explanation. Eds. Jane Anyon et al. New York: Routledge, 2009. 153-174. Print.

Lewiecki-Wilson, Cynthia, and Brenda Jo Brueggemann, eds. Disability and the Teaching of Writing: A Critical Sourcebook. Boston: Bedford St. Martins, 2008. Print.

Lutz, Tom. "Antielitism Left and Right: an Interview with Catherine Liu.” Los Angeles Review of Books. 8 Jan. 2012. 11 Web. Apr. 2014.

Mayer, Richard E. Thinking, Problem Solving, Cognition. $2^{\text {nd }}$ ed. New York Freeman, 1992. Print.

Mayo, Cris. LGBTQ Youth and Education: Policies and Practices. New York: Teachers College, 2014. Print.

Macrorie, Ken. The I-Search Paper. Portsmouth, NH: Heinemann, 1988. Print.

Mathieu, Paula. Tactics of Hope: The Public Turn in English Composition. Portsmouth, NH: Heinemann, 2005. Print. 
McCann, Thomas M, et al. Talking in Class: Using Discussion to Enhance Teaching and Learning. Urbana, IL: NCTE, 2006. Print.

McDonald, Peter, and Michael Riendeau. “A Copernican Revolution in Learning.” Independent School (2003): 84-88. Print.

McKee, Heidi A., and Danielle Nicole DeVoss, eds. Digital Writing Research: Technologies, Methodologies, and Ethical Issues. Creskill, NJ: Hampton Press, 2007. Print.

McKinney, Jackie Grutsch. "New Media Matters: Tutoring in the Late Age of Print." The Routledge Reader on Writing Centers and New Media. Eds. Sohui Lee and Russell Carpenter. New York: Routledge, 2014. 242-256. Print.

New London Group. “A Pedagogy of Multiliteracies: Designing Social Future.” Harvard Education Review 66.1 (Spring 1996): 60-92. Web.

Newstrom, John W. “The Management of Unlearning: Exploding the Clean Slate Fallacy.” Training and Development Journal 37.8 (1983): 36-39.

Nickoson, Lee, and Mary P. Sheridan, eds. Writing Studies Research in Practice: Methods and Methodologies. Carbondale: Southern Illinois UP, 2012. Print.

Nieto, Sonia. "Public Schools and the Work of Teachers.” Why We Teach. Ed. Sonia Nieto. New York: Teacher’s College Press, 2005. 3-11. Print.

Nystrom, Paul, and William H. Starbuck. “To Avoid Organization Crisis, Unlearn.” Organization Dynamics 12.4 (1984): 53-65. Print.

O’Doherty, Brian. Inside the White Cube: Notes on the Gallery Space.” Santa Monica, CA: The Lapis Press, 1976. Print.

Peele, Thomas. “Composition Studies, Heteronormativity, and Popular Culture.” Computers and Composition Online (Fall 2004). Web.

Popen, Shari. “Aesthetic Spaces/Imaginative Geographies.” A Boal Companion: Dialogues on Theatre and Cultural Politics. Eds. Jan Cohen-Cruz and Mady Schutzman. New York: Routledge, 2006. 125-134. Print.

Powell, Karina M., and Pamela Takayoshi. Practicing Research in Writing Studies: Reflexive and Ethically Responsible Research. New York: Hampton Press, 2012. Print. 
Prior, Paul A. and Julie A. Hengst. "Introduction: Exploring Semiotic Remediation.” Exploring Semiotic Remediation as Discourse Practice. Eds. Paul A. Prior and Julie A. Hengst. New York: Palgrave Macmillan, 2010. 1-24. Print.

Prior, Paul et al. "Re-situating and Remediating the Canons: A Cultural Historical Remapping of Rhetorical Activity.” Kairos 11.3 (2007): n.p. Web.

Prior, Paul, and Jody Shipka. "Chronotopic Laminations: Tracing the Contours of Literate Activity.” Writing Selves/Writing Societies: Research from Activity Perspectives. Eds. Charles Bazerman and David R. Russell. Fort Collins, CO: The WAC Clearinghouse, 2003. 180-238. Web.

Pullen, Christopher, and Margaret Cooper. LGBT Identity and Online New Media. New York: Routledge, 2010. Print.

Rabinow, Paul. The Foucault Reader. New York: Pantheon, 1984. Print.

Reynolds, Nedra. Geographies of Writing: Inhabiting Places and Encountering Difference. Carbondale: Southern Illinois UP, 2004. Print.

Reid, Kim, and Jan Weatherly Valle. "The Discursive Practice of Learning Disability: Implications for Instruction and Parent-School Relations. Journal of Learning Disabilities 37.6 (2004): 466-481. Print.

Rhodes, Jacqueline. "Sexualities, Technologies, and Literacies: Metonymy and Material.” Computers and Composition Online. (Fall 2004). Web.

Rickert, Thomas, and Michael Salvo. “...And They Had Pro Tools” Computers and Composition Online. (Fall 2006) Web.

Ritter, Kelley, and Paul Kei Matsuda. Exploring Composition Studies: Sites, Issues, Perspectives. Logan, UT: Utah State UP, 2012. Print.

Robinson, Ken. Out of Our Minds: Learning to Be Creative. West Sussex, Eng.: Wiley, 2011. Print.

Rowsell, Jennifer. Working with Multimodality: Rethinking Literacy in a Digital Age. London: Routledge, 2013. Print.

Sandin, Gunnar. "Keys to Heterotopia: An Actinal Approach to Landfills as Societal Mirrors." Nordic Journal of Architectural Research 20.2 (2008): 13 pages. PDF.

Selfe, Richard J. Sustainable Computer Environments: Cultures of Support in English Studies and Language Arts. Creskill, NJ: Hampton Press, 2004. Print.

Selfe, Cynthia L., and Gail E. Hawisher. "Exceeding the Bounds of the Interview: 
Feminism, Mediation, Narrative, and Conversations about Digital Literacy.” Writing Studies Research in Practice: Methods and Methodologies. Eds. Lee Nickoson and Mary P. Sheridan. Carbondale: Southern Illinois UP, 2012. 36-50. Print.

Selfe, Cynthia L., and Gail E. Hawisher, eds. Literate Lives in the Information Age: Narratives of Literacy from the United States. Mahwah, NJ: Lawrence Erlbaum Associates, 2004. Print.

Selfe, Cynthia L., and Gail E. Hawisher, eds. Gaming Lives in the Twenty-First Century: Literate Connections. New York: Palgrave, 2007. Print.

Sharp-Hoskins, Kellie, and Erin A. Frost. "Cultural Historical Activity Theory.” The Illinois State University Writing Project. (Spring 2012). 4 Apr. 2014. Web.

Shipka, Jody. “ 'On the Many Parts it Took Throughout' Engineering a Multipart, Multiple Sight Rhetorical Event.” Exploring Semiotic Remediation as Discourse Practice. Eds. Paul A. Prior and Julie A. Hengst. New York: Palgrave Macmillan, 2010. 52-76. Print.

Skrtic, Thomas M. “A Political Economy of Learning Disabilities.” Learning Disability Quarterly 28 (2005): 149-155. Print.

Sleeter, Christine E. "Radical Structuralist Perspectives on the Creation and Use of Learning Disabilities.” Disability and Democracy: Reconstructing Special Education for Postmodernity. Ed. Thomas M. Skrtic. New York: Teachers College Press, 1995. 153-165. Print.

Smith, Craig R. Rhetoric and Human Consciousness: A History. $3^{\text {rd }}$ ed. Long Grove, IL: Waveland, 2009. Print.

Soja, Edward W. Postmodern Geographies: The Reassertion of Space in Critical Social Theory. London: Verso, 1989.

Stake, Robert E. The Art of Case Study Research. Thousand Oaks, CA: Sage Publications, 1995. Print.

Stevens, Sharon McKenzie. "Dreaming to Change Our Situation: Reconfiguring the Exigence for Student Writing.” Active Voices: Composing a Rhetoric of Social Movements. Eds. Sharon McKenzie Stevens and Patricia M. Malesh. Albany: SUNY, 2009. 47-65. Print.

Strauss, Alfred A., and Newell C. Kephart. Psychopathology and Education of the BrainInjured Child. Pro-ed Classic Series, 1989. Print.

Street, Brian V. Literacy and Development. London: Routledge, 2001. Print. 
Sullivan, Patricia, and James E. Porter. Opening Spaces: Writing Technologies and Critical Research Practices. Westport,CT: Ablex, 1997. Print.

Tate, Gary, et al. A Guide to Composition Pedagogies. $2^{\text {nd }}$ ed. New York: Oxford University Press, 2014. Print.

"Ted Talks: Angela Lee Duckworth — The Key to Success? Grit.” Films on Demand. Films Media Group, 2013. Web. 3 March 2014.

Thomas, Njoke. (2011) Towards A New Definition of Unlearning: Rethinking Individual Level Unlearning and Its Implications for Practice Change (Master's thesis). Case Western Reserve University. Cleveland, OH. WP-11-01. PDF.

Tough, Paul. How Children Succeed: Grit, Curiosity, and the Hidden Power of Character. New York: Harcourt, 2012. Print.

U.S. Department Education. Promoting Grit, Tenacity, and Perseverance: Critical Factors of Success for the $21^{\text {st }}$ Century. Center for Technology and Learning: SRI International. (Feb. 14, 2013) Web. 1 Apr. 2014.

White, Linda Feldmeier. "Learning Disability, Pedagogies, and Public Discourse.” College Composition and Communication 53.4 (2002): 705-735. Print.

Williams, Brownwyn T. "Dancing with Don, or Waltzing with 'Expressivism'.” Enculturation. 13 (2012). n.p. Web. 15 April. 2014.

Yergeau, Melanie. "Disable All The Things.” The Conference on Computers and Writing. Washington State University, Pullman, WA. 2014.

Yergeau, Melanie et al. "Multimodality in Motion: Disability and Kairotic Spaces." Kairos: A Journal of Rhetoric, Technology, and Pedagogy, 18.1 (2013). Web.

Yin, Robert K. Applications of Case Study Research. $3^{\text {rd }}$ ed. Thousand Oaks, CA: Sage Publications, 2012. Print.

Yin, Robert K. Case Study Research: Design and Methods. $5^{\text {th }}$ ed. Los Angeles: Sage Publications, 2014. Print. 


\section{APPENDIX A}

\section{WRITERS’ WORKSHOP SYLLABUS}

\section{Overview:}

Welcome to Writers' Workshop. This course will meet in terms one through six. The premise of this course is to reimagine writing broadly as composition and how you can use different modes of communication to reach audiences effectively. I just used two strange words: modes and audiences. A mode is a way to communicate. In our course we will learn and experiment with five modes: linguistic, visual, aural, spatial, and gestural. When you compose a text with more than one mode, your text is multimodal. An audience is a person or group of people for whom your text is intended and even sometimes a person or group of people for whom your text is unintended! We'll compose for many different audiences this year.

Over the course of this class, you will compose in a couple of traditional school genres, and you will also design three "nontraditional" projects: a rhetorical analysis, a semiotic remediation project, and a final multimodal project. You will also be responsible for keeping a book of reflections, where you will write down your thoughts and feelings about the course; what your impressions of assignments are; what you like about the course; and what you think I could do to make this course better for future students.

In addition, each day in class, you will participate in class discussion. You may not keep your head down in class (If you are the sleepy type, wake up!). The Writers' Workshop course allows a great deal of freedom in regards to topics studied, as the focus of the course is to reimagine what writing can writing be and then improve your writing.

\section{Class Materials:}

laptop or tablet (daily)

highlighter (daily)

folder for handouts (daily)

various composing tools (pens, pencils, crayons, markers, etc ...) (daily) 


\section{Possible Projects:}

Fan Letter Project

Found Poetry Project

Rhetorical Analysis

Opinion-editorial

Complaint letter

Semiotic Remediation Project

Multimodal Project

Two vocabulary qui zzes

Please remain positive when the work gets complicated

Your projects are graded on your process and growth as a writer

\section{Classroom Rules:}

This studio space is designed to help you learn to improve on your writing skills, so most of the classroom rules are designed to help facilitate that learning. I am pretty laid back, but there do need to be a few rules to help manage our class time together. Please observe the following:

\section{Have Fun!}

Please do not interrupt others while they are speaking ... you don't have to raise your hand, but don't speak over others. Be respectful of yourself and each other.

Be patient, kind with yourselves, your peers, and your teacher.

No gossiping or rumor-starting

Everyone is entitled to their opinion; you do not have to agree with others, but you also don't need to make it a personal attack. Agree to disagree and be mindful of how your words affect others.

I don't mind if you listen to music while you are working on a project, with the following conditions: 
I should not be able to hear your music through your headphones; too many requests to turn it down will result in the loss of this privilege.

If the music is a distraction, you will no longer be allowed to listen to it while working.

Music should be turned off during class discussion or at other times when you are not actively reading or writing.

Set your music in the beginning of the period and LEAVE IT ALONE ... you should not be focusing on finding the best song online for the majority of the period!

With wireless internet available at all times, and with much of your research being completed online, the temptation to go to websites not related to school is strong. However, you all know how to visit non-academic websites, so you really don't need any more practice with this. If I see you on a site not related to the task at hand, you will automatically earn 40 minutes of detention.

Food and beverage are allowed in the studio space as long as you do not make a mess...but NO BEGGING! If someone else has food and doesn't want to share, leave them alone and bring your own food next time.

Please feel free to let Mr. Kim know if you have difficulty with the reading, assignments, or anything else related to class. I am always happy to help, but can only do so if I know that there is a problem. I am really looking forward to working with you all and I hope that we have a great year! 


\section{APPENDIX B \\ MICHEL FOUCAULT’S SIX PRINCIPLES OF HETEROTOPIA}

1. The space is "reserved for individuals who are, in relation to society and the human environment in which they live, in a state of crisis: adolescents, menstruating women, pregnant women, the elderly, etc., and the heterotopia of deviation is a place for "individuals whose behavior is deviant in relation to the required norm” (Foucault, “Of Other Spaces” 18).

2. Heterotopias' function is affected as history unfolds, or, in other words, society, as its history unfolds, can make an existing heterotopia function in a very different fashion.

3. A heterotopia is "capable of juxtaposing in a single real place several spaces, several sites that are in themselves incompatible” (20).

4. A heterotopia "should be linked to slices of time."

5. The fifth principle for a heterotopia states:

Heterotopias always presuppose a system of opening and closing that both isolates them and makes them penetrable. In general, the heterotopic site is not freely accessible like a public space. Either the entry is compulsory, as in entering the barracks or a prison, or else the individual has to submit to rites and purifications. (21)

6. The sixth principle is the relationship between the heterotopia and society. 


\section{APPENDIX C \\ LITERACY INTERVIEW QUESTIONNAIRE WITH ANSWERS}

\section{Can you talk about the strategies you have learned for learning in school and living in your community being ide ntified as having learning disabilities?}

Alice responds that several of the strategies she has acquired to be learning disabled in school and in other spaces have come from a course unique to Eagle Hill School called Seminar on Learning. This course provides students with a general overview of the history and development of the field of special education (social and cultural factors are addressed). More importantly, students develop a self-awareness pertaining to their own individual learning styles, identifying areas of academic strengths and those in needs of further development. Learning strategies are introduced and explained, providing students with the opportunity to utilize these strategies in their current coursework in other subject areas. Students are exposed to a series of multimodal instructional tools that introduce and explain the importance of self-advocacy, as well as understanding the process of appropriately addressing one's own academic needs. Martha McGee, the Pragmatics Department chair, and one of Alice's teachers, shares this with me:

In some classes, I have had to spend more time on self-advocacy and specific learning strategies; some classes we did not spend as much time on the history and development of special education because the 
students had good background knowledge already. It really depends on the dynamics of the class on which area I feel I need to spend more time on. I go over different learning (dis)abilities and talk about them with them. Some kids are more open to this and talk about themselves and their own LD. Some don't. I have had some mix of classes over the years for sure, but it is also about comfort level with them. They need to develop trust with new teachers and know it is a safe environment to talk about things they may have difficulty with. Some students, most it seems, come from having some really horrible experiences in previous schools that have affected how they feel about learning in general, never mind about learning more about themselves. I would have to say that I spend a good amount of time with most of the kids helping them to understand that they can learn, to move past some of the real negative things teachers have said to them and to focus on strengths. They are also encouraged to work on things that they could improve because we can all do that. Giving students strategies and a safe zone to talk about learning and how it can be a struggle is my focus and my goal.

Delevan, on the other hand, writes he has learned no strategies for being learningdisabled in school or at work. It is important to note that Delevan, unlike Alice, has not been here for a full four years and he has not taken the Seminar on Learning class that Hubacz offers. 


\section{What types of conversations have you had with teachers about having learning disabilities?}

Alice has talked a lot with her adviser about learning disabilities: “My adviser, Debbie Shanks, has helped me talk about being trans and about academics. I had a oneon-one reading and writing class with her and I learned a lot about reading and writing strategies. We have talked about going to college being LD in almost all my senior courses.”

Delevan, on the other hand, firmly responds to this question: “At my previous school not a single conversation was had other than the ones that were about my struggles. Here at EHS I have only talked about LD in the context of this research project. It is not a topic that I think is worth talking about.”

What types of conversations have you had with your friends at Eagle Hill about having learning disabilities?

Both Alice and Delevan report almost never having conversations with their friends about learning disabilities. Alice responds that among her and her friends it is just understood that each is at Eagle Hill for generally the same reason. Delevan believes that having conversations with friends about learning disabilities will offer him nothing in the way of insights.

\section{Do you have any role models who are learning disabled? Talk about the m with me.}

Alice finds Albert Einstein to be a role model: "He was a man of science who had dyslexia along with other disabilities, yet he did amazing things.” Delevan does not have any role models with learning disabilities and does not want any role models. For Delevan, "role models do not define us.” 


\section{What do you understand about the social histories of learning disabilities?}

Alice responds that it is to her understanding, "if you were to go back to the times of queens and kings people with learning disabilities were seen as the town fools. If you go back to the time of Lincoln people who have disabilities are seen as slackers. If you go back to the time of Martin Luther King people with disabilities were locked up into prison because they were seen as mentally unfit for society.” Delevan responds that he was not aware that learning disabilities have their own histories.

\section{Do you identify yourself as learning disabled on a college application or a job application?}

Alice responds that she would identify herself as having learning disabilities on a college application and a job application. Delevan said he would put on a college application that he has learning disabilities, but not on a job application. He writes: "Hell no, I would rather put 'don't hire me because I'm stupid.' ”

\section{How has coming to Eagle Hill helped or hindered your coming out process?}

Alice responds:

Eagle Hill has brought me to new people rather than just the types of people who live near my “home”, showing new opportunities that I never thought were possible for me in the past. I have never been exposed to anything of the Rainbow Community before Eagle Hill and did not know that I would be part of it because of such a situation. The friends that I made here were more open to things and thus showed me new things without me having to worry or giving the fear that I would be rejected. 
Delevan responds that Eagle Hill has not helped at all with his coming out

process.

\section{What types of conversations have you had with your teachers at Eagle Hill about sexuality?}

Alice:

My sexuality has not been the focus of conversations with teachers, but rather my Gender Identity. The first conversation that almost always comes up and will 90 percent of the time be first is the conversation of why. This question has always confused me. What are they asking why to? People always assume I like to wear a dress just because I want to be a girl or that I like to just dress that way just "because.” This is not the case. I like to wear dresses, skirts, and just try and be pretty because I feel like a girl, not that I want to be. Biologically I do wish to be a girl but gender-ly I already am a girl. Even after I try to explain this people say they understand but then go on to make comments to show that they clearly don't understand what I had just explained.

Delevan responds that he often has conversations not only about sexuality but also about human rights: "People at Eagle Hill are very active in human rights, and I have at least one conversation a day about how being a homosexual is fine.” 


\section{What strategies have you learned at Eagle Hill about being open about your sexuality in a social setting?}

Both Alice and Delevan do not believe that Eagle Hill has provided strategies for being open about sexuality in a social setting. However, Alice, a day student, does reference that she is part of an LGBT community group.

\section{Do you have any role models who are openly LGBT?}

Alice responds: "Kim Petris. She has had an amazing transition but is targeted by other gender-queers because she has had it so much easier than most. They love her because she is symbolic as a trans woman; but, at the same time she is hated because she has not had to be the guy in a skirt with hairy arms and a beard.”

Delevan does not have role models, per se, but he does look up to people he considers allies. He writes that he "looks up to P!nk, who is a huge LGBT advocate."

\section{Do you feel like the institution as a whole has supported you as an LGBT}

\section{individual?}

Alice: “I feel like Eagle Hill as a whole has supported most in their 'LGB' even with some teachers obviously finding it odd, but I find it hard to find a lot that will support the ' $\mathrm{T}$ '.”

Delevan: "Yes! Because I demand it.”

\section{What do you understand about LGBT history?}

Alice: “I understand that 'LG' has been bashed, ridiculed, rejected, and humiliated in the past. I understand that ' $\mathrm{B}$ ' is still something kinda new to the world and at least half of the population thinks it's something fake in order to be a 'Slut/Man- 
whore'. I understand that ' $\mathrm{T}$ ' is the newest as it has only recently been added and yet it is the least accepted.”

Delevan: "We have come from rubble and are still trying to crawl our way out, one bubbly gay float parade at a time. There is no real deep history to us other than in history you'll see authors and movie directors hiding gay themes as much as possible but having them still there.” 